\title{
Dynamic Bank Capital Requirements
}

\author{
Tetiana DavydiuK*
}

Job MARKet PAPER

Current Draft: January 23, 2017

[Link to the Latest Version]

\begin{abstract}
The Basel III Accord requires countercyclical capital buffers to protect the banking system against potential losses associated with excessive credit growth and buildups of systemic risk. In this paper, I provide a rationale for time-varying capital requirements in a dynamic general equilibrium setting. An optimal policy trades off reduced inefficient lending with reduced liquidity provision. Quantitatively, I find that the optimal Ramsey policy requires a capital ratio that mostly varies between $4 \%$ and $6 \%$ and depends on economic growth, bank supply of credit, and asset prices. Specifically, a one standard deviation increase in the bank credit-to-GDP ratio (GDP) translates into a $0.1 \%(0.7 \%)$ increase in capital requirements, while each standard deviation increase in the liquidity premium leads to a $0.1 \%$ decrease. The welfare gain from implementing this dynamic policy is large when compared to the gain from having an optimal fixed capital requirement.
\end{abstract}

Keywords: Ramsey policy, capital requirements, liquidity provision, countercyclical buffers

\footnotetext{
*Contact: davydiuk@wharton.upenn.edu, +1 (215)-863-1659, the Wharton School, University of Pennsylvania, Finance Department, 2254 Steinberg-Dietrich Hall, 3620 Locust Walk, Philadelphia, PA 19104.

${ }^{\dagger}$ I am deeply indebted to my advisers Joao F. Gomes (co-chair), Amir Yaron (co-chair), Itay Goldstein, and Christian Opp for their insightful comments, guidance, and encouragement. I also want to thank Anna Cororaton, Amr Elsaify, Vincent Glode, Urban Jermann, Roni Kisin, Doron Levit, Karen Lewis, Tatyana Marchuk, Pricila Maziero, Ryan Peters, Krishna Ramaswamy, Scott F Richard, Jose Victor Rios Rull, Michael Roberts, Nikolai Roussanov, Ruslan Sverchkov, Mathieu Taschereau-Dumouchel, Ram Yamarthy and seminar participants at the Wharton School for helpful comments. I am especially grateful to Deeksha Gupta for her valuable feedback and support throughout the program. Financial support by the Macro Financial Modeling Group dissertation grant from Becker Friedman Institute at the University of Chicago, as well as the research grant from the Rodney L. White Center for Financial Research, is gratefully acknowledged.
} 


\section{Introduction}

The recent financial crisis renewed attention on the stability of the banking sector and on capital regulation. Both policymakers and academics have recognized that risk-based capital requirements, such as those in the 2004 Basel II Accord, tend to exacerbate business-cycle fluctuations, leading to an overly cyclical credit supply. To protect the banking sector from periods of excess credit growth and leverage buildup, the 2010 Basel III Accord introduced the countercyclical capital buffer $(\mathrm{CCyB})$ framework. The proposed adjustment effectively translates into capital ratios that vary over time. Despite a few recent trials to implement $\mathrm{CCyB}$ regimes within countries in the European Union, there is no consensus at the practical or theoretical level about the implications of CCyBs on the macroeconomy. ${ }^{1}$

The goal of this paper is to investigate both the theoretical and quantitative implications of the optimal state-dependent capital requirements. By comparison, most of the existing literature has limited itself to examining the costs and benefits of the overall level of capital requirements. ${ }^{2}$ To this end, I develop a tractable general equilibrium model and use it to characterize the optimal bank capital requirements. The problem of choosing an optimal capital policy follows from the work of Ramsey (1927) and builds on the primal approach used in the optimal taxation literature ${ }^{3}$.

My model has three key features. First, high-quality production projects are scarce, especially during economic downturns. Second, banks benefit from government guarantees in the form of bank bailouts, which lowers their borrowing cost, thereby creating incentives to risk-shift. Third, I assume in the model that households value money-like assets in the form of bank debt. This implies that bank debt is priced at a discount and is a cheaper source of funding than equity. ${ }^{4}$ The last two features create a trade-off: while tighter capital ratios can help to mitigate a bank's motives to risk-shift and rule out inefficient lending, at the same time they can reduce the bank's supply of credit and the creation of safe liquid assets.

\footnotetext{
${ }^{1}$ The expectation is that the buffer will be at zero through most of the business cycle and increase to the maximum $2.5 \%$ points only at the peak of the credit cycle. Even though under 2010 Basel Accord the CCyB regime will be phased in globally between 2016 and 2019, individual EU members have already introduced the CCyBs. For instance, the Bank of England maintained the buffer rate equal to 0\% starting from 2014:Q2, while the Norwegian authorities set a 1\% countercyclical capital buffer rate for the period 2015:Q3-2016:Q2 and 1.5\% from 30 June, 2016. The European Systemic Risk Board (ESRB) provides an overview of the national countercyclical capital buffer rates. See: https://www.esrb.europa.eu/national_policy/ccb/applicable/html/index.en.html.

${ }^{2}$ Some examples include Diamond and Rajan (2000), Diamond and Rajan (2001), Hellmann, Murdock and Stiglitz (2000), Repullo (2004), Morrison and White (2005), Van den Heuvel (2008), Admati, DeMarzo, Hellwig and Pfeiderer (2010), DeAngelo and Stulz (2013), Nguyen (2014), Begenau (2016),

${ }^{3}$ See, for example, Lucas and Stokey (1983), Chari, Christiano and Kehoe (1991) and Atkinson and Stiglitz (2015).

${ }^{4}$ In this paper, I interchangeably use debt and deposits, even though in the data as of 2014 deposits amounted only to $77 \%$ of bank liabilities.
} 
In the model, procyclical capital requirements emerge endogenously as an optimal policy scheme in a Ramsey equilibrium - thus providing the best implementable competitive equilibrium. ${ }^{5}$ In line with empirical evidence, excessive investment in risky and inefficient projects builds-up during periods of high economic growth. ${ }^{6}$ Because of better lending opportunities during expansions, banks increase the supply of credit. As a result, expected bailout subsidies become larger, thereby lowering banks borrowing costs and translating into an even higher level of lending. Consequently, heightened capital regulation can be most beneficial through credit booms. At the same time, tight capital requirements can have a contractionary effect on bank lending and deposit creation especially during downturns, when liquidity is more valuable to households and, as a result, equity financing is more costly for banks. ${ }^{7}$ This implies that optimal capital charges should be lower during credit freezes, thereby reinforcing the cyclicality of optimal capital ratios.

My results also show that the optimal Ramsey policy used as a single policy tool is not sufficient to restore both the socially optimal level of lending and liquidity provision. To provide some intuition behind the design of optimal capital regulations, I solve separately for the "lending capital requirement" - restoring the first-best level of investment but admitting a reduced level of deposits - and the "liquidity capital requirement" - ensuring the first-level of liquidity provision but also allowing for excessive lending. Such policies focus only on one dimension of the problem, either dampening incentives of banks to risk-shift or stimulating creation of safe and liquid assets. By contrast, the Ramsey capital requirement balances reduced inefficient lending with reduced liquidity provision.

The model highlights important trade-offs one needs to consider when regulating bank capital. However, for effective policy making, it is also crucial to assess these guidelines quantitatively. I therefore calibrate the model to best match key macroeconomic quantities, as well as bank data counterparts. Using this choice of parameters, I solve numerically for the optimal policy

\footnotetext{
${ }^{5}$ This is consistent with the "countercyclical capital buffer" instituted with Basel III. The required buffer is called countercyclical because the goal is to dampen the impact of capital regulation on the cyclicality of bank lending. The buffer itself is procyclical.

${ }^{6}$ Even though there is no unifying theory of bank risk-taking over the business cycle, empirical evidence suggests that credit booms are associated with declines in lending standards, greater recourse to riskier contract structure, and changes in leverage (Mian and Sufi (2010), Demyanyk and Hemert (2011), DellAriccia, Igan and Laeven (2012b)). Besides, there is indirect evidence that risks tend to build-up during periods of high economic growth: credit booms do not just proceed but rather cause financial crises (Lorenzoni (2008), Dell'Ariccia, Igan, Laeven and Tong (2012a), Borio (2014)).

${ }^{7}$ It is important to differentiate between the ongoing costs of holding equity on the balance sheet and the costs of raising new external equity finance. One of the theories why equity is more expensive on ongoing basis has to do with the liquidity premium on safe "money-like" assets produced by banks. Provided that investors value liquidity most when the supply of safe assets is low (e.g., Krishnamurthy and Vissing-Jorgensen (2012)), the liquidity premium is high during recessions when banks reduce their lending activity and deposit creation. This is turn implies that equity financing is more costly during economic slowdowns.
} 
in the implementable Ramsey equilibrium. Specifically, I characterize the optimal state-contingent capital regulation and the set of allocations for bank lending and liquidity provision that maximize consumers' lifetime utility. Ramsey allocations have the property that they can be implemented as a competitive equilibrium when banks encounter the prescribed capital requirements.

Based on quantitative implementation of the model, I find that the optimal Ramsey policy requires a cyclical capital ratio that mostly varies between $4 \%$ and $6 \%$ and depends on key indicators of economic growth and asset prices. This range of values is roughly comparable with a $2.5 \%$ upper bound of the CCyB proposed by the Basel III Accord. Importantly, the optimal policy rule is not capped at $6 \%$, and can rise above it during periods of abnormal economic growth. In addition, the mean Ramsey capital requirement is around 5\%. This is one percentage point higher than the level of the leverage ratio and one percentage point lower than the Tier 1 capital ratio as recommended by the Basel III Accord. ${ }^{8}$

Implementing the optimal Ramsey policy delivers a permanent increase in the annual consumption of households relative to the current capital ratios. ${ }^{9}$ Although the exact magnitude of the welfare gain depends on the attitude of households toward risk, more than $60 \%$ is attributed to having state-dependent capital requirements. The remaining welfare improvement is achieved by setting an optimal fixed capital requirement equal to the mean Ramsey capital ratio. The optimal policy leads to a reduction in the cyclicality of bank credit - reducing inefficient lending during expansions, but increasing the supply of credit during economic slowdowns - and, as a result, achieves on average a higher level of consumption and deposit creation.

The main contribution of the paper is to characterize the optimal policy rule in terms of measurable macroeconomic and bank aggregates. While the Basel Committee recommends adjusting the capital requirements based on "credit gap", the deviation of the credit-to-GDP ratio with respect to its long-term trend, I show the credit gap alone fails to capture the time variation in the optimal Ramsey policy. Instead, I find the optimal policy rule takes into account the joint behavior of the credit gap, GDP, and the liquidity premium. Specifically, the optimal Ramsey policy is well approximated by the following rule:

$$
5 \%+0.1 \% \times \text { credit gap }+0.7 \% \times G D P-0.1 \% \times \text { liquidity premium }
$$

where the liquidity premium is a discount on the price of safe liquid assets. ${ }^{10} \mathrm{~A}$ one standard

\footnotetext{
${ }^{8}$ Note that these two ratios - Tier 1 capital ratio (Tier 1 capital divided by total risk-weighted assets) and the leverage ratio (Tier 1 capital divided by total assets) - are the same in the model, even though it is not the case in the data.

${ }^{9}$ In the model, utility of households is defined over consumption and deposits according to a CES aggregator $v(C, D)$. To this extent, I measure the welfare costs in terms of changes in $v(C, D)$ rather than in $C$.
} 
deviation increase in the credit-to-GDP ratio (GDP) translates into a $0.1 \%(0.7 \%)$ increase in the capital charges, while a one standard deviation increase in the liquidity premium leads to a $0.1 \%$ drop. Growth in bank credit, along with the output growth, act as indicators of banks' incentives to risk-shift. By contrast, the liquidity premium serves as an indicator of how expensive equity financing is for banks and how valuable liquid assets are for investors.

The paper proceeds as follows: In Section 2, I provide the details of bank regulation, as well as review the related literature. I develop the baseline model in Section 3. I characterize the first-best allocation in this economy in Section 4, as well as the competitive equilibria with and without capital regulations in place. In Section 5, I examine the lending and liquidity capital requirements within the baseline model. I provide the quantitative assessment of the model in Section 6, as well as present the optimal policy rule. Concluding remarks are give in Section 7.

\section{Bank Regulation and Related Literature}

\subsection{The Basel Accords}

The Basel Accords, developed by the Basel Committee on Bank Supervision (BCBS), consolidate capital requirements as the cornerstone of bank regulation. The 1988 Basel Accord, known as Basel I (BCBS (1988)), was criticized for the risk-insensitivity of capital charges. To address this critique, the internal ratings-based (IRB) approach was introduced with the publication of Basel II in 2004. Under risk-based regulation, the amount of capital that a bank is required to hold against a given exposure depends on the estimated credit risk of that exposure, which in turn is determined by the probability of default (PD), loss given default (LGD), exposure at default (EAD), and maturity. The key implication of the IRB approach is that riskier exposures carry a higher capital charge. The intention of this approach is to reduce bank failures and the associated systemic costs by holding the bank probability of default below some fixed target.

Both policymakers and academics have recognized that risk-sensitive capital regulations, such as that in Basel II, tend to exacerbate the inherent cyclicality of bank lending and, consequently, distort investment decisions. This is because in economics downturns losses erode bank capital, and the remaining (non-defaulted) loans are downgraded by the relevant credit risk model, delivering higher capital charges. To the extent that it is difficult or costly for a bank to raise new capital during recessions, it will be forced to cut back on its lending activity. Kashyap, Rajan and Stein

\footnotetext{
${ }^{10}$ The three indicators are expressed in log-deviations from their steady states and normalized by their standard deviations. The GDP growth variable has been orthogonolized with respect to the credit gap variable.
} 
(2008) provide empirical evidence that equity-raising was sluggish during the recent financial crisis.

Kashyap and Stein (2004) argue that the IRB approach is largely microprudential in nature and ignores the importance of the function of bank lending. In line with the literature on capital crunches in banking, they claim that the shadow value of bank capital increases during recessions and a capital requirement that is too high when bank capital is scarce may result in reduced funding of positive net present value projects. So, if the government's objective is both to protect the financial system against the costs of bank defaults and sustain bank-lending efficiency, the capital charges should be adjusted to the state of the business cycle (for any degree of credit-risk exposure).

An important argument that is sometimes made is that during periods of economic growth banks may hold capital in excess of the minimum regulatory requirements that could neutralize potential cyclicality problems. Repullo and Suarez (2012) develop a dynamic model of relationship lending, in which banks hold voluntary capital buffers as a precaution. They find that the capital buffers set aside during expansions are typically not sufficient to prevent credit supply shrinkage during recessions. They also document that the optimal capital requirements are higher and less cyclically-varying than the requirements of Basel II when the social cost of bank failure is high.

In an attempt to strengthen bank balance sheets against future financial upheavals, Basel III introduced the countercyclical capital buffers, which range from zero to $2.5 \%$ of risk-weighted assets. As mentioned before, the BCBS proposed to adjust the level of the buffer based on the credit gap, meanwhile acknowledging that it may not be a good indicator of stress in downturns. For example, Repullo and Saurina (2011) find that the credit gap for many countries is negatively correlated with GDP growth. This can be traced to the fact that the supply of credit typically lags the business cycle, especially in downturns.

Kashyap and Stein (2004), Gordy and Howells (2006), Saurina and Trucharte (2007), and Kashyap et al. (2008), among others, focus on the correction of risk-based capital requirements in a macroprudential direction. Using Spanish data, Repullo, Saurina and Trucharte (2010) analyze different procedures aimed at mitigating the procyclical effects of capital regulation and conclude that the most appealing one is to use a business cycle multiplier based on GDP growth. The proposed adjustment maintains the risk sensitivity in the cross-section (i.e., banks with riskier portfolios would bear a higher capital charge), but a cyclically-varying scaling factor would increase capital requirements in good times and reduce them in bad times. In line with this study, I propose a cyclical policy rule that depends positively on indicators of economic growth. In my setting, state-contingent capital requirements emerge endogenously as an optimal policy scheme. Optimal 
regulations promote the stability of the banking sector without contracting the supply of bank credit and deposit creation. Arguments in favor of time-varying capital regulations are also found in Kashyap et al. (2008), Hanson, Kashyap and Stein (2011), and Malherbe (2015). Note that I abstract from the cross-sectional dimension of capital regulation and focus on the time-series dimension.

\section{$2.2 \quad$ Literature Review}

This research project is at the intersection of a large literature on optimal banking regulation theory and dynamic macroeconomic models of financial intermediation. The recent financial crisis has brought to the forefront the discussion of whether the capital requirements of banks should be increased (Admati et al. (2010)). On one side, Hellmann et al. (2000), Repullo (2004), and Morrison and White (2005) argue that stringent capital regulation can induce prudent behavior by banks. On the other side, Diamond and Rajan (2000), Diamond and Rajan (2001), and DeAngelo and Stulz (2013) provide theoretical evidence that tightening capital requirements may distort banks' provision of liquidity services, while Dewatripont and Tirole (2012) show that stricter capital requirements may introduce governance problems. In line with the existing literature, I suggest that reduced moral hazard is the key rationale for imposing restrictive capital regulation with reduced liquidity provision being the main downside.

This paper is most closely related to other quantitative studies on the welfare impact of capital requirements (Van den Heuvel (2008), Nguyen (2014), Begenau (2016), Van den Heuvel (2016)) and leverage constraints (Bigio (2010), Martinez-Miera and Suarez (2012), Corbae and D'Erasmo (2014), and Christiano and Ikeda (2014)). Among the most recent studies estimating the optimal level of fixed capital requirements are Nguyen (2014) and Begenau (2016). Nguyen (2014) finds that consumers' lifetime utility is maximized at $8 \%$ capital ratio, while the optimal number estimated by Begenau (2016) is $14 \%$. A common feature in these two papers is that government guarantees incentivize banks to engage in excessive risk-taking, while capital regulation helps to address these distortions. Begenau (2016) also extends the banks' role to providing liquidity services, which are valued by households. I complement this branch of literature by developing a tractable framework to quantify the benefits and costs of capital regulation over the business cycle. This allows me to provide not only qualitative, but also quantitative recommendations on the policy design. To the best of my knowledge, this paper is the first to solve for the stage-contingent capital requirements within the Ramsey framework.

There are few empirical contributions on the effects of higher capital requirements on bank 
lending and bank cost of capital. Looking at the data on large financial institutions, Kashyap, Stein and Hanson (2010) find that even if the minimum capital ratio is increased by $10 \%$, the impact on loan rates is likely to be modest, in the range of 25 to 45 bps. In a similar vein, Baker and Wurgler (2013) calibrate that a ten-percentage point increase in capital requirements would translate into a higher weighted average cost of capital by $60-90$ bps per year. Kisin and Manela (2013) estimate the perceived costs of capital requirements by employing the data on banks' participation in a costly loophole that helped them to bypass capital regulations. They document that a ten-percentage point increase in Tier 1 capital to risk-weighted assets leads to, at most, a 3 bps increase in banks' cost of capital. Even though these studies shed light on the potential impact of capital regulations on the real economy, it is difficult to assess the overall welfare implications of a time-varying capital requirement in their setting.

More broadly, this paper fits a strand of macroeconomic literature on the role of financial intermediation in the development of economic crises. The transmission mechanism by which the effects of small shocks persist, amplify, and spread to the macroeconomy is first identified in the seminal works of Bernanke and Gertler (1989), Kiyotaki and Moore (1995), and Bernanke, Gertler and Gilchrist (1999). The more recent studies of the balance sheet channel include Gertler and Kiyotaki (2010), Gertler and Karadi (2011), He and Krishnamurthy (2012), Di Tella (2013), and Brunnermeier and Sannikov (2014).

\section{Model Setup}

To focus on the novel mechanisms associated with dynamic bank capital requirements, I first layout the baseline model, which is kept as parsimonious as possible. I later augment the model to quantify policy recommendations on what defines optimal time variation in capital requirements of banks.

In the model, time is discrete and runs for an infinite number of periods. Financial intermediaries own the production technology and the stock of capital in this economy. They are financed either partially or entirely with deposits. The presence of deposit insurance distorts banks' optimal choices of investment. Households consume the final goods produced in the banking sector and invest any savings in the banks' deposits. To finance bailout expenditures, the government levies taxes on households in lump-sum fashion. 


\subsection{Banking Sector}

I start by characterizing a banking sector in detail. At any point in time the economy is populated with a continuum of ex ante identical banks of measure one, indexed by $j \in \Omega=[0,1]$. Each bank has access to decreasing returns to scale technology and produces a final good $y_{j, t}$, using capital as the only input,

$$
y_{j, t}=e^{\omega_{j, t}+a_{t}} l_{j, t}^{\alpha},
$$

where $a_{t}$ is an aggregate productivity shock, which follows:

$$
a_{t}=\left(1-\rho_{a}\right) \bar{a}+\rho_{a} a_{t-1}+\sigma_{a} \epsilon_{t}, \quad \epsilon_{t} \sim \operatorname{iid} \mathcal{N}(0,1)
$$

and $\omega_{j, t}$ is an idiosyncratic disturbance, which is identically distributed across time and across banks:

$$
\omega_{j, t}=-\frac{1}{2} \sigma_{\omega}^{2}+\sigma_{\omega} \varepsilon_{j, t}, \quad \varepsilon_{j, t} \sim \operatorname{iid} \mathcal{N}(0,1) .
$$

In the cross-section, the bank-specific shocks average to zero. This setup is isomorphic to the one, where a consumption good is produced by penniless firms, who have been credit rationed in the capital markets due to unmodeled information asymmetries, and whose only source of funding is bank loans. ${ }^{11}$ The capital used in banks' production process can be correspondingly interpreted as the amount of bank loans issued to these types of borrowers. From this point on, I refer to $l_{j, t+1}$ as bank lending. The decreasing returns to scale assumption is crucial to capture the idea that borrowers are not homogeneous and that there is a finite number of creditworthy borrowers, or equivalently a finite number of positive net present value (NPV) production projects. This setup ensures that banks internalize that each extra lending unit (borrower) is not as productive (creditworthy) as the previous one.

Bank $j$ enters period $t$ with $l_{j, t}$ lending units, financed with $d_{j, t}$ units of debt and $n_{j, t}$ units of

\footnotetext{
${ }^{11}$ Suppose that each bank operates on an island $j$; one can think of an island as an industry or a state. On each island, there is a continuum of cashless firms who require a unit investment at time $t$ for production at time $t+1$. Firms on each island are ranked according to their productivity. Specifically, a firm $i$ on an island $j$ (where $i$ denotes the firm's ranking) produces $\alpha e^{\omega_{j, t}+a_{t}} i^{\alpha-1}$ units of a consumption good. At time $t$, the bank on island $j$ issues loans to the first $l_{j, t+1}$ firms with the total amount equal to:

$$
\int_{0}^{l_{j, t+1}} 1 d i=l_{j, t+1}
$$

The monopolist bank on the island can extract all surplus. In particular, at time $t+1$ the bank on island $j$ receives from the firms:$$
\int_{0}^{l_{j, t+1}} \alpha e^{\omega_{j, t+1}+a_{t+1}} i^{\alpha-1} d i=e^{\omega_{j, t+1}+a_{t+1}} l_{j, t+1}^{\alpha} .
$$ 
equity. The balance sheet equates risky assets to bank debt and equity:

\begin{tabular}{c|c}
\hline$l_{j, t}-$ loans & $n_{j, t}-$ net worth \\
\cline { 2 - 2 } & $d_{j, t}-$ debt
\end{tabular}

The bank's revenues realized at time $t$ are equal to its earnings on the production net of the interest payments on its liabilities:

$$
\pi_{j, t}=e^{\omega_{j, t}+a_{t}} l_{j, t}^{\alpha}-l_{j, t}-\left(R_{d, t}-1\right) d_{j, t}
$$

Next, I assume that when a financial intermediary does not have sufficient funds to service its deposit liabilities, depositors are bailed out with probability one. ${ }^{12}$ In particular, banks will default on their credit obligations whenever their idiosyncratic shock $\omega_{j, t}$ is below a cutoff level $\omega_{j, t}^{*}$, defined by the expression:

$$
\pi_{j, t}+n_{j, t}=0 \Leftrightarrow e^{\omega_{j, t}^{*}+a_{t}} l_{j, t}^{\alpha}=R_{d, t} d_{j, t} .
$$

The net worth, $n_{j, t+1}$, available to banks at the end of period $t$ (going into period $t+1$ ), evolves according to:

$$
\begin{aligned}
n_{j, t+1} & =\left\{\pi_{j, t}+n_{j, t}\right\}^{+}-z_{j, t} \\
& =\left\{\left(e^{\omega_{j, t}+a_{t}} l_{j, t}^{\alpha-1}-R_{d, t}\right) l_{j, t}+R_{d, t} n_{j, t}\right\}^{+}-z_{j, t},
\end{aligned}
$$

where $\{\cdot\}^{+}$denotes the maximum operator $\max \{\cdot, 0\}$ and captures that banks are subject to limited liability and government guarantees. $z_{j, t}$ is the net payouts to the bank's shareholders. A positive net transfer, $z_{j, t}>0$, means that the equityholders receive dividends, while a negative one, $z_{j, t}<0$, means that there is an equity issuance. Equation (3) demonstrates that any growth in bank equity above the deposit return depends on the premium that the financial intermediary earns on its assets, as well as the total amount of lending. To finance the difference between the capital investment and available net worth, the financial intermediary borrows an amount $d_{j, t+1}$ from households, given by:

$$
d_{j, t+1}=l_{j, t+1}-n_{j, t+1} .
$$

\footnotetext{
${ }^{12}$ The banking sector is subject to government guarantees for reasons that I do not explicitly model. As has been acknowledged by the academics and practitioners, without government protection, economies are prone to bank runs. Bank runs were a recurrent feature during the Great Depression in the U.S. and continue today, including recent episodes of bank failures in the U.S. (Countrywide, IndyMac), Great Britain (Northern Rock), and India (ICICI Bank). With many bank failures, there is a disruption of the monetary system and a reduction in production (Bernanke (1983), Calomiris and Mason (2003), Dell'Ariccia, Detragiache and Raghuram (2008)). With the goal of protecting the economy against the potential welfare losses associated with bank runs, deposit insurance was introduced along with a number of implicit government guarantees.
} 
Finally, banks are subject to capital regulations, which require them to have a minimum amount of equity as a fraction of assets. Since loans are the only type of asset in my model, the capital requirement $\mathrm{I}$ instate is that equity needs be at least a fraction $\zeta_{t}$ of loans for a bank to be able to operate:

$$
n_{j, t+1} \geq \zeta_{t} l_{j, t+1}
$$

In each period, bank $j$ decides how many loans to issue, $l_{j, t+1}$, and makes a leverage choice to maximize the discounted sum of the equity payouts:

$$
\begin{aligned}
& \max _{z_{j, t}, l_{j, t+1}, d_{j, t+1}, n_{j, t+1}} E\left[\sum_{t=0}^{\infty} \beta^{t} z_{j, t}\right] \\
& \text { s.t. } \quad n_{j, t+1}=\left\{e^{\omega_{j, t}+a_{t}} l_{j, t}^{\alpha}-R_{d, t} d_{j, t}\right\}^{+}-z_{j, t}, \\
& l_{j, t}=n_{j, t}+d_{j, t}, \\
& n_{j, t+1} \geq \zeta_{t} l_{j, t+1}, \\
& n_{j, 0}, d_{j, 0} \quad \text { given. }
\end{aligned}
$$

\subsection{Household Sector}

The economy is populated by a measure one of identical households. There are two types of members in each household: savers and bankers (Gertler and Karadi (2011)). Savers hold deposits at a diversified portfolio of financial institutions and return the interest earned to their household. Bankers, on the other hand, manage financial intermediaries and similarly return any earnings back to the household. The savers hold deposits at the banks that its household does not own, otherwise in the absence of tax frictions, the Modigliani-Miller theorem would hold and the irrelevance of banks' capital structure would follow. Savers' and bankers' earnings are perfectly shared across the entire household to secure a representative agent framework.

Let $C_{t}$ denote family consumption and $D_{t+1}$ denote the holdings of bank deposits. Households are risk-neutral and have a discount rate of $\beta \in(0,1) \cdot{ }^{13} \mathrm{I}$ also assume that households value the non-pecuniary services provided by bank deposits and, hence, enjoy the additional flow of utility $v\left(D_{t+1}\right)$, which is a concave non-decreasing function of the supply of deposits $D_{t+1} \cdot{ }^{14}$

In each period, the household chooses a consumption level and deposit holdings to maximize

\footnotetext{
${ }^{13}$ A household's consumption can be both positive and negative, as in Brunnermeier and Sannikov (2014). Negative consumption can be interpreted as disutility from labor.

${ }^{14}$ See, for example, Nataliya, Pfeil, Rochet and De Nicolo (2016). This particular utility function allows me to derive the analytical solutions for the baseline model, but it is generalized when I move to the quantitative assessment of the optimal capital requirements.
} 


\section{Figure 1: Rate of Return on Deposits}

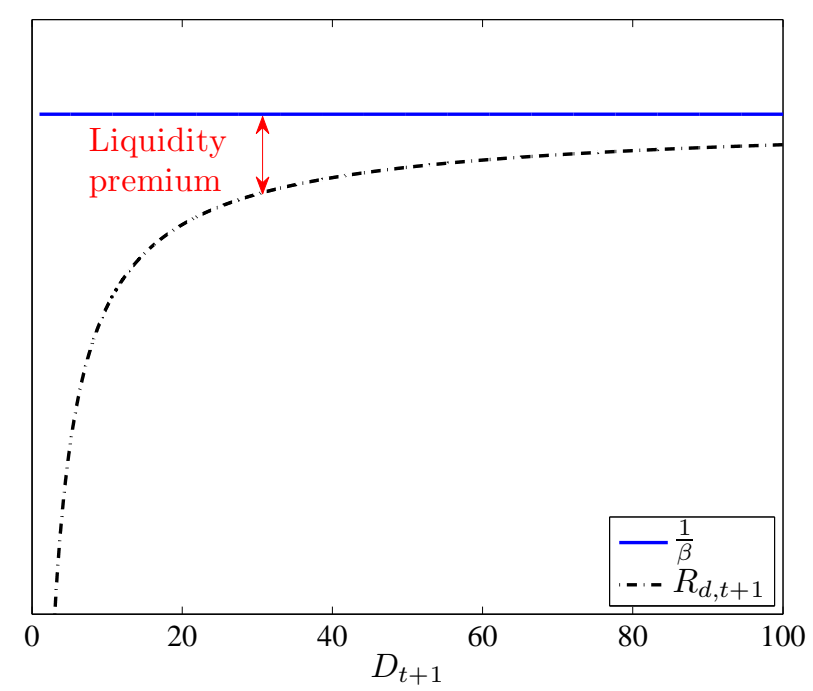

This figure depicts the rate of return on deposits $R_{d, t+1}$ as a function of the deposits supply $D_{t+1}$ and the rate of return on other safe assets $\frac{1}{\beta}$. The scale of $y$-axis is omitted, as the numbers in this parameterized example do not have economic meaning. The parameter values are set to $\beta=0.98, \eta=0.8, \alpha=0.85, \delta=1, \rho_{a}=0.97, \sigma_{a}=0.02$, and $\sigma_{\omega}=0.2$.

their utility subject to the budget constraint:

$$
\begin{array}{ll} 
& \max _{C_{t}, D_{t+1}} E\left[\sum_{t=0}^{\infty} \beta^{t}\left(C_{t}+v\left(D_{t+1}\right)\right)\right] \\
\text { with } & v\left(D_{t+1}\right)=\frac{D_{t+1}^{1-\eta}}{1-\eta}, \quad \eta<1 \\
\text { s.t. } & C_{t}=R_{d, t} D_{t}-D_{t+1}+Z_{t}-T_{t}, \\
& D_{0} \text { given, }
\end{array}
$$

where $T_{t}$ is a lump-sum tax levied by the government. Households are the owners of financial intermediaries and at the end of each period receive the net proceeds of bank activity, $Z_{t}$. A unit of deposits issued in period $t$ yields a gross return of $R_{d, t+1}$ at time $t+1$.

The presence of the government guarantees implies that $R_{d, t+1}$ is a return on a riskless asset. The first-order conditions of (5) impart that the interest rate on deposits is equal to:

$$
R_{d, t+1}=\frac{1}{\beta}-\underbrace{\frac{1}{\beta} D_{t+1}^{-\eta} .}_{\text {liquidity premium }}
$$


Since households exhibit a preference for bank debt, there is a discount on its interest rate, which is the amount households are willing to relinquish in exchange for holding a risk-free asset, which gives a flow of utility compared to a risk-free asset that does not give a flow of utility. ${ }^{15}$ Figure 1 shows that liquidity premium is a decreasing function in the supply of bank deposits. This implies that liquid deposits become more valuable to the household when they are scarce.

Diamond and Dybvig (1983) were among the first to analyze household demand for liquidity. They find that bank deposits provide better risk-sharing possibilities to consumers, justifying the existence of the liquidity premium. Stein (2011) and Gorton and Metrick (2012) argue that collateralized short-term debt issued by banks yields a "money-like" convenience premium based on its relative safety and the transactions services that safe claims provide. Further, Krishnamurthy and Vissing-Jorgensen (2012) and Krishnamurthy and Vissing-Jorgensen (2015) document that investors value the money-like features of Treasuries the most, when the supply of Treasuries is low. The welfare implications of the presence of liquidity premium via its effects on the lending costs of banks have also been studied by Begenau (2016) and Van den Heuvel (2016).

\subsection{Government}

The role of the government is to provide deposit insurance. To finance its expenditures on bank bailouts, the government levies a lump-sump tax on households in accordance with a balanced budget rule:

$$
T_{t}=\int_{0}^{1} \max \left\{R_{d, t} d_{j, t}-e^{\omega_{j, t}+a_{t}} l_{j, t}^{\alpha}, 0\right\} d j .
$$

\section{Equilibrium Characterization}

Definition. A competitive equilibrium is a set of prices $\left\{R_{d, t+1}\right\}_{t=0}^{\infty}$, government policies $\left\{\zeta_{t}, T_{t}\right\}_{t=0}^{\infty}$, and allocations $\left\{C_{t}, D_{t+1},\left\{z_{j, t}, l_{j, t+1}, n_{j, t+1}, d_{j, t+1}\right\}_{j \in \Omega}\right\}_{t=0}^{\infty}$, such that:

(i) Given prices $\left\{R_{d, t+1}\right\}_{t=0}^{\infty}$, government policies $\left\{T_{t}\right\}_{t=0}^{\infty}$ and initial amount of savings, $D_{0}$, households maximize their life-time utility given by (5);

\footnotetext{
${ }^{15}$ In this setting, the rate of return on any other safe asset other than bank debt is equal to $\frac{1}{\beta}$. As long as households derive utility from bank deposits and the economy is not fully saturated with liquidity, the interest rate on bank debt is always lower than the interest rate on any other risk-free asset,

$$
\lim _{D_{t+1} \rightarrow \infty} R_{d, t+1}=\frac{1}{\beta}
$$
}


(ii) Given prices $\left\{R_{d, t+1}\right\}_{t=0}^{\infty}$, government policies $\left\{\zeta_{t}, T_{t}\right\}_{t=0}^{\infty}$ and initial capital structure $\left\{n_{j, 0}, d_{j, 0}\right\}_{j \in \Omega}$, each bank $j \in \Omega$ maximizes the discounted sum of equity payouts given by (4);

(iii) The government budget constraint (7) is satisfied;

(iv) Market clearing conditions hold:

- resource constraint

$$
C_{t}+\int_{0}^{1} l_{j, t+1} d j=\int_{0}^{1} y_{j, t} d j
$$

- deposits market

$$
D_{t+1}=\int_{0}^{1} d_{j, t+1} d j
$$

The nature of the bank's problem (4) implies that the equilibrium is symmetric and all banks make identical decisions. The realization of the bank-specific shock $\omega$ induces a bailout transfer from the government to a subgroup of banks, but does not affect the optimal decisions of banks. To see this result, it is useful to define the value of the bank to its shareholders as follows:

$$
J\left(l_{j, t}, n_{j, t}, \omega_{j, t}, S_{t}\right)=\max \left\{\pi_{j, t}+n_{j, t}, 0\right\}+V\left(S_{t}\right),
$$

where the continuation value $V(\cdot)$ obeys the following Bellman equation:

$$
\begin{aligned}
V\left(S_{t}\right) & =\max _{n_{j, t+1}, l_{j, t+1}}\left\{-n_{j, t+1}+E_{t}\left[\beta M_{t, t+1} \int_{0}^{+\infty} J\left(l_{j, t+1}, n_{j, t+1}, \omega_{j, t+1}, S_{t+1}\right) d F\left(\omega_{j, t+1}\right)\right]\right\} \\
& =\max _{n_{j, t+1}, l_{j, t+1}}\left\{-n_{j, t+1}+E_{t}\left[\beta M_{t, t+1}\left(\int_{\omega_{j, t+1}^{*}}^{+\infty}\left(\pi_{j, t+1}+n_{j, t+1}\right) d F\left(\omega_{j, t+1}\right)+V\left(S_{t+1}\right)\right)\right]\right\} .
\end{aligned}
$$

The conditional expectation $E_{t}$ is taken only over the distribution of aggregate productivity shocks and $S_{t}$ denotes the aggregate state of the economy. To the extent that bank-specific shocks are not persistent and there is no equity issuance costs, all financial intermediaries are ex ante the same and make identical decisions. In particular, $l_{j, t+1}=L_{t+1}, n_{j, t+1}=N_{t+1}$, and $d_{j, t+1}=D_{t+1}, \forall j \in \Omega$.

To uncover the inefficiencies introduced with the presence of government subsidies, I first solve for the socially optimal allocation in this economy. Next, I characterize a competitive equilibrium when banks face no capital regulations and then compare the optimal decisions of banks in the two equilibria. 


\subsection{First-Best Allocation}

A social planner chooses consumption and supply of liquid deposits to maximize households' lifetime utility subject to the resource constraint:

$$
\begin{gathered}
\max _{C_{t}, L_{t+1}, D_{t+1} \leq L_{t+1}} E\left[\sum_{t=0}^{\infty} \beta^{t}\left(C_{t}+\frac{D_{t+1}^{1-\eta}}{1-\eta}\right)\right] \\
\text { s.t. } \quad C_{t}+L_{t+1}=e^{a_{t}} L_{t}^{\alpha},
\end{gathered}
$$

where the regulator takes into account that the competitive equilibrium is symmetric and that the deposit's supply is bounded by the stock of capital in the banking sector. I characterize the socially optimal allocation in Proposition 1.

Proposition 1 The first-best allocation is characterized by:

(i) Bank's optimal finance policy:

$$
D_{t+1}^{F B}=L_{t+1}^{F B}, \quad N_{t+1}^{F B}=0 .
$$

(ii) Optimal level of bank lending, $L_{t+1}^{F B}$, defined by:

$$
E_{t}\left[R_{l, t+1}^{F B}\right]=R_{d, t+1}^{F B}
$$

with

$$
R_{l, t+1}^{F B}=\alpha e^{a_{t+1}}\left(L_{t+1}^{F B}\right)^{\alpha-1} \quad \text { and } \quad R_{d, t+1}^{F B}=\frac{1}{\beta}-\frac{1}{\beta}\left(D_{t+1}^{F B}\right)^{-\eta}
$$

Proposition 1 follows directly from the first order conditions to (9). The proofs of all propositions are given in Appendix A. Because households value money-like securities, it is optimal to finance all bank production with debt. The expression (10) pins down the first-best level of lending by equating the marginal productivity of bank capital stock to the marginal cost of lending (Figure 2). The social marginal cost of funding is equal to the rate of return at which a household is willing to hold deposits at the financial intermediaries, $R_{d, t+1}^{F B}$. It seems implausible that the social planner would find it optimal not to keep any equity on the bank's balance sheet. As an extension, I can introduce the social cost of bank default. In such a setup, the optimal level of a bank net worth, $N_{t+1}^{F B}>0$, would trade off reduced liquidity provision and reduced social cost of bank default.

I interpret the first-best level of lending, $L_{t+1}^{F B}$, as an upper limit on the amount of positive NPV loans (creditworthy borrowers) in the economy. The model captures endogenously that there are 


\section{Figure 2: Socially Optimal Allocation}

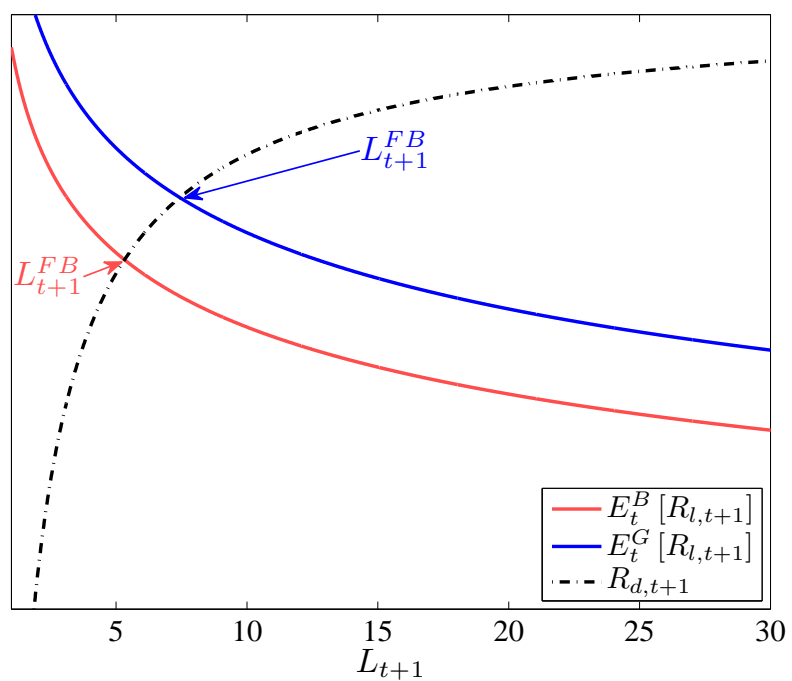

This figure depicts the social marginal cost of bank lending $R_{d, t+1}$ (black dash-dotted line) and the social marginal benefit of lending during recessions $E_{t}^{B}\left[R_{l, t+1}\right]$ (red solid line) and during expansions $E_{t}^{G}\left[R_{l, t+1}\right]$ (blue solid line) as a function of bank lending $L_{t+1}$. The optimal level of lending is at the intersection of the social marginal costs and benefits. The scale of $y$-axis is omitted, as the numbers in this parameterized example do not have economic meaning. The parameter values are set to $\beta=0.98, \eta=0.8, \alpha=0.85, \delta=1, \rho_{a}=0.97, \sigma_{a}=0.02$, and $\sigma_{\omega}=0.2$.

fewer good lending opportunities during economic slowdowns than during expansions, as I state in Proposition 2.

Proposition 2 The socially optimal level of lending, $L_{t+1}^{F B}$, is procyclical:

$$
\frac{\partial L_{t+1}^{F B}}{\partial a_{t}}>0
$$

Proposition 2 is established using the equilibrium condition (10) and an implicit function theorem (see Appendix A). Since the marginal productivity of lending is higher in good times, when the marginal cost is acyclical (Figure 2), it is optimal to maintain a higher level of production during expansions. This naturally advocates for a less stringent government regulations during periods of economic growth, when there are more lending opportunities.

\subsection{Competitive Equilibrium with No Capital Regulation}

To highlight the economic mechanism at the heart of the model, I now provide a detailed characterization of the bank's lending and capital structure choice in a competitive equilibrium. In this section, suppose that financial intermediaries face no capital regulation or, equivalently, 


\section{Figure 3: Competitive Equilibrium Allocation}

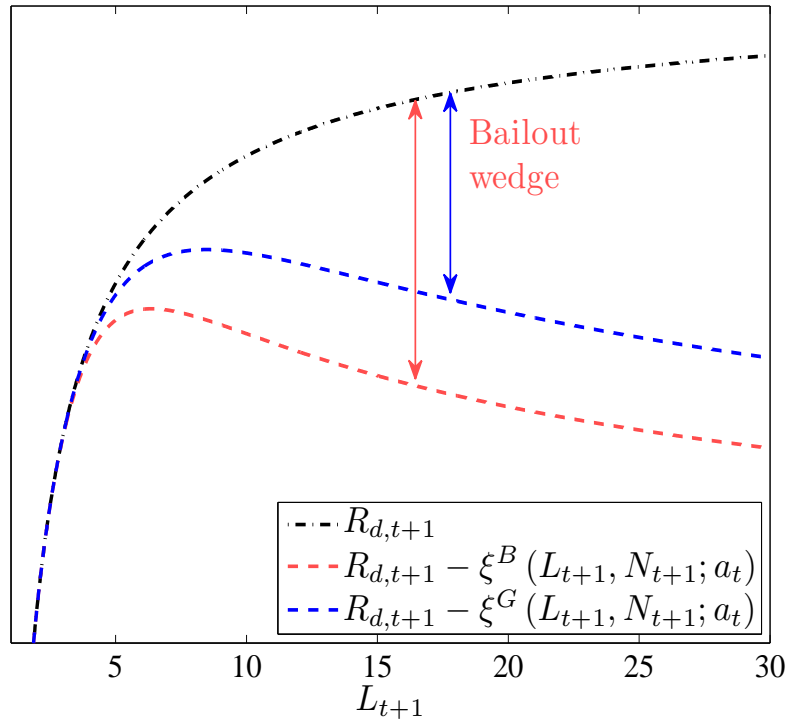

Panel A:

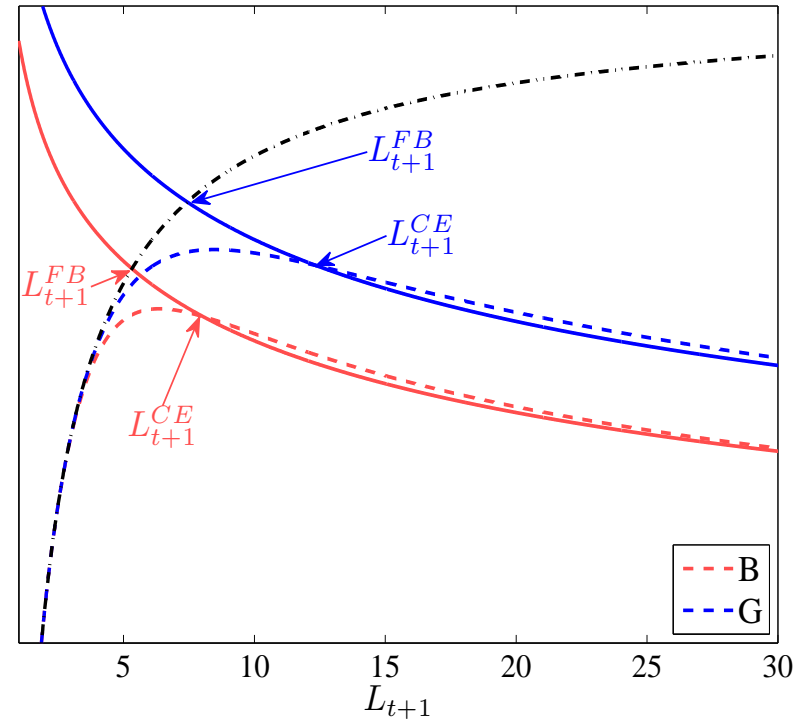

Panel B:

Panel A of this figure depicts the social marginal cost of bank lending $R_{d, t+1}$ (black dash-dotted line) and the private marginal cost of lending during recessions $R_{d, t+1}-\xi^{B}\left(L_{t+1}, N_{t+1} ; a_{t}\right)$ (red dashed line) and during expansions $R_{d, t+1}-\xi^{G}\left(L_{t+1}, N_{t+1} ; a_{t}\right)$ (blue dashed line) as a function of bank lending $L_{t+1}$. Panel B additionally depicts the marginal cost of lending $E_{t}\left[R_{l, t+1}\right]$ during recessions (red solid line) and expansions (blue solid line). The optimal level of lending at social optimum is at the intersection of the social marginal costs and benefits. The optimal level of lending in the competitive equilibrium is at the intersection of the private marginal costs and benefits. The social and private marginal benefits are identical. The scale of $y$-axis is omitted, as the numbers in this parameterized example do not have economic meaning. The parameter values are set to $\beta=0.98, \eta=0.8, \alpha=0.85, \delta=1, \rho_{a}=0.97$, $\sigma_{a}=0.02$, and $\sigma_{\omega}=0.2$.

$\zeta_{t}=0, \forall t$

The banks' first order conditions with respect to lending and the amount of equity financing are, respectively, given by:

$$
\begin{gathered}
E_{t}\left[R_{l, t+1}\right]=R_{d, t+1}-E_{t}\left[\int_{0}^{\omega_{t+1}^{*}}\left(R_{d, t+1}-e^{\omega} R_{l, t+1}\right) d \Phi(\omega)\right], \\
-\left(\frac{1}{\beta}-R_{d, t+1}\right)-E_{t}\left[\int_{0}^{\omega_{t+1}^{*}} R_{d, t+1} d \Phi(\omega)\right]<0,
\end{gathered}
$$

where the implicit (aggregate) rate of return on loans is equal to $R_{l, t+1}=\alpha e^{a_{t+1}} L_{t+1}^{\alpha-1}$ and the bailout threshold is defined by $e^{\omega_{t+1}^{*}+a_{t+1}} L_{t+1}^{\alpha}=R_{d, t+1}\left(L_{t+1}-N_{t+1}\right) . \Phi(\cdot)$ denotes the normal distribution with mean $-\frac{1}{2} \sigma_{\omega}^{2}$ and standard deviation $\sigma_{\omega}$.

The presence of government guarantees generates a bailout wedge in the bank's cost of lending, 
defined by:

$$
\xi\left(L_{t+1}, N_{t+1} ; a_{t}\right) \equiv E_{t}\left[\int_{0}^{\omega_{t+1}^{*}}\left(R_{d, t+1}-e^{\omega} R_{l, t+1}\right) d \Phi(\omega)\right] .
$$

This bailout wedge captures the difference between the social and private marginal cost of lending (see equations (10) and (11)). The bank does not fully internalize the risk costs, since those are partially borne by the taxpayers. In particular, whenever the bank's profits are hit by a sufficiently low idiosyncratic shock $\omega<\omega_{t+1}^{*}$, their credit liabilities are covered by the government. An important property of the bailout wedge is that for a given level of lending it is decreasing in the aggregate productivity, $\partial \xi / \partial a_{t}<0$ (Panel A of Figure 3). The economy is less likely to transition to a recession next period if it is currently in an expansion, implying a lower bailout wedge during periods of economic growth.

The expression (12) demonstrates that equity is relatively a more expensive source of funding for banks than debt. The reasons for this are twofold. By holding equity on their balance sheets, banks forgo government subsidies and, at the same time, relinquish the liquidity premium. As a result, the financial intermediaries will tilt their capital structure towards debt and hold no equity on their balance sheets.

The funding wedge is strictly positive $\xi\left(L_{t+1}, N_{t+1} ; a_{t}\right)>0$, implying that the social marginal cost of lending is strictly greater than the private one. Therefore, there exists an excessive lending in a competitive equilibrium when the banks face no capital regulations, $L_{t+1}^{C E}>L_{t+1}^{F B} \cdot{ }^{16}$ It is a well documented in the banking literature, that government guarantees incentivize banks to risk-shift. Contrary to the literature, in my model banks risk-shift in terms of quantity, rather than in terms of quality. By issuing more loans, banks move further into the distribution of the projects' quality (borrowers' creditworthiness), meaning that more loans result in a lower quality loan portfolio. I lay out a characterization of the competitive equilibrium in Proposition 3.

Proposition 3 The competitive equilibrium with no capital regulation in place is characterized by:

(i) Optimal level of lending, $L_{t+1}^{C E}$, defined by:

$$
E_{t}\left[R_{l, t+1}^{C E}\right]=R_{d, t+1}^{C E}-\xi\left(L_{t+1}^{C E}, N_{t+1}^{C E} ; a_{t}\right)
$$

with

$$
R_{l, t+1}^{C E}=\alpha e^{a_{t+1}}\left(L_{t+1}^{C E}\right)^{\alpha-1} \quad \text { and } \quad R_{d, t+1}^{C E}=\frac{1}{\beta}-\frac{1}{\beta}\left(D_{t+1}^{C E}\right)^{-\eta} .
$$

\footnotetext{
${ }^{16} \xi\left(L_{t+1}, N_{t+1} ; a_{t}\right)>0$ as long as $L_{t+1}>1$, which ensures a positive rate of return on deposits.
} 
(ii) Bank's optimal finance policy:

$$
D_{t+1}^{C E}=L_{t+1}^{C E}>L_{t+1}^{F B}, \quad N_{t+1}^{C E}=N_{t+1}^{F B}=0 .
$$

In the competitive equilibrium with the risk-shifting mechanism in place, the optimal level of lending continues to be pro-cyclical (see Proposition 4). On the one side, lending is more productive during expansions, calling for a higher level of investment. On the other side, bank cost of lending goes up in good times because of a reduced bailout wedge, pushing the optimal level of lending down (Panel B of Figure 3). Under log-normality of the aggregate productivity shock, the former channel dominates the later and, hence, the procyclicality of the optimal level of lending follows.

Proposition 4 In a competitive equilibrium with no capital regulations in place, the optimal level of lending is procyclical:

$$
\frac{\partial L_{t+1}^{C E}}{\partial a_{t}}>0
$$

Using capital regulations, the government will aim to restrict inefficient lending that arises in a competitive equilibrium. And whether tight capital requirements will be more beneficial during expansions or recessions will depend on how the level of excessive investment, $L_{t+1}^{C E} / L_{t+1}^{F B}-1$, behaves over the business cycle. Proposition 5 provides the condition under which the lending level in a competitive equilibrium is more procyclical than the first-best allocation.

Proposition 5 The level of overinvestment is procyclical if and only if

$$
-\bar{\xi}_{a, t}<\frac{\partial \xi\left(L_{t+1}^{C E}, N_{t+1}^{C E} ; a_{t}\right)}{\partial a_{t}}<0 .
$$

The threshold value $\bar{\xi}_{a}$ is defined in Appendix A. There are a number of channels in force that indicate how banks' risk-shifting incentives change over the business cycle. First, a decreasing returns to scale production technology generates a scale effect: in proportionate terms banks riskshift, by the same amount across the states of the economy, but since in good times they risk-shift on a larger scale, the overinvestment is higher in absolute terms. This mechanism can be demonstrated in the setup in which the bailout wedge is proportionate to the deposit rate and the deposit rate is constant. The second channel arises due to the fact that the bailout wedge is increasing in lending, $\partial \xi / \partial L_{t+1}>0$, as shown in Panel A of Figure 3. The more loans that banks issue, the bigger is the size of the government transfer in case a bailout happens. This property of the bailout wedge results from the concave preferences for liquid assets and decreasing returns to scale in production. 
On the one side, a higher level of investment during periods of economic growth implies a higher deposit rate, since the economy is saturated with deposits and households are willing to relinquish a smaller premium on safe assets. On the other side, decreasing returns to scale imply a lower income that is forgone in a bailout when banks increase lending. A higher deposit rate and a lower rate of return on loans, in turn, deliver a larger bailout wedge during expansions. Third, assuming everything else is equal, the bailout wedge is decreasing in the productivity shock $a_{t}$, meaning that the amount of inefficient lending is reduced in good times. The restriction (14) ensures that in the equilibrium the bailout wedge or, equivalently, the banks' risk-shifting motives are procyclical.

\subsection{Competitive Equilibrium with Capital Regulation}

Next suppose that equity needs be at least a fraction $\zeta_{t}>0$ of loans for banks to be able to operate. Given that in my model equity is a relatively more expensive form of finance for banks than debt, the capital constraint is binding in each period of time (see Proposition 6).

Proposition 6 The capital constraint is binding:

$$
N_{t+1}^{C E}=\zeta_{t} L_{t+1}^{C E}, \quad D_{t+1}^{C E}=\left(1-\zeta_{t}\right) L_{t+1}^{C E}
$$

To demonstrate what are the implications of capital regulation on bank cost of lending, I now provide the banks' first-order conditions with respect to lending and the amount of equity financing, respectively, given by:

$$
\begin{aligned}
E_{t}\left[R_{l, t+1}^{C E}\right] & =R_{d, t+1}^{C E}-\xi\left(L_{t+1}^{C E}, N_{t+1}^{C E} ; a_{t}\right)+\underbrace{\frac{1}{\beta} \lambda_{t} \zeta_{t},}_{\text {equity wedge }} \\
\frac{1}{\beta} \lambda_{t} & =E_{t}\left[\int_{0}^{\omega^{*}} R_{d, t+1}^{C E} d F(\omega)\right]+\left(\frac{1}{\beta}-R_{d, t+1}^{C E}\right),
\end{aligned}
$$

where $\lambda_{t}$ is a Lagrange multiplier on the capital constraint. Imposing capital regulation introduces an equity wedge into the bank's cost of funding. The first term of equation (16) captures that a better capitalized bank forgoes the government subsidies and, as a result, faces higher lending costs. A positive level of capital requirement also means that the bank's supply of deposits is reduced, implying a higher liquidity premium and, as a result, a higher equity wedge, as captured by the second term of equation (16).

To better understand the costs and benefits of capital regulation, it is useful to decompose 
Figure 4: Effects of Capital Regulations on the Bank's Lending Costs

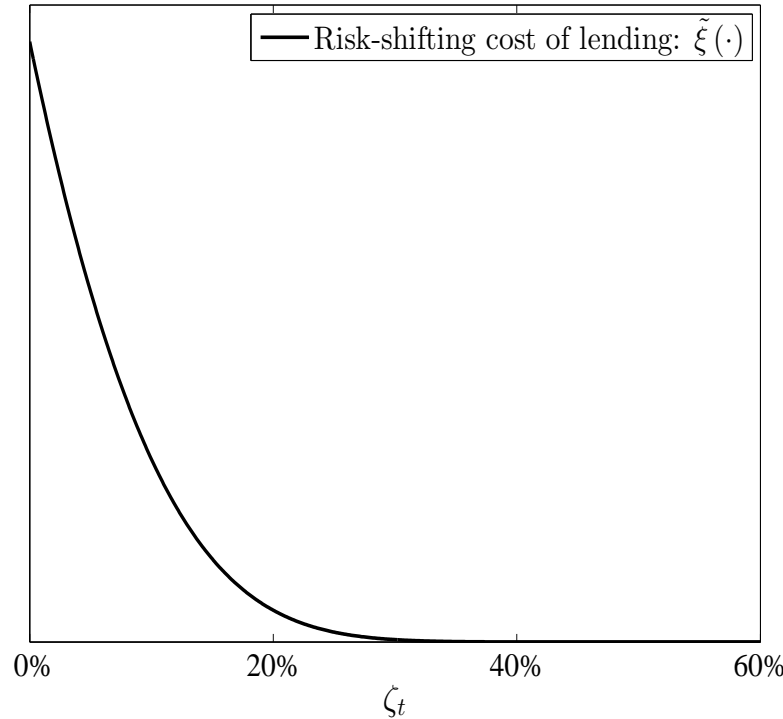

Panel A

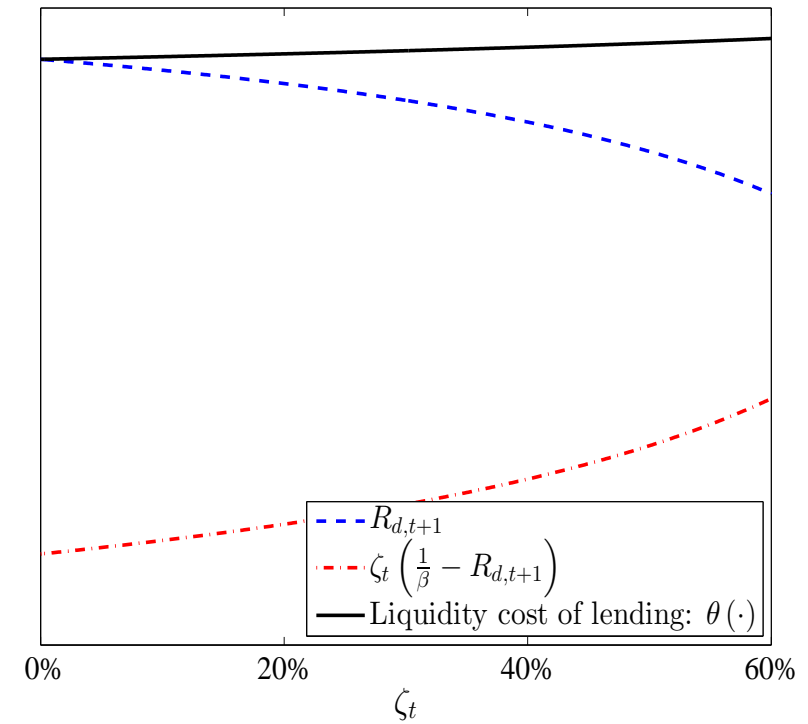

Panel B

Panel A of this figure depicts the risk-shifting costs of bank lending as a function of capital requirements $\zeta_{t}$ (holding lending and productivity fixed). Panel B depicts the liquidity costs of bank lending (black solid line) and its two components: (i) the deposits rate (blue dashed line) and (ii) the equity wedge (red dash-dotted line) as a function of capital requirements $\zeta_{t}$. The scale of $y$-axis is omitted, as the numbers in this parameterized example do not have economic meaning. The parameter values are set to $\beta=0.98, \eta=0.8, \alpha=0.85, \delta=1, \rho_{a}=0.97, \sigma_{a}=0.02$, and $\sigma_{\omega}=0.2$.

the bank's funding costs into (i) the liquidity channel and (ii) the risk-shifting channel, which are, correspondingly, defined by:

$$
\begin{aligned}
\theta\left(L_{t+1}, \zeta_{t}\right) & \equiv R_{d, t+1}+\zeta_{t}\left(\frac{1}{\beta}-R_{d, t+1}\right) \\
\tilde{\xi}\left(L_{t+1}, \zeta_{t} ; a_{t}\right) & \equiv E_{t}\left[\int_{0}^{\omega_{t+1}^{*}}\left(\left(1-\zeta_{t}\right) R_{d, t+1}-e^{\omega} R_{l, t+1}\right) d \Phi(\omega)\right] .
\end{aligned}
$$

The obvious benefit of tightened capital requirements is reduced risk-shifting incentives for banks. As shown in Panel A of Figure 4, the bailout wedge adjusted for the presence of capital regulations $\tilde{\xi}$ decreases as capital regulations are tightened, implying that less inefficient firms are financed. There are two reinforcing mechanisms in place: the bailout threshold $\omega_{t+1}^{*}$, as well as the size of a government transfer in case of a bank failure $\left(\left(1-\zeta_{t}\right) R_{d, t+1}-e^{\omega} R_{l, t+1}\right)$, falls as capital requirements become more stringent.

The level of the liquidity costs of lending $\theta$ is mainly determined by the amount of deposits supplied to households. A higher capital requirement means that the supply of liquid assets is 
reduced and, as a result, a liquidity premium is magnified. From the bank's perspective, this implies a lower required rate of return on debt, but a higher equity wedge (Panel B of Figure 4). As long as $\eta<1$, the liquidity cost of lending is strictly increasing in $\zeta_{t}$. Overall, capital regulations translate into a heightened lending costs for banks, suggesting that excessive lending can be restrained by imposing a sufficiently high capital requirement.

\subsection{Optimal Capital Requirements}

The goal of a social planner when choosing an optimal level of capital requirements is to dampen bank's risk-shifting incentives, but without restricting the bank' supply of high-quality loans and deposits. As a matter of fact, it is not feasible to restore both first-best level of lending and liquidity provision at the same time with only the help of capital requirements. Suppose for now that the only goal of the regulator is to restore a socially optimal lending level and to achieve this goal the capital requirement is set to $\zeta_{t}^{L}>0$, which is the "lending capital requirement". This translates into a level of liquidity provision $D_{t+1}^{\zeta^{L}}$ that is below the socially optimal lending level:

$$
D_{t+1}^{\zeta^{L}}=\left(1-\zeta_{t}^{L}\right) L_{t+1}^{F B}<L_{t+1}^{F B}=D_{t+1}^{F B}
$$

Similarly, consider a social planner who aims to recover a socially optimal level of deposits and imposes a capital requirement of $\zeta_{t}^{D}$, which is the "liquidity capital regulation". This capital requirement, however, allows inefficient lending from a social perspective:

$$
L_{t+1}^{\zeta^{D}}=\frac{D_{t+1}^{\zeta^{D}}}{1-\zeta_{t}^{D}}=\frac{L_{t+1}^{F B}}{1-\zeta_{t}^{D}}>L_{t+1}^{F B}
$$

To provide the intuition behind the design of the optimal capital regulations, I first solve for the lending and liquidity capital requirements in the baseline model. This allows me to demonstrate the cyclical properties of capital regulation in a fairly simple way.

\subsubsection{Lending Capital Requirement}

Suppose now that the only goal of the social planner is to rule out excessive bank lending. To do so, she institutes the lending capital requirement, defined in Proposition 7.

Proposition 7 The first-best level of bank lending, $L_{t+1}^{\zeta^{L}}=L_{t+1}^{F B}$, is restored when a capital 
Figure 5: Lending Capital Requirement

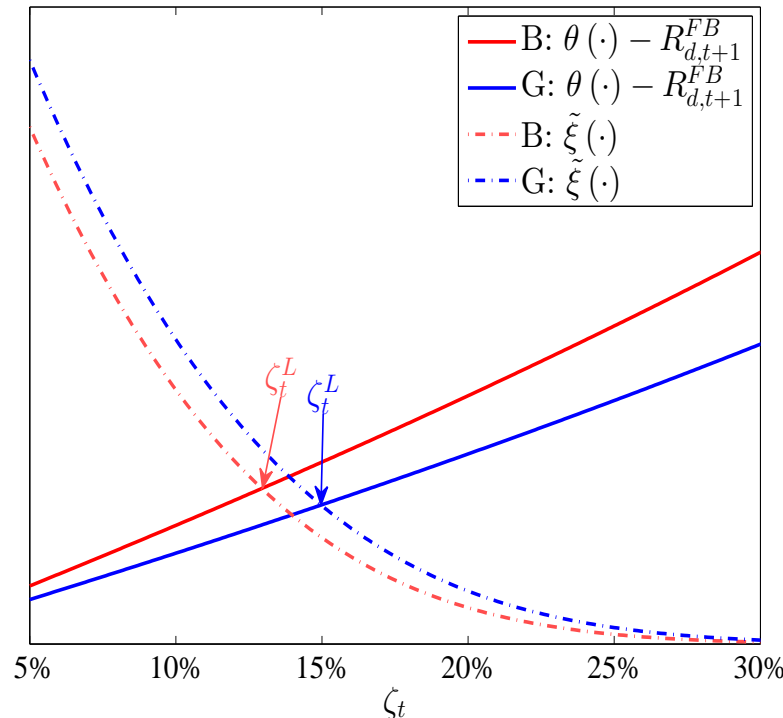

Panel A

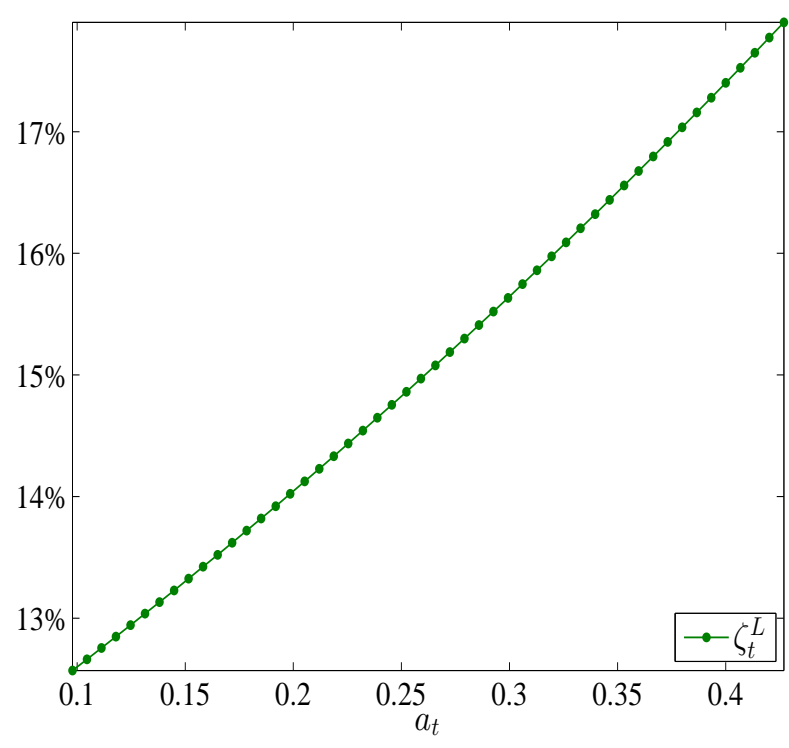

Panel B

Panel A in this figure depicts (i) the benefit of capital requirements during recessions (dash-dotted red line) and during expansions (dash-dotted blue line) and (ii) the cost of capital requirements during recessions (solid red line) and during expansions (solid blue line) as a function of $\zeta_{t}$. Panel B depicts the liquidity capital requirement as a function of the aggregate productivity. The scale of $y$-axis is omitted, as the numbers in this parameterized example do not have economic meaning. The parameter values are set to $\beta=0.98, \eta=0.8, \alpha=0.85, \delta=1, \rho_{a}=0.97$, $\sigma_{a}=0.02$, and $\sigma_{\omega}=0.2$.

requirement is set to $\zeta_{t}^{L}$, defined by:

$$
\theta\left(L_{t+1}^{F B}, \zeta_{t}^{L}\right)-R_{d, t+1}^{F B}=\tilde{\xi}\left(L_{t+1}^{F B}, \zeta_{t}^{L} ; a_{t}\right)
$$

The expression (17) equates the bank's private cost of lending to the social one, ensuring that the bank chooses the first-best level of lending when it encounters a capital requirement of $\zeta_{t}^{L}$. The right-hand side of the equation (17) captures a key benefit of capital requirements - reduced risk-shifting incentives - depicted in Panel A of Figure 5 by the dash-dotted lines. The tighter the capital regulations the lower the expected government subsidies and, hence, the lower the bank's overinvestment. As discussed earlier, a capital regulation that is too restrictive can amplify the liquidity costs of lending via an equity wedge, leading to reduced liquidity provision and potentially restricting the funding of high-quality projects. Panel A of Figure 5 shows that the spread between the private liquidity cost of lending and the social one depicted by the solid lines is increasing in $\zeta_{t}^{L}$. The primary question I address in this paper is how optimal bank capital requirements behave over the business cycle. This essentially means answering whether the risk-shifting incentives for banks 
are stronger in good or bad economic environments, and whether equity financing is more costly during expansions or recessions.

The risk-shifting incentives for banks are defined by the bailout wedge $\tilde{\xi}$. Differentiating this wedge with respect to the productivity shock,

$$
\frac{d \tilde{\xi}\left(L_{t+1}^{F B}, \zeta_{t}^{L} ; a_{t}\right)}{d a_{t}}=\frac{\partial \tilde{\xi}\left(L_{t+1}^{F B}, \zeta_{t}^{L} ; a_{t}\right)}{\partial a_{t}}+\underbrace{\frac{\partial \tilde{\xi}\left(L_{t+1}^{F B}, \zeta_{t}^{L} ; a_{t}\right)}{\partial L_{t+1}^{F B}}}_{>0} \underbrace{\frac{\partial L_{t+1}^{F B}}{\partial a_{t}}}_{>0} \lessgtr 0
$$

demonstrates that there are two competing effects in place. On the one hand, the probability of a bank bailout decreases with the productivity shock, implying a smaller wedge in the bank's lending costs. On the other hand, during periods of economic growth there are more lending opportunities, indicating that more projects will be funded in the first best. Because the bailout wedge expands when lending is higher, the risk-shifting motives become stronger during expansions. Panel A of Figure 5 shows that under chosen parameter values, the latter channel dominates the former and, as a result, the bailout wedge is procyclical, suggesting that a higher capital requirement is necessary during periods of economic growth.

Households' preference for safe assets implies that equity is costly, especially during recessions. To the extent a bank's balance sheet shrinks during a recession, less safe assets are created by banks and the economy is less saturated with liquidity. This translates into a higher liquidity premium and, as a result, a higher liquidity cost of lending. Panel A of Figure 5 shows that for a given level of $\zeta_{t}$, the cost of capital requirements is countercyclical, suggesting that capital charges should be reduced during economic slowdowns.

The two effects - the countercyclical cost and procyclical benefit of capital regulation - reinforce each other and deliver a capital requirement, $\zeta_{t}^{L}$, that is high in times during periods of economic growth and low during downturns (Panel B of Figure 5).

\subsubsection{Liquidity Capital Requirement}

Consider now a type of capital regulation designed to restore the first-best level of liquidity provision (i.e., the first-best level of deposit supply). Proposition 8 provides a characterization of the liquidity capital requirement.

Proposition 8 The first-best level of deposits, $D_{t+1}^{\zeta^{D}}=D_{t+1}^{F B}$, is achieved, when the social planner 
sets the capital requirement equal to $\zeta_{t}^{D}$, defined by:

$$
\left(1-\zeta_{t}^{D}\right)^{\alpha-1} \theta\left(\frac{L_{t+1}^{F B}}{1-\zeta_{t}^{D}}, \zeta_{t}^{D}\right)-R_{d, t+1}^{F B}=\left(1-\zeta_{t}^{D}\right)^{\alpha-1} \tilde{\xi}\left(\frac{L_{t+1}^{F B}}{1-\zeta_{t}^{D}}, \zeta_{t}^{D} ; a_{t}\right)
$$

As opposed to the lending capital requirement, the liquidity capital requirement allows inefficient bank lending in the amount of $\frac{\zeta_{t}^{D}}{1-\zeta_{t}^{D}} L_{t+1}^{F B}$. This results in a larger bailout wedge $\tilde{\xi}$, as well as a higher liquidity cost of lending $\theta$, since the economy is more saturated with safe assets. Importantly, when a bank's balance sheet grows, the rate of return on loans drops due to a decreasing returns to scale. This loss in a bank's productivity can be viewed as an additional cost that arises with the liquidity capital requirement, and it is captured by the factor $\left(1-\zeta_{t}\right)^{\alpha-1} \geq 1$.

When setting the level of liquidity capital requirement, the underlying trade-off remains the same. On the one side, tight capital regulations restrict banks' risk-shifting incentives as captured by the right-hand side of the equation (18). But, on the other side, it increases banks' lending costs via the liquidity channel and, as a result, may lead to a reduction in bank loans and deposits as captured by the left-hand side of the equation (18). Similar to the case with the lending capital requirement, stringent capital ratios are of most use during periods of economic growth, but are also less costly, delivering a liquidity capital requirement that is procyclical.

Both lending and liquidity capital requirements focus only on one dimension of the problem either dampening banks' incentives to risk-shift or stimulating banks' creation of liquid assets. In order to ensure highest lifetime utility of households in this economy, I solve for an optimal Ramsey policy that balances reduced inefficient lending and reduced liquidity provision. The Ramsey capital requirement is characterized in Section 5 .

\section{Quantitative Assessment}

In this section, I quantify policy recommendations on what defines optimal time variation in bank capital requirements. First, I extend the baseline model and calibrate it to a fixed capital requirement to match key macroeconomic quantities, as well as their counterparts in the bank data. Next, I solve for the optimal policy rule using the chosen parameter specification and characterize it in terms of the relevant macroeconomic aggregates. 


\subsection{Quantitative Model}

To best match the data, I generalize the households' preferences in the quantitative model, as well as introduce a bank-independent production sector.

Household sector. In the model, households have constant relative risk aversion (CRRA) preferences with the risk-aversion coefficient $\gamma$. The households' utility is defined over consumption and deposit holdings according to a constant elasticity of substitution (CES) aggregator:

$$
v\left(C_{t}, D_{t+1}\right)=\left(C_{t}^{\frac{\tilde{\eta}-1}{\tilde{\eta}}}+\chi D_{t+1}^{\frac{\tilde{\eta}-1}{\tilde{\eta}}}\right)^{\frac{\tilde{\eta}}{\tilde{\eta}-1}},
$$

where $\chi$ is a share parameter and $\tilde{\eta}$ is the elasticity of substitution between consumption and liquidity services.

The households' first-order conditions imply that the rate of return on bank debt satisfies:

$$
E_{t}\left[M_{t, t+1} R_{d, t+1}\right]=1-\chi\left(\frac{D_{t+1}}{C_{t}}\right)^{-\frac{1}{\eta}}
$$

where $M_{t, t+1}$ is the stochastic discount factor equal to:

$$
M_{t, t+1}=\left(\frac{v\left(C_{t+1}, D_{t+2}\right)}{v\left(C_{t}, D_{t+1}\right)}\right)^{\frac{1}{\tilde{\eta}}-\gamma}\left(\frac{C_{t+1}}{C_{t}}\right)^{-\frac{1}{\tilde{\eta}}} .
$$

Similar to the baseline case, there is a discount on the deposits rate compared to the rate of return on any other safe asset. ${ }^{17}$ In the quantitative model, the liquidity premium depends on the ratio of deposit holdings and consumption, rather than just the level of deposit holdings. This helps to capture the idea that higher consumption increases the marginal utility of liquidity of households.

Production sector. By and large, the economy's production sector is reliant either on bank debt or access to capital markets to undertake production projects. To the extent that some borrowers lack access to capital markets, typically due to informational asymmetries, agents can be broadly classified into two groups. The first group is small businesses and households, who have their financial needs fulfilled by bank loans and mortgages. The second group is borrowers who have access to public markets and use multiple forms of debt financing. To capture this heterogeneity in borrowers, the model now includes both a banking sector and a bank-independent sector. The bank-independent sector includes firms with access to capital markets.

For the most part, the banking sector remains the same in the quantitative as in the baseline

\footnotetext{
${ }^{17}$ In the quantitative model, the rate of return on any other safe asset other than bank debt is equal to $1 / E_{t}\left[M_{t, t+1}\right]$.
} 
model. Each bank $j \in \Omega$ operates a sector-specific production technology:

$$
e^{\omega_{j, t}+\bar{a}_{b}+a_{t}} l_{j, t}^{\alpha_{b}}
$$

where the aggregate productivity shocks follows an $\mathrm{AR}(1)$ process:

$$
a_{t}=\rho_{a} a_{t-1}+\sigma_{a} \epsilon_{t}, \quad \epsilon_{t} \sim i i d \mathcal{N}(0,1)
$$

The constant $\bar{a}_{b}$ is introduced to better match the fraction of output produced in the banking sector. The bank-specific shock is iid across time and banks, with the law of motion given by:

$$
\omega_{j, t}=-\frac{1}{2} \sigma_{\omega}\left(a_{t}\right)^{2}+\sigma_{\omega}\left(a_{t}\right) \varepsilon_{j, t}, \quad \varepsilon_{j, t} \sim \text { iid } \mathcal{N}(0,1)
$$

Consistent with Bloom, Floetotto, Jaimovich, Saporta-Eksten and Terry (2012), idiosyncratic productivity risk varies countercyclically with the aggregate productivity; specifically, I choose $\sigma_{\omega}\left(a_{t}\right)=\sigma_{\omega} e^{-\nu a_{t}}$

The capital in the banking sector depreciates at rate $\delta$ and accumulates according to:

$$
l_{j, t+1}=(1-\delta) l_{j, t}+i_{b, j, t}
$$

Further, the financial intermediaries incur an operating cost $o_{b}$ per unit of intermediated assets. One could think of this cost as the resources spent to monitor bank borrowers. As before, the banks finance production using a mixture of equity and debt financing. Since there is neither equity issuance costs nor adjustments costs to capital, the equilibrium continues to be symmetric and all banks make identical decisions $l_{j, t+1}=L_{t+1}, n_{j, t+1}=N_{t+1}$, and $d_{j, t+1}=D_{t+1}, \forall j \in \Omega$. Hence, the output produced in the banking sector equals to $Y_{b, t}=e^{\bar{a}_{b}+a_{t}} L_{t}^{\alpha_{b}}$.

The bank's first-order conditions imply that the capital constraint is binding, while the optimal level of lending satisfies:

$$
E_{t}\left[M_{t, t+1}\left(R_{l, t+1}+\left(1-\delta-o_{b}\right)\right)\right]=\theta_{t}-\tilde{\xi}_{t}
$$


where the liquidity and risk-shifting costs of lending are, respectively, defined by:

$$
\begin{aligned}
& \theta_{t}=E_{t}\left[M_{t, t+1} R_{d, t+1}\right]+\zeta_{t}\left(1-E_{t}\left[M_{t, t+1} R_{d, t+1}\right]\right) \\
& \tilde{\xi}_{t}=E_{t}\left[M_{t, t+1}\left(\int_{0}^{\omega^{*}}\left(\left(1-\zeta_{t}\right) R_{d, t+1}-e^{\omega} R_{l, t+1}-\left(1-\delta-o_{b}\right)\right) d \Phi(\omega)\right)\right] .
\end{aligned}
$$

with the loan rate being equal to

$$
R_{l, t}=e^{\bar{a}_{b}+a_{t}} L_{t}^{\alpha_{b}-1}
$$

The firms in the bank-independent sector similarly employ a decreasing returns to scale and produce consumption goods, using capital $K_{f, t}$ as the only input, $Y_{f, t}=e^{a_{t}} K_{f, t}^{\alpha_{f}}$. To form output, the firms rent out capital from the household sector at the rate of return:

$$
R_{k, t}=\alpha_{f} e^{a_{t}} K_{f, t}^{\alpha_{f}-1}
$$

The households are the owners of the financial intermediaries, as well as of the firms in the bank-independent sector. Therefore, at the end of each period, they receive proceeds from the banks' activity $Z_{t}$, as well as the firms' profits $\Pi_{t}$. Because the households own the capital used in production in the bank-independent sector, they are the ones who make the capital investment choices. To invest in capital, households must pay a small operational cost $o_{f}$. The capital in the non-banking sector depreciates at the same rate as in the banking sector and accumulates according to:

$$
K_{f, t+1}=(1-\delta) K_{f, t}+I_{f, t}
$$

\subsection{Calibration}

Data for the aggregate sector - the banking and non-banking sectors - comes from the Financial Accounts of the United States Z.1 issued by the Board of Governors of the Federal Reserve ${ }^{18}$ and from National Income and Product Accounts (NIPA) from the Bureau of Economic Analysis. ${ }^{19}$ In particular, the output produced in the total economy, $Y$, is measured using the income approach as the gross value added by all sectors, except Financial Business. ${ }^{20}$ Similarly, I exclude the financial

\footnotetext{
${ }^{18}$ https://www.federalreserve.gov/releases/z1/.

${ }^{19}$ http://www.bea.gov/itable/index.cfm.

${ }^{20}$ The sectors included are Households and Nonprofit Institutions Serving Households, Nonfinancial Noncorporate Business, Nonfinancial Corporate Business and Government. The data is collected from the Financial Accounts, S.2. Selected Aggregates for Total Economy and Sectors
} 
sector when measuring gross fixed capital formation, $I$, and stock of fixed assets, $K{ }^{21}$ Consumption is defined as the sum of expenditures on non-durable goods and services. All the quantities are deflated with the Consumer Price Index and normalized by the NIPA population. The data on CPI inflation are from the Bureau of Labor Statistics, with the price level being normalized to 1 as of December of 2009.

The challenging part of mapping the model to the data is to differentiate the data on output into the value added by the banking sector and the bank-independent sector. In the model, the final goods produced by financial intermediaries, $Y_{b}$, are viewed as the value added by bank borrowers (predominantly, small businesses and households) and, consequently, is measured as the the gross value added by Households and Nonprofit Institutions Serving Households and Nonfinancial Noncorporate Business sectors. ${ }^{22}$ The output produced by borrowers with access to capital markets, $Y_{f}$, is measured as the gross value added by Nonfinancial Corporate Business and Government sectors. ${ }^{23}$ As documented in Rauh and Sufi (2010), corporate businesses both use bonds and utilize bank debt as funding sources. In this sense, I overestimate the value-added by the bank-independent sector and, as a result, underestimate the costs associated with tight capital requirements, as reduced lending translates into a smaller loss in the aggregate output. According to this measure the banking sector accounts for about $28 \%$ of the output produced in the economy. I pursue the same split between borrowers when measuring gross fixed capital formation and stock of capital in the two-sectors.

The model is calibrated at annual frequency for the 1980-2008 period. I exclude the post Great Recession period to avoid zero-lower bound concerns. The parameters are calibrated to satisfy the steady-state conditions of the model, along with the target first and second moments in the data.

Long run behavior. The subjective discount factor is set to $\beta=0.975$, which is a value traditionally used in macroeconomics. The Cobb-Douglas function parameters $\alpha_{b}$ and $\alpha_{f}$ are chosen to match a capital-output ratio in the banking and non-banking sectors, respectively. In the data, a capital-output ratio of the financial intermediaries (or, equivalently, of firms in the banking sector) is equal to 4.9, which is roughly twice as high as a capital-output ratio of the bank-independent firms (see Appendix Table B2). As a result, the $\alpha_{b}=0.78$ decreasing return to scale parameter for the banks is larger than the $\alpha_{f}=0.355$ corresponding for the firms. The scalar

\footnotetext{
${ }^{21}$ The data on investment are from the Financial Accounts, S.2. Selected Aggregates for Total Economy and Sectors, while the data on capital stock are collected from the NIPA Fixed Assets tables, specifically, Table 6.1. Current-Cost Net Stock of Private Fixed Assets by Industry Group and Legal Form of Organization and Table 7.1A. Current-Cost Net Stock of Government Fixed Assets

${ }^{22}$ The data are from the Financial Accounts, S.2. Selected Aggregates for Total Economy and Sectors.

${ }^{23}$ The data are from the Financial Accounts, S.2. Selected Aggregates for Total Economy and Sectors.
} 
$\bar{a}_{b}$ is set so that a ratio of loans to a total stock of capital in the model is identical to the one in the data. By construction, I also match a market fraction of the banking sector in terms of the produced output, as well as a capital-output ratio of the aggregate sector. The capital depreciation rate is set to $\delta=0.075$ to produce a plausible value for the model-implied ratio of investment-tocapital. The operating cost in the banking sector $o_{b}$ is calibrated to match a bank's profit-to-loan ratio. The bank data stems from the aggregated regulatory filings, the so-called call reports, as reported by the Federal Deposit Insurance Corporation (FDIC). ${ }^{24}$ A bank's loans are measured as the total assets net of the securities, fixed assets,and cash and due to depository institutions, while a bank's profits are measured as the total interest and non-interest income net of the securities interest income and total interest expense. The operating cost in the bank-independent sector is determined using the standard deviation of firms' capital investment.

Productivity shocks. Estimates of Solow residuals typically imply a highly persistent AR(1) process for the $\log$ productivity $a_{t}$. I use a standard value of 0.95 for the autoregressive coefficient and choose a $\sigma_{a}$ of $0.02(\sqrt{4} \cdot 0.01)$ to match the standard deviation of the aggregate output in the data.

Idiosyncratic shocks. I use the parameter $\sigma_{\omega}$ to determine both the risk choice of banks (i.e., level of inefficient lending) and, for the most part, the fraction of banks being bailed out each period. To the extent that there is no default in the model, I define the bailout rate as a fraction of failed banks, both assisted and not assisted by the government. The data on bank failures are from the fail bank list issued by the FDIC. ${ }^{25}$ On average, $0.76 \%$ of all insured institutions fail each year, delivering $\sigma_{\omega}$ equal to 0.325 . The parameter $\mu_{\omega}$ is set to normalize the mean of idiosyncratic shock $\omega$ to 1 . The level of $\nu$ is chosen to generate the range of the idiosyncratic volatility dispersion $\sigma_{\omega}^{2}\left(a_{t}\right)$ consistent with the empirical evidence in Bloom et al. (2012). Specifically, I target a $15 \%$ increase of the volatility dispersion in recessions relative to expansions. This is on the conservative end of the values reported in Bloom et al. (2012).

Capital adequacy ratios. Even though my aim is to characterize optimal capital regulation that varies over the time, the model is calibrated with a fixed level of capital requirement in place, $\bar{\zeta}$. In accordance with Basel III capital standards, FDIC-insured depository institutions are required to maintain the leverage ratio (Tier 1 capital divided by total assets) of $4 \%$ and the Tier 1 capital ratio (Tier 1 capital divided by total risk-weighted assets) of $6 \% .{ }^{26}$ Obviously, these two ratios

\footnotetext{
${ }^{24}$ https://www5.fdic.gov/idasp/advSearch_warp_download_all.asp?intTab=4.

${ }^{25}$ https://www5.fdic.gov/hsob/SelectRpt.asp?EntryTyp=30\&Header=1\&tab=bankFailures.

${ }^{26}$ Core capital elements (Tier 1 ) consists of common stockholders' equity capital, noncumulative perpetual preferred stock, and minority interests in the equity capital accounts of consolidated subsidiaries.
} 
are different in the data, but are the same in the model. On average, depository institutions hold $7.26 \%$ of total assets and $10.20 \%$ of total risk-weighted assets in terms of core capital ${ }^{27}$. In the benchmark calibration, I set $\bar{\zeta}$ to $7.26 \%$.

Liquidity premium. The financial intermediaries play a special role in creating liquidity; they transform illiquid long-term assets into liquid short-term liabilities that offer non-pecuniary services to investors. In accordance with this view, when mapping $D$ to the data, I aim to capture the short-term part of bank debt that is used to finance risky assets. Following Krishnamurthy and Vissing-Jorgensen (2015), this measure of bank debt equals the sum of all deposits and the other forms of short-term debt categories net of short-term assets and holdings of Treasuries. ${ }^{28}$ Further, I assume that the short-term Treasuries and bank debt are perfect substitutes and, as a result, require the same rate of return. Under this assumption, the liquidity premium is constructed as the spread between the rates of return on the 3-month AA Commercial Paper and the 3-month Treasury bill, similar to Krishnamurthy and Vissing-Jorgensen (2012). ${ }^{29,30}$

The preference of households for bank debt is governed by a share parameter, $\chi$, and by elasticity of substitution between consumption and liquidity services, $\tilde{\eta}$. The level of $\tilde{\eta}$ is set to match the volatility of a ratio of the bank debt to consumption. Given the value of $\tilde{\eta}$, the scalar $\chi$ is set so that the steady-state level of the liquidity premium is equal to $0.57 \%$ (annually).

In Table B1 in Appendix B, I summarize the benchmark configuration of the model parameters. Tables B2 and B3 report the implications of the chosen parameters for the first and second unconditional moments of the key variables. Overall, the model can successfully match a number of moments for the main aggregates. The model has a hard time matching the volatility of bank lending and, because of the binding capital constraint, also the volatility of bank debt. In the model, bank lending is a stock variable and is quite persistent, therefore having rather modest

\footnotetext{
${ }^{27}$ The data on capital adequacy ratios are collected from the "Ratios by Asset Size Group" table issued by the FDIC. Due to the availability of the data, I calculate the average leverage ratio for the sample period $1984-2008$ and the average Tier 1 capital ration for the sample period 1990 - 2008.

${ }^{28}$ An alternative approach is to map $D$ to "core" deposits, which is the largest source of bank funding and the major source of safe and liquid assets for households (see, for example, Drechsler, Savov and Schnabl (2016)). Core deposits include checking and money market accounts, as well as small time deposits. The cyclical properties of this measure, however, change over the sample period of 1960-2015: while deposits exhibit strong positive correlation with output growth in the earlier part of the sample, they become mildly countercyclical in the later one. Yet, over the sample period I consider in this paper deposits co-move positively with output overall. Nonetheless, I focus on a broader notion of the liquidity supply as it better captures the role of banks in creation of safe and liquid assets.

${ }^{29}$ For the period of $1997-2008$, the rate of return on Commercial Paper is calculated as the average of the rate of return on Financial and Non-Financial Commercial Paper.

${ }^{30}$ Other potential measures include (i) the spread between the rates of return on the Resolution Funding Corporation (Refcorp) bonds and the Treasury bills (Longstaff (2002)), and (ii) the spread between the interest rates on general collateral repurchase agreement (GC repo) and the Treasury bills (Nagel (2014)). These measures produce quantitatively similar results.
} 
fluctuation over the business cycle. The low volatility of bank debt, in turn, translates into low volatility of the liquidity premium. As a potential remedy, I can introduce a stochastic process for one of the parameters governing a demand function for safe assets $(\chi$ or $\eta$ ). For parsimony of the results, for now I consider the calibration without liquidity shocks. As reported in Table B4, the model generates the correct signs for the business cycle correlations, but overstates their magnitudes. This is a common characteristic of the standard real business cycle model with one shock in the economy.

To understand the model dynamics, I now analyze the impulse response functions of key quantities to a one standard deviation positive total factor productivity (TFP) shock. As shown in Appendix Figure B1, following a positive shock, lending in the banking sector increases immediately by $1 \%$ and continues to grow for a number of years. This is the case because lending opportunities improve. An increase in lending, in turn, is accompanied by an increase in deposits $(0.03 \%$ increase in the deposits-to-consumption ratio) and, as a result, a reduction in the liquidity premium. This result reaffirms the conjecture in the baseline model that equity financing is relatively less expensive during expansions than recessions. Moreover, this is line with the empirical evidence that the liquidity premium is countercyclical (see Table B4). At the same time, a positive shock to productivity results in a reduced probability of default in the current period. But in the subsequent periods, the probability of default spikes up. This is in response to a heightened risk-shifting by banks, as captured by the impulse response function of the bailout wedge. Note that the bailout wedge is the expected (not realized) bailout subsidy at time $t+1$, conditional on time $t$ information and, most importantly, on the time $t$ choice of lending $L_{t+1}$.

\subsection{Ramsey Equilibrium}

The Ramsey problem characterizes a set of allocations that can be implemented as a competitive equilibrium when banks face the prescribed capital requirements. A Ramsey planner maximizes the 
lifetime utility of households subject to the resource constraint and implementability conditions:

$$
\begin{array}{ll} 
& \underset{ }{\operatorname{argmax}} E\left[\sum_{t=0}^{\infty} \beta^{t} u\left(C_{t}, D_{t+1}\right)\right] \\
\text { with } \quad & u\left(C_{t}, D_{t+1}\right)=\frac{v\left(C_{t}, D_{t+1}\right)^{1-\gamma}}{1-\gamma}-1 \\
\text { s.t. } \quad & C_{t}=R_{d, t} D_{t}-D_{t+1}+R_{k, t} K_{f, t}^{\alpha_{f}}-I_{f, t}-o_{f} K_{f, t}+Z_{t}+\Pi_{t}-T_{t}, \\
& E_{t}\left[M_{t, t+1}\left(R_{k, t+1}+\left(1-\delta-o_{f}\right)\right)\right]=1, \\
& N_{t+1}+D_{t+1}=L_{t+1}, \\
& E_{t}\left[M_{t, t+1}\left(R_{l, t+1}+\left(1-\delta-o_{b}\right)\right)\right]=\theta_{t}-\tilde{\xi}_{t}, \\
& C_{t}+I_{b, t}+I_{f, t}=Y_{b, t}+Y_{f, t}-o_{b} L_{t}-o_{f} K_{f, t},
\end{array}
$$

where the taxes and net proceeds from banks' and firms' activity are, respectively, equal to:

$$
\begin{aligned}
T_{t} & =\int_{0}^{1} \max \left\{R_{d, t} D_{t}-e^{\omega_{j, t}+a_{t}} L_{t}^{\alpha_{b}}-\left(1-\delta-o_{b}\right) L_{t}, 0\right\} d j, \\
Z_{t} & =\int_{0}^{1} z_{j, t} d j, \quad \text { with } \quad z_{j, t}=\max \left\{e^{\omega_{j, t}+a_{t}} L_{t}^{\alpha_{b}}+\left(1-\delta-o_{b}\right) L_{t}-R_{d, t} D_{t}, 0\right\}-N_{t+1}, \\
\Pi_{t} & =Y_{f, t}-R_{k, t} K_{f, t} .
\end{aligned}
$$

The rate of return on deposits, the stochastic discount factor, the liquidity and risk-shifting cost of lending, the rate of return on loans and capital are defined by (19), (20), (21), (22), (23) and (24), correspondingly. I provide further details in Appendix C. The optimal Ramsey policy - a capital requirement that implements the Ramsey allocations $\left\{C_{t}^{*}, L_{t+1}^{*}, N_{t+1}^{*}, D_{t+1}^{*}, K_{f, t+1}^{*}\right\}_{t=0}^{\infty}$ - requires a capital ratio that equals $\zeta_{t}^{*}=N_{t+1}^{*} / L_{t+1}^{*}$. The set of Ramsey allocations and policies constitute a Ramsey equilibrium.

Using the chosen configuration of parameters (Table B1), I solve for the Ramsey equilibrium. Not surprisingly, the optimal policy rule for bank capital ratios $\zeta_{t}^{*}=\zeta\left(S_{t}, S_{t-1}\right)$ is a function of all state variables $S_{t}=\left\{\zeta_{t-1}, L_{t}, K_{f, t}, a_{t}\right\}$ in the model, including the previous period capital requirement, capital stock in the two sectors, and the productivity shock. I find that the Ramsey capital requirement, for the most part, fluctuates between $4 \%$ and $6 \%$, with the mean at $5 \%$. This range of values is based on one standard deviation of the Ramsey capital requirement above and below its mean, and is roughly consistent with an upper bound of the CCyB proposed by the Basel III Accord. Importantly, the optimal policy rule is not capped at $6 \%$, and in periods of abnormal economic growth can go far above $6 \%$. The steady state value of $\zeta_{t}^{*}$ is substantially lower than the 
Tier 1 leverage ratio observed in the data, but at the same time 1\% higher than the level prescribed by the Basel III Accord. As shown in Figure B2, the effect of a positive TFP shock on the optimal policy rule is quite persistent: a one standard deviation positive TFP shock increases the capital ratio by $0.2 \%$ immediately and this effect lasts for a number of periods.

To uncover the implications of the capital regulation that varies over time, I now examine the impulse response reactions to a one standard deviation positive TFP shock in a Ramsey equilibrium. Figure B2 demonstrates that the Ramsey capital requirement indeed helps to reduce the procyclicality of bank lending, by dampening overinvestment during expansions and boosting bank credit during downturns. This reduced overinvestment, in turn, translates into a lower bailout wedge and, consequently, a lower probability of default. At the same time, the optimal policy rule dampens the procyclicality of the deposits, as there are two channels in place. The first channel is via bank lending directly: to the extent that a bank's balance sheet may shrinks during recessions, the supply of deposits contracts, but less so in a Ramsey equilibrium. The second channel is via capital regulation itself: for a given amount of bank lending, in a Ramsey equilibrium, a larger fraction of production is financed with bank debt during recessions as compared to a competitive equilibrium with a fixed capital requirement. In this instance, the optimal policy rule goes down in a response to a negative productivity shock.

\subsection{Optimal Policy Rule}

For effective policy recommendations, it is useful to express the Ramsey capital requirement $\zeta\left(S_{t}, S_{t-1}\right)$ as a function of key observable macro and bank quantities. To do so, I perform the following exercise: I simulate the model with the Ramsey optimal policies in place for 1,000 times. Then, I estimate a regression of the Ramsey capital requirement on a number of model aggregates for each simulated sample:

$$
\zeta_{t}^{*}=\zeta_{s s}+\sum_{j=1}^{N} \zeta_{x_{j}} x_{t}^{j}+\varepsilon_{t} .
$$

Admittedly, this policy rule is forward-looking: $\zeta_{t}^{*}$ is a level of capital requirement set at time $t$, but regulating a bank's choice of capital structure at time $t+1$. The results in Panel A of Table B5 demonstrates that credit gap used as the only indicator to adjust the capital charges over the business cycle does not capture the dynamics of the optimal policy rule $\left(R^{2}=14 \%\right)$. I find that that using the credit gap along with GDP (in log deviations from their steady states) delivers an 
$R^{2}=99.98 \%$. In particular, $\zeta_{t}^{*}$ is characterized by the following policy rule: ${ }^{31}$

$$
4.9 \%+3 \times\left(\log \frac{L_{t}}{Y_{t}}-\log \frac{L_{s s}}{Y_{s s}}\right)+8 \times\left(\log Y_{t}-\log Y_{s s}\right)
$$

In particular, a one percentage increase in the credit gap leads to a $0.03 \%$ increase in capital charges, while a one percentage point increase in GDP translates into a $0.08 \%$ increase. Equivalently, a one standard deviation increase in the credit gap leads to a $0.1 \%$ increase in capital requirements, while a one standard deviation increase in GDP translates into a $0.7 \%$ increase (Panel B of Table B5). This finding aligns with my main model prediction: in periods when banks are incentivized to riskshift, that is in periods of high GDP and credit growth, the optimal capital requirement is increased. Interestingly, the liquidity premium plays little role if included as an additional explanatory variable in a regression (see Panel A of Table B5). However, this result does not continue to hold if the model includes liquidity shocks.

\subsection{Welfare Implications}

Following the classic work of Lucas (1987), I calculate the potential welfare benefits (costs) associated with different types of capital regulation. To do so, I denote the expected lifetime utility of households in a world with capital regulation $\zeta_{t}$ by

$$
E_{\zeta_{t}}\left[\sum_{t=0}^{+\infty} \beta^{t} \frac{\tilde{C}_{t}^{1-\gamma}-1}{1-\gamma}\right]
$$

where the aggregate consumption is defined by $\tilde{C}_{t}=v\left(C_{t}, D_{t+1}\right)$, accounting for the value of liquid assets to the households. The question is how much the households would be willing to pay or have to be compensated to move from the economy with a fixed level of capital requirement $\zeta_{t}=\zeta^{0}, \forall t$ to the world with a capital ratio of $\zeta^{1}$ or to the economy where banks face the optimal Ramsey policy $\zeta_{t}^{*}$. This compensating variation $\varpi$ is defined as:

$$
E_{\zeta^{0}}\left[\sum_{t=0}^{+\infty} \beta^{t} \frac{\left((1+\varpi) \tilde{C}_{t}\right)^{1-\gamma}-1}{1-\gamma}\right]=E_{\zeta^{1}}\left[\sum_{t=0}^{+\infty} \beta^{t} \frac{\tilde{C}_{t}^{1-\gamma}-1}{1-\gamma}\right]
$$

\footnotetext{
${ }^{31}$ The GDP growth variable is orthogonalized with respect to the credit gap variable, since the two indicators are strongly positively correlated.
} 
Figure 6: Welfare Implications

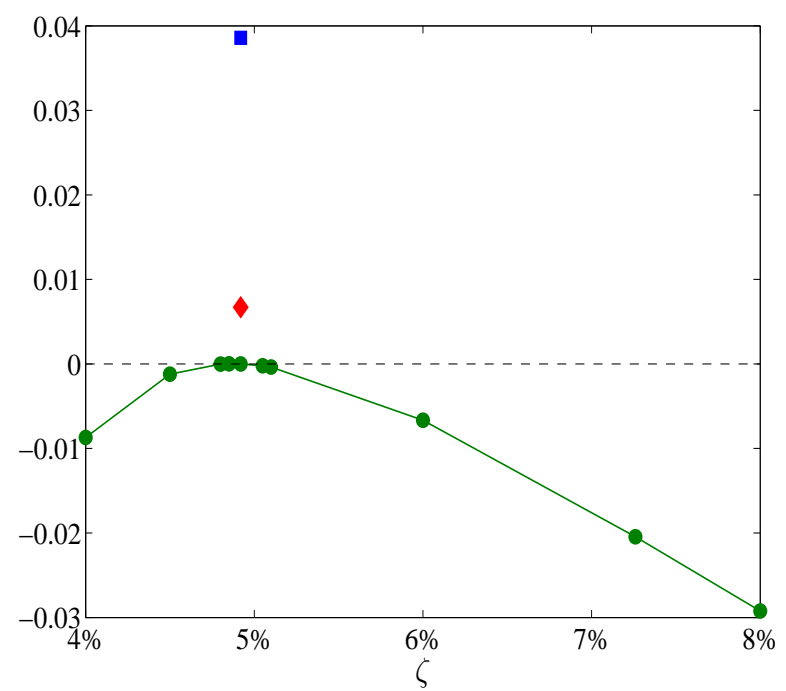

The Figure depicts the variation compensation, $\varpi$, as a function of different levels of fixed capital charges (green dots), as well as the welfare compensation corresponding to the Ramsey policy (blue square) and the policy solely based on the credit gap (red diamond). The variation compensation is expressed in percentage points.

or, equivalently:

$$
\varpi=\left(\frac{E_{\zeta^{1}}\left[\sum_{t=0}^{+\infty} \beta^{t} \tilde{C}_{t}^{1-\gamma}\right]}{E_{\zeta^{0}}\left[\sum_{t=0}^{+\infty} \beta^{t} \tilde{C}_{t}^{1-\gamma}\right]}\right)^{\frac{1}{1-\gamma}}-1 .
$$

Unlike the Lucas cost of business cycle, the above measure captures the changes in consumption instability across different economies, as well as the changes in steady state levels of consumption. I provide more detains on the calculation of welfare costs in Appendix D.

Figure 6 depicts the variation compensation, $\varpi$, as a function of different levels of fixed capital charges, $\zeta^{1} \in[0,1]$, as well as the welfare result for the Ramsey economy. As the benchmark, I choose a world with an optimal fixed level capital requirement, which happens to be the stochastic steady state of the Ramsey policy. Moving from the current level of capital ratio $7.26 \%$ to the Ramsey policy translates into a $0.06 \%$ permanent increase in the annual consumption of households, although the exact magnitude of the gain depends on the attitude of consumers towards risk. ${ }^{32}$ Two-thirds of this welfare improvement is attributed to a transition from the optimal fixed capital requirement to the time-varying one. Admittedly, the welfare gain from implementing the policy rule that is solely based on the credit gap is significantly smaller as compared to the welfare gain from having the optimal capital ratios. Implementing the optimal Ramsey policy leads to $15.5 \%$

\footnotetext{
${ }^{32}$ This is within the range of values documented by Lucas (1987), Alvarez and Jermann (2004), and Van den Heuvel (2008).
} 
decrease in the cyclicality of the bank credit (relative to a world with an optimal fixed level capital requirement): the banks engage in less excessive lending during periods of economic growth, but at the same time avoid contraction of lending activities during recessions. This in turn translates on average into a higher level of lending $(+0.93 \%)$ and consumption $(+0.11 \%)$. In addition, the increase in bank lending stimulates banks' creation of liquid assets $(+0.88 \%)$. The time-varying capital ratios also lead to a reduction in the volatility of both lending $(-0.13 \%)$ and deposits $(-0.17 \%)$, but to an increase in the consumption volatility $(+0.08 \%)$.

\subsection{Model with Liquidity Shocks}

For robustness, I also consider a model with liquidity shocks. Namely, suppose that a share parameter in the CES aggregator over consumption and deposits follows an $\operatorname{AR}(1)$ process:

$$
\log \left(\chi_{t}\right)=\left(1-\rho_{\chi}\right) \bar{\chi}+\rho_{\chi} \log \left(\chi_{t-1}\right)+\sigma_{\chi} u_{t}, \quad u_{t} \sim \operatorname{iid} \mathcal{N}(0,1)
$$

The $\bar{\chi}=0.01$ parameter is set to the value of a share parameter used in the benchmark calibration of the model without demand chocks. The standard deviation of the demand shock $\sigma_{\chi}=0.1$ is calibrated to better match the volatility of the liquidity premium. I choose a persistence parameter of $\rho_{\chi}=0.95$. As shown in Appendix Figure B4, a one standard deviation liquidity shock leads to a $0.1 \%$ decrease in the optimal capital ratio. A positive liquidity shock means that the households enjoy holding liquid assets more and, as a result, are willing to accept a lower rate of return on deposits, as captured by the impulse response function of the liquidity premium. For a given capital requirement, an increased liquidity premium translates into lower liquidity costs of lending. At the same time, banks' incentives to risk-shift become weaker, since the deposit rate is lower and so are the banks' credit liabilities. The liquidity channel dominates the risk-shifting channel, therefore bank lending increases mildly to satisfy the households' demand for liquidity.

If I continue to use the GDP and bank credit as the only two indicators to guide the dynamics of capital requirements, the $\mathrm{R}^{2}$ drops to $91 \%$ (see Panel A of Table B6). Including the liquidity premium as an additional indicator increases the $\mathrm{R}^{2}$ to $98 \%$. The Ramsey policy rule can now be characterized with the following rule: ${ }^{33}$

$$
4.9 \%+2 \times\left(\log \frac{L_{t}}{Y_{t}}-\log \frac{L_{s s}}{Y_{s s}}\right)+9 \times\left(\log Y_{t}-\log Y_{s s}\right)-139 \times\left(\left(r_{f, t}-r_{d, t}\right)-\left(r_{f, s s}-r_{d, s s}\right)\right) .
$$

A one percentage point increase in the liquidity premium leads to a $1.4 \%$ decrease in capital charges

\footnotetext{
${ }^{33}$ The GDP growth variable has been orthogonolized with respect to the credit gap variable.
} 
or, equivalently, a one standard deviation increase in the liquidity premium generates a $0.1 \%$ drop in capital ratios. The liquidity premium serves as an indicator of how expensive for banks is equity financing, as well as how valuable for investors are liquid assets. In line with the baseline model, when the liquidity premium increases, banks' lending costs go up, potentially leading to a cut in deposits . This suggests that the capital requirements should be reduced to satisfy the investors' demand for safe assets.

\section{Conclusions}

Due to government guarantees, banks have incentives to engage in excessive risk-taking and undertake inefficient investments from a social point of view. To prevent such risk-shifting, financial regulators have instituted capital requirements. There is an ongoing debate, however, about whether they are effective, and if so, what level is most efficient. In this paper, I provide a rationale for the use of a time-varying capital requirement, employing a dynamic general equilibrium setting. A sufficiently high capital requirement can be used to rule out excessive lending, but at the same time it may limit banks from financing high-quality investments and lead to reduced liquidity provision. In the model, an optimal capital requirement trades off reduced risk-shifting incentives with reduced liquidity provision. Given that banks are most incentivized to risk-shift during periods of economic growth and holding equity is most costly during recessions, when the economy is the least liquid, a procyclical capital regulation emerges endogenously as a solution to the Ramsey problem.

In this paper, I also quantify policy recommendations on which macroeconomic and bank aggregates drive the optimal time variation in capital requirements. In line with the predictions of the baseline model, the optimal Ramsey policy would respond positively to the credit gap and growth in GDP, where the two serve as indicators of a banks' incentives to risk-shift. At the same time, the Ramsey capital requirement would adjust negatively to an increase in the liquidity premium, which indicates investor's demand for safe and liquid assets. Two-thirds of the welfare gain generated by implementing the optimal Ramsey policy is achieved by having statedependent capital ratios, while the remaining improvement is attributed to an optimal fixed capital requirement. This leads me to conclude that implementing the CCyBs, as recommended by the Basel III Accord, is a crucial step in promoting the stability of the financial sector. 


\section{References}

Admati, A., P.M. DeMarzo, M.F. Hellwig, and M.F. Pfeiderer, "Fallacies, Irrelevant Facts, and Myths in the Discussion of Capital Regulation: Why Bank Equity is Not Expensive," 2010.

Alvarez, Fernando and Urban J. Jermann, "Using Asset Prices to Measure the Cost of Business Cycles," Journal of Political Economy, 2004, 112 (6), 1223-1256.

Atkinson, Anthony B and Joseph E Stiglitz, "Lectures on public economics," 2015.

Baker, Malcolm P and Jeffrey Wurgler, "Would stricter capital requirements raise the cost of capital? Bank capital regulation and the low risk anomaly," Working Paper No. 19018, National Bureau of Economic Research 2013.

Begenau, J., "Capital Requirements, Risk Choice, and Liquidity Provision in a Business Cycle Model," Job Market Paper, Stanford University, Department of Economics 2016.

Bernanke, B., "Non-Monetary Effects of the Financial Crisis in Propagation of the Great Depression," American Economic Review, 1983, 73, 257-276.

Bernanke, Ben and Mark Gertler, "Agency costs, net worth, and business fluctuations," The American Economic Review, 1989, pp. 14-31.

Bernanke, Ben S, Mark Gertler, and Simon Gilchrist, "The financial accelerator in a quantitative business cycle framework," Handbook of macroeconomics, 1999, 1, 1341-1393.

Bigio, Saki, "Endogenous liquidity and the business cycle," Technical Report 2010.

Bloom, Nicholas, Max Floetotto, Nir Jaimovich, Itay Saporta-Eksten, and Stephen J Terry, "Really uncertain business cycles," Technical Report, National Bureau of Economic Research 2012.

Borio, Claudio, "The financial cycle and macroeconomics: What have we learnt?," Journal of Banking \& Finance, 2014, 45 (C), 182-198.

Brunnermeier, Markus K and Yuliy Sannikov, "A macroeconomic model with a financial sector," The American Economic Review, 2014, 104 (2), 379-421.

Calomiris, C. and J. Mason, "Consequences of Bank Distress During the Great Depression," American Economic Review, 2003, 93, 937-947. 
Chari, Varadarajan V, Lawrence J Christiano, and Patrick J Kehoe, "Optimal fiscal and monetary policy: Some recent results," Journal of Money, Credit and Banking, 1991, 23 (3), $519-539$.

Christiano, Lawrence and Daisuke Ikeda, "Leverage Restrictions in a Business Cycle Model," Working Paper 18688, National Bureau of Economic Research January 2014.

Corbae, Dean and Pablo D'Erasmo, "Capital requirements in a quantitative model of banking industry dynamics," Working Paper No. 14-13, FRB of Philadelphia 2014.

DeAngelo, Harry and Ren M. Stulz, "Why High Leverage is Optimal for Banks," Working Paper 19139, National Bureau of Economic Research June 2013.

Dell'Ariccia, G., D. Igan, L. Laeven, and H. Tong, "Policies for Macrofinancial Stability: How to Deal with Credit Booms," Discussion note, International Monetary Fund 2012.

_ E. Detragiache, and R. Raghuram, "The Real Effect of Banking Crises," Journal of Financial Intermediation, 2008.

DellAriccia, Giovanni, Deniz Igan, and Luc Laeven, "Credit Booms and Lending Standards: Evidence from the Subprime Mortgage Market," Journal of Money, Credit and Banking, 03 2012, 44, 367-384.

Demyanyk, Yuliya and Otto Van Hemert, "Understanding the Subprime Mortgage Crisis," The Review of Finacial Studies, 2011, 24(6), 1848-1880.

den Heuvel, Skander J. Van, "The Welfare Cost of Bank Capital Requirements," 2008, 55 (2). , "The Welfare Effects of Bank Liquidity and Capital Requirements," Working Paper 2016.

Dewatripont, Mathias and Jean Tirole, "Macroeconomic Shocks and Banking Regulation," Journal of Money, Credit and Banking, 2012, 44, 237-254.

Diamond, Douglas W and Raghuram G Rajan, "A theory of bank capital," The Journal of Finance, 2000, 55 (6), 2431-2465.

_ and _ _ "Liquidity risk, liquidity creation and financial fragility: A theory of banking," Journal of Political Economy, 2001, 109 (2), 287-327.

Diamond, W. D. and P.H. Dybvig, "Bank runs, deposit insurance, and liquidity," The Journal of Political Economy, 1983, 91 (3), 401-419. 
Drechsler, Itamar, Alexi Savov, and Philipp Schnabl, "The deposits channel of monetary policy," Technical Report, National Bureau of Economic Research 2016.

Gertler, Mark and Nobuhiro Kiyotaki, "Financial intermediation and credit policy in business cycle analysis," Handbook of monetary economics, 2010, 3 (11), 547-599.

_ and Peter Karadi, "A model of unconventional monetary policy," Journal of monetary Economics, 2011, 58 (1), 17-34.

Gordy, Michael B and Bradley Howells, "Procyclicality in Basel II: Can we treat the disease without killing the patient?," Journal of Financial Intermediation, 2006, 15 (3), 395-417.

Gorton, Gary and Andrew Metrick, "Securitized banking and the run on repo," Journal of Financial Economics, 2012.

Hanson, Samuel G, Anil K Kashyap, and Jeremy C Stein, "A macroprudential approach to financial regulation," The Journal of Economic Perspectives, 2011, pp. 3-28.

He, Zhigu and Arvind Krishnamurthy, "A model of capital and crises," The Review of Economic Studies, 2012, 79 (2), 735-777.

Hellmann, Thomas F, Kevin C Murdock, and Joseph E Stiglitz, "Liberalization, moral hazard in banking, and prudential regulation: Are capital requirements enough?," American economic review, 2000, pp. 147-165.

Kashyap, Anil K and Jeremy C Stein, "Cyclical implications of the Basel II capital standards," Economic Perspectives-Federal Reserve Bank Of Chicago, 2004, 28 (1), 18-33.

$\ldots$ _ requirements on large financial institutions," Technical Report 2010.

Kashyap, Anil, Raghuram Rajan, and Jeremy Stein, "Rethinking capital regulation," Maintaining stability in a changing financial system, 2008, pp. 431-471.

Kisin, Roni and Asaf Manela, "The shadow cost of bank capital requirements," Working paper 2013.

Kiyotaki, Nobuhiro and John Moore, "Credit Cycles," Working Paper 5083, National Bureau of Economic Research April 1995. 
Krishnamurthy, Arvind and Annette Vissing-Jorgensen, "The Aggregate Demand for Treasury Debt," Journal of Political Economy, 2012, 120 (2), 233-267.

_ _ and _ _ "The Impact of Treasury Supply on Financial Sector Lending and Stability," Working Paper 2015.

Longstaff, Francis A, "The flight-to-liquidity premium in US Treasury bond prices," Technical Report, National bureau of economic research 2002.

Lorenzoni, Guido, "Inefficient Credit Booms," Review of Economic Studies, 2008, 75, 809-833.

Lucas, R.E.Jr., Models of Business Cycles, Basil Blackwell, New York, 1987.

Lucas, Robert and Nancy Stokey, "Optimal fiscal and monetary policy in an economy without capital," Journal of Monetary Economics, 1983, 12 (1), 55-93.

Malherbe, F., "Optimal capital requirements over the business and financial cycles," Working Paper 2015.

Martinez-Miera, David and Javier Suarez, "A macroeconomic model of endogenous systemic risk taking," CEPR Discussion Paper No. DP9134 2012.

Mian, Atif and Amir Sufi, "Household Leverage and the Recession of 200709," IMF Economic Review, 2010, 58(1), 74-117.

Morrison, Alan D. and Lucy White, "Crises and Capital Requirements in Banking," American Economic Review, 2005, 95 (5), 1548-1572.

Nagel, Stefan, "The liquidity premium of near-money assets," Technical Report, National Bureau of Economic Research 2014.

Nataliya, Klimenko, Sebastien Pfeil, Jean-Charles Rochet, and Gianni De Nicolo, "Aggregate Bank Capital and Credit Dynamics," Working Paper 2016.

Nguyen, T., "Bank Capital Requirements: A Quantitative Analysis," Job Market Paper, The Wharton School, University of Pennsylvania 2014.

on Banking Supervision BCBS, Basel Committee, "Inteenational Convergence of Capital Measurement and Capital Standards," Technical Report, Basel: Bank for International Settlements 1988 . 
Ramsey, F. P., "A Contribution to the Theory of Taxation," The Economic Journal, 1927, 37 (145), 47-61.

Rauh, Joshua D and Amir Sufi, "Capital structure and debt structure," Review of Financial Studies, 2010, p. hhq095.

Repullo, Rafael, "Capital requirements, market power, and risk-taking in banking," Journal of financial Intermediation, 2004, 13 (2), 156-182.

_ and Javier Suarez, "The Procyclical Effects of Bank Capital Regulation," Review of Financial Studies, 2012, 26 (2), 452-490.

and Jesús Saurina, The countercyclical capital buffer of Basel III: A critical assessment, Centre for Economic Policy Research, 2011.

_ _ _ and Carlos Trucharte, "Mitigating the Pro-cyclicality of Basel II," Economic Policy, 2010, 25 (64), 659-702.

Saurina, J. and C. Trucharte, "An Assessment of Basel II Procyclicality in Mortgage Portfolios," Journal of Financial Services Research, 2007, (32), 81-101.

Stein, Jeremy C, "Monetary policy as financial-stability regulation," Technical Report, National Bureau of Economic Research 2011.

Tella, S.T. Di, Essays on Finance and Macroeconomics, Massachusetts Institute of Technology, Department of Economics, 2013. 


\section{Appendices}

\section{A Proofs}

\section{Proposition 1}

The social planner's problem (9) can be equivalently stated as:

$$
\mathcal{L}=\max _{L_{t+1}, D_{t+1}} E\left[\sum_{t=0}^{\infty} \beta^{t}\left(e^{a_{t}} L_{t}^{\alpha}-L_{t+1}+\frac{D_{t+1}^{1-\eta}}{1-\eta}+\varphi_{t}\left(D_{t+1}-L_{t+1}\right)\right)\right],
$$

where $\varphi_{t}$ is the Lagrange multiplier on the deposits supply constraint.

The first-order conditions are given by:

$$
\begin{aligned}
\left(\frac{\partial \mathcal{L}}{\partial D_{t+1}}\right): \quad\left(D_{t+1}^{F B}\right)^{-\eta}+\varphi_{t} & <0, \\
& =0 \quad \text { if } D_{t+1}^{F B}>0, \\
\left(\frac{\partial \mathcal{L}}{\partial L_{t+1}}\right): \quad-1-\varphi_{t}+\beta E_{t}\left[\alpha e^{a_{t+1}}\left(L_{t+1}^{F B}\right)^{\alpha-1}\right] & \leq 0, \\
& =0 \quad \text { if } L_{t+1}^{F B}>0, \\
\left(\frac{\partial \mathcal{L}}{\partial \varphi_{t}}\right): \quad D_{t+1}^{F B}-L_{t+1}^{F B} & \leq 0, \\
& =0 \quad \text { if } \varphi_{t}>0 .
\end{aligned}
$$

The first-order condition (A.1) along with (A.3) delivers a corner solution for the socially optimal level of bank debt, $D_{t+1}^{F B}=L_{t+1}^{F B}$. This in turn implies that $N_{t+1}^{F B}=0$. Provided that the following condition holds:

$$
\lim _{L_{t+1}^{F B} \rightarrow 0}\left\{-1+\left(L_{t+1}^{F B}\right)^{-\eta}+\beta E_{t}\left[\alpha e^{a_{t+1}}\left(L_{t+1}^{F B}\right)^{\alpha-1}\right]\right\}=+\infty
$$

I have an interior solution for the socially optimal level of lending, $L_{t+1}^{F B}>0$.

The second-order condition with respect to lending,

$$
\left(\frac{\partial^{2} \mathcal{L}}{\partial L_{t+1}^{2}}\right): \quad \beta E_{t}\left[\alpha(\alpha-1) e^{a_{t+1}}\left(L_{t+1}^{F B}\right)^{\alpha-2}\right]<0
$$

ensures that $L_{t+1}^{F B}$ is a global maximum of the social planner's problem. Rearranging equation (A.2) and using that $\varphi_{t}=\left(L_{t+1}^{F B}\right)^{-\eta}$ completes the proof 


\section{Proposition 2}

Define:

$$
F\left(L_{t+1}^{F B}, a_{t}\right) \equiv E_{t}\left[\alpha e^{a_{t+1}}\left(L_{t+1}^{F B}\right)^{\alpha-1}\right]-R_{d, t+1}^{F B}=0 .
$$

Using an implicit function theorem and condition (A.4), the procyclicality of $L_{t+1}^{F B}$ follows from:

$$
\frac{d L_{t+1}^{F B}}{d a_{t}}=-\frac{\frac{\partial F\left(L_{t+1}^{F B}, a_{t}\right)}{\partial a_{t}}}{\frac{\partial F\left(L_{t+1}^{F B}, a_{t}\right)}{\partial L_{t+1}^{F+1}}}=-\frac{E_{t}\left[\alpha \rho e^{a_{t+1}}\left(L_{t+1}^{F B}\right)^{\alpha-1}\right]}{E_{t}\left[\alpha(\alpha-1) e^{a_{t+1}}\left(L_{t+1}^{F B}\right)^{\alpha-2}\right]-\frac{\partial R_{d, t+1}^{F B}}{\partial L_{t+1}^{F B}}},
$$

where I use that:

$$
\frac{\partial R_{d, t+1}^{F B}}{\partial \bar{L}_{t+1}}=\eta \frac{1}{\beta}\left(L_{t+1}^{F B}\right)^{-\eta-1}>0 \quad \text { and } \quad \frac{\partial E_{t}\left[e^{a_{t+1}}\right]}{\partial a_{t}}=\rho E_{t}\left[e^{a_{t+1}}\right]>0 .
$$

\section{Proposition 3}

Under symmetric equilibrium, each bank solves:

$$
\mathcal{L}=\max _{L_{t+1}, N_{t+1} \leq L_{t+1}} E\left[\sum_{t=0}^{\infty} \beta^{t}\left(\left\{e^{\omega_{t}+a_{t}} L_{t}^{\alpha}-R_{d, t} L_{t}+R_{d, t} N_{t}\right\}-\left\{e^{\omega_{t}+a_{t}} L_{t}^{\alpha}-R_{d, t} L_{t}+R_{d, t} N_{t}\right\}^{-}-N_{t+1}\right)\right] .
$$

The first-order conditions are given by:

$$
\begin{gathered}
\left(\frac{\partial \mathcal{L}}{\partial N_{t+1}}\right):-1+\beta R_{d, t+1}^{C E}-\beta E_{t}\left[\int_{0}^{\omega_{t+1}^{*}} R_{d, t+1}^{C E} d \Phi(\omega)\right]<0 . \\
\left(\frac{\partial \mathcal{L}}{\partial L_{t+1}}\right): E_{t}\left[\alpha e^{a_{t+1}}\left(L_{t+1}^{C E}\right)^{\alpha-1}\right]-R_{d, t+1}^{C E}+E_{t}\left[\int_{0}^{\omega_{t+1}^{*}}\left(R_{d, t+1}^{C E}-\alpha e^{\omega+a_{t+1}}\left(L_{t+1}^{C E}\right)^{\alpha-1}\right) d \Phi(\omega)\right] \leq 0 \\
\quad=0 \quad \text { if } L_{t+1}^{C E}>0
\end{gathered}
$$

where $\omega_{t+1}^{*}$ is defined by $e^{\omega_{t+1}^{*}+a_{t+1}}\left(L_{t+1}^{C E}\right)^{\alpha}=R_{d, t+1}^{C E}\left(L_{t+1}^{C E}-D_{t+1}^{C E}\right)$.

Without loss of generality, I restrict attention to the case when the deposit rate is strictly positive. In the equilibrium, the deposit rate is equal to $R_{d, t+1}^{C E}=\frac{1}{\beta}-\frac{1}{\beta}\left(L_{t+1}^{C E}-N_{t+1}^{C E}\right)^{-\eta}$, implying that bank's objective function is strictly decreasing in the amount of equity financing, delivering a corner solution $N_{t+1}^{C E}=0$. Provided that the following condition holds:

$$
\lim _{L_{t+1}^{C E} \rightarrow 0}\left(E_{t}\left[\alpha e^{a_{t+1}}\left(L_{t+1}^{C E}\right)^{\alpha-1}\right]-R_{d, t+1}^{C E}+E_{t}\left[\int_{0}^{\omega_{t+1}^{*}}\left(R_{d, t+1}^{C E}-\alpha e^{\omega+a_{t+1}}\left(L_{t+1}^{C E}\right)^{\alpha-1}\right) d \Phi(\omega)\right]\right)=+\infty,
$$

I have an interior solution for the optimal level of lending, $L_{t+1}^{C E}>0$.

For ease of exposition, define the random variable $v_{t+1}=e^{\omega+a_{t+1}}$, which is, conditionally on time $t$ information, log-normally distributed with mean $\bar{v}_{t} \equiv-\frac{1}{2} \sigma_{\omega}+\left(1-\rho_{a}\right) \bar{a}+\rho_{a} a_{t}$ and standard deviation $\sigma_{v} \equiv \sqrt{\sigma_{\omega}^{2}+\sigma_{a}^{2}}$. The change of variables allows me to re-write the first-order conditions with respect to 
lending as follows:

$$
F O C\left(L_{t+1}\right) \equiv \int_{v_{t+1}^{*}}^{+\infty}\left(\alpha v_{t+1} L_{t+1}^{\alpha-1}-R_{d, t+1}\right) d F_{t}\left(v_{t+1}\right),
$$

where the bailout threshold equals to

$$
v_{t+1}^{*}=\frac{R_{d, t+1}\left(L_{t+1}-N_{t+1}\right)}{L_{t+1}^{\alpha}} .
$$

The second-order condition with respect to lending implies that the objective function is neither concave, nor convex in $L_{t+1}$ :

$$
\left(\frac{\partial^{2} \mathcal{L}}{\partial L_{t+1}^{2}}\right): \int_{v_{t+1}^{*}}^{+\infty} \alpha(\alpha-1) v_{t+1} L_{t+1}^{\alpha-2} d F_{t}\left(v_{t+1}\right)+\frac{\partial v_{t+1}^{*}}{\partial L_{t+1}}\left(R_{d, t+1}-\alpha v_{t+1}^{*} L_{t+1}^{\alpha-1}\right) f_{t}\left(v_{t+1}^{*}\right) \lessgtr 0,
$$

where

$$
\frac{\partial v_{t+1}^{*}}{\partial L_{t+1}}=\frac{R_{d, t+1}\left(L_{t+1}^{\alpha}+\alpha L_{t+1}^{\alpha-1}\left(L_{t+1}-N_{t+1}\right)\right)}{\left(L_{t+1}\right)^{2 \alpha}}>0 .
$$

Given that $N_{t+1}^{C E}=0, \forall L_{t+1} \in[0,+\infty)$, I can re-write the SOC as follows:

$$
\operatorname{SOC}\left(L_{t+1}\right) \equiv \int_{v_{t+1}^{*}}^{+\infty} \alpha(\alpha-1) v_{t+1} L_{t+1}^{\alpha-2} d F_{t}\left(v_{t+1}\right)+R_{d, t+1}^{2}(1-\alpha)^{2} L_{t+1}^{-\alpha} f_{t}\left(v_{t+1}^{*}\right) .
$$

The definition of the bailout threshold delivers that $R_{d, t+1}=v_{t+1}^{*} L_{t+1}^{\alpha-1}$, which allows me to further iterate the SOC:

$$
\operatorname{SOC}\left(L_{t+1}\right)=(1-\alpha) L_{t+1}^{\alpha-2}\left(-\alpha \int_{v_{t+1}^{*}}^{+\infty} v_{t+1} d F_{t}\left(v_{t+1}\right)+v_{t+1}^{* 2}(1-\alpha) f_{t}\left(v_{t+1}^{*}\right)\right) .
$$

Note that:

$$
\operatorname{SOC}\left(L_{t+1}\right)<0 \Leftrightarrow \alpha>\alpha\left(v_{t+1}^{*}\right) \equiv \frac{v_{t+1}^{* 2} f_{t}\left(v_{t+1}^{*}\right)}{\int_{v_{t+1}^{*}}^{+\infty} v_{t+1} d F_{t}\left(v_{t+1}\right)+v_{t+1}^{* 2} f_{t}\left(v_{t+1}^{*}\right)} .
$$

I have that:

1.

$$
\lim _{v_{t+1}^{*} \rightarrow 0} \alpha\left(v_{t+1}^{*}\right)=\frac{\{0\}}{E_{t}\left[v_{t+1}\right]+\{0\}}=0
$$

2 .

$$
\lim _{v_{t+1}^{*} \rightarrow+\infty} \alpha\left(v_{t+1}^{*}\right)=\lim _{v_{t+1}^{*} \rightarrow+\infty} \frac{1}{1+\frac{\int_{v_{t+1}^{*}}^{+\infty} v_{t+1} d F_{t}\left(v_{t+1}\right)}{v_{t+1}^{* 2} f_{t}\left(v_{t+1}^{*}\right)}}=1
$$

since

$$
\lim _{v_{t+1}^{*} \rightarrow+\infty} \frac{\int_{v_{t+1}^{*}}^{+\infty} v_{t+1} d F_{t}\left(v_{t+1}\right)}{v_{t+1}^{* 2} f_{t}\left(v_{t+1}^{*}\right)}=\lim _{v_{t+1}^{*} \rightarrow+\infty} \frac{-v_{t+1}^{*} f_{t}\left(v_{t+1}^{*}\right)}{v_{t+1}^{*} f_{t}\left(v_{t+1}^{*}\right)\left(1-\frac{\log v_{t+1}^{*}-\bar{v}_{t}}{\sigma_{v}^{2}}\right)}=\lim _{v_{t+1}^{*} \rightarrow+\infty} \frac{1}{\frac{\log v_{t+1}^{*}-\bar{v}_{t}}{\sigma_{v}^{2}}-1}=0
$$


3.

$$
\frac{\partial \alpha\left(v_{t+1}^{*}\right)}{\partial v_{t+1}^{*}}>0
$$

since

$$
\begin{gathered}
\operatorname{sign}\left\{\frac{\partial \alpha\left(v_{t+1}^{*}\right)}{\partial v_{t+1}^{*}}\right\}=\operatorname{sign}\left\{v_{t+1}^{*} f_{t}\left(v_{t+1}^{*}\right)\left(1-\frac{\log v_{t+1}^{*}-\bar{v}_{t}}{\sigma_{v}^{2}}\right) \int_{v_{t+1}^{*}}^{+\infty} v_{t+1} d F_{t}\left(v_{t+1}\right)+v_{t+1}^{* 3} f_{t}\left(v_{t+1}^{*}\right)^{2}\right\} \\
=\operatorname{sign}\left\{\left(1-\frac{\log v_{t+1}^{*}-\bar{v}_{t}}{\sigma_{v}^{2}}\right) \int_{v_{t+1}^{*}}^{+\infty} v_{t+1} d F_{t}\left(v_{t+1}\right)+v_{t+1}^{* 2} f_{t}\left(v_{t+1}^{*}\right)\right\},
\end{gathered}
$$

and provided that:

(a)

$$
\left(1-\frac{\log v_{t+1}^{*}-\bar{v}_{t}}{\sigma_{v}^{2}}\right) \int_{v_{t+1}^{*}}^{+\infty} v_{t+1} d F_{t}\left(v_{t+1}\right)+v_{t+1}^{* 2} f_{t}\left(v_{t+1}^{*}\right)>0, \quad v_{t+1}^{*}<\exp \left\{\bar{v}+\sigma_{v}^{2}\right\}
$$

(b)

$$
\begin{gathered}
\frac{\partial}{\partial v_{t+1}^{*}}\left(\left(1-\frac{\log v_{t+1}^{*}-\bar{v}_{t}}{\sigma_{v}^{2}}\right) \int_{v_{t+1}^{*}}^{+\infty} v_{t+1} d F_{t}\left(v_{t+1}\right)+v_{t+1}^{* 2} f_{t}\left(v_{t+1}^{*}\right)\right)= \\
=-\frac{1}{\sigma_{v}^{2} v_{t+1}^{*}} \int_{v_{t+1}^{*}}^{+\infty} v_{t+1} d F_{t}\left(v_{t+1}\right)<0
\end{gathered}
$$

(c)

$$
\begin{gathered}
\lim _{v_{t+1}^{*} \rightarrow+\infty}\left(\left(1-\frac{\log v_{t+1}^{*}-\bar{v}_{t}}{\sigma_{v}^{2}}\right) \int_{v_{t+1}^{*}}^{+\infty} v_{t+1} d F_{t}\left(v_{t+1}\right)+v_{t+1}^{* 2} f_{t}\left(v_{t+1}^{*}\right)\right)= \\
=\lim _{v_{t+1}^{*} \rightarrow+\infty}\left(\int_{v_{t+1}^{*}}^{+\infty} v_{t+1} d F_{t}\left(v_{t+1}\right)\right) \cdot \lim _{v_{t+1}^{* 2} \rightarrow+\infty}\left(\left(1-\frac{\log v_{t+1}^{* 2}-\bar{v}_{t}}{\sigma_{v}^{2}}\right)+\frac{v_{t+1}^{* 2} f_{t}\left(v_{t+1}^{*}\right)}{\int_{v_{t+1}^{*}}^{+\infty} v_{t+1} d F_{t}\left(v_{t+1}\right)}\right)=0 .
\end{gathered}
$$

Condition (A.5), along with the properties of $\alpha\left(v_{t+1}^{*}\right)$, implies that there exists $v_{t+1}^{* *}$, such that:

$$
\operatorname{SOC}\left(L_{t+1}\right) \begin{cases}<0, & v_{t+1}^{*} \in\left[0, v_{t+1}^{* *}\right) \\ =0, & v_{t+1}^{*}=v_{t+1}^{* *} \\ >0, & v_{t+1}^{*} \in\left(v_{t+1}^{* *},+\infty\right)\end{cases}
$$

where $v_{t+1}^{* *}$ is defined by:

$$
\alpha=\alpha\left(v_{t+1}^{* *}\right) .
$$

Provided that $v_{t+1}^{*}$ is monotonically increasing in $L_{t+1}$, there exists a corresponding $L_{t+1}^{* *}$, such that:

$$
\operatorname{SOC}\left(L_{t+1}\right) \begin{cases}<0, & L_{t+1} \in\left[0, L_{t+1}^{* *}\right) \\ =0, & L_{t+1}=L_{t+1}^{* *} \\ >0, & L_{t+1} \in\left(L_{t+1}^{* *},+\infty\right)\end{cases}
$$


Consequently, I have that for $L_{t+1} \in\left(L_{t+1}^{* *},+\infty\right)$

$$
\frac{\partial}{\partial L_{t+1}} F O C\left(L_{t+1}\right)>0
$$

which together with

$$
\lim _{L_{t+1} \rightarrow+\infty} F O C\left(L_{t+1}\right)=0
$$

delivers that:

$$
F O C\left(L_{t+1}\right)<0, \quad \forall L_{t+1} \in\left(L_{t+1}^{* *},+\infty\right) .
$$

This implies that the objective function is strictly decreasing in the convex region, i.e., when $L_{t+1} \in$ $\left(L_{t+1}^{* *},+\infty\right)$. Finally, provided that the following conditions hold:

$$
\begin{gathered}
\lim _{L_{t+1} \rightarrow 0} F O C\left(L_{t+1}\right)=+\infty \\
\frac{\partial}{\partial L_{t+1}} F O C\left(L_{t+1}\right)<0, \quad L_{t+1} \in\left[0, L_{t+1}^{* *}\right)
\end{gathered}
$$

and

$$
\operatorname{FOC}\left(L_{t+1}^{* *}\right)<0
$$

there exists a unique $L_{t+1}^{C E} \in\left(0, L_{t+1}^{* *}\right)$, such that:

$$
F O C\left(L_{t+1}^{C E}\right)=0
$$

To sum up, the bank's objective function is concave in lending in the region $L_{t+1} \in\left(0, L_{t+1}^{* *}\right)$ and strictly decreasing when $L_{t+1} \in\left(L_{t+1}^{* *},+\infty\right)$. Hence, $L_{t+1}^{C E}$ is a unique global maximum.

\section{Proposition 4}

Define

$$
\begin{aligned}
F\left(L_{t+1}^{C E}, a_{t}\right) & =E_{t}\left[\alpha e^{a_{t+1}}\left(L_{t+1}^{C E}\right)^{\alpha-1}\right]-R_{d, t+1}^{C E}+\xi\left(L_{t+1}^{C E}, N_{t+1}^{C E} ; a_{t}\right) \\
& =\int_{v_{t+1}^{*}}^{+\infty}\left(\alpha v_{t+1}\left(L_{t+1}^{C E}\right)^{\alpha-1}-R_{d, t+1}^{C E}\right) d F_{t}\left(v_{t+1}\right)=0
\end{aligned}
$$

Taking derivative of (A.7) with respect to lending delivers

$$
\begin{aligned}
\frac{\partial F\left(L_{t+1}^{C E}, a_{t}\right)}{\partial L_{t+1}^{C E}} & =\int_{v_{t+1}^{*}}^{+\infty}\left(\alpha(\alpha-1) v_{t+1}\left(L_{t+1}^{C E}\right)^{\alpha-2}-\frac{\partial R_{d, t+1}^{C E}}{\partial L_{t+1}^{C E}}\right) d F_{t}\left(v_{t+1}\right)+\frac{\partial v_{t+1}^{*}}{\partial L_{t+1}^{C E}}\left(R_{d, t+1}^{C E}-\alpha v_{t+1}^{*}\left(L_{t+1}^{C E}\right)^{\alpha-1}\right) f_{t}\left(v_{t+1}^{*}\right) \\
& =S O C\left(L_{t+1}^{C E}\right)-\frac{\partial R_{d, t+1}^{C E}}{\partial L_{t+1}^{C E}}\left(1-F_{t}\left(v_{t+1}^{*}\right)\right)<0
\end{aligned}
$$


since the rate of return on deposits is increasing in bank lending

$$
\frac{\partial R_{d, t+1}^{C E}}{\partial L_{t+1}^{C E}}=\eta \frac{1}{\beta}\left(L_{t+1}^{C E}\right)^{-\eta-1}
$$

Before differentiating (A.7) with respect to productivity shock, it is useful to re-write $F\left(L_{t+1}^{C E}, a_{t}\right)$ as follows:

$$
F\left(L_{t+1}^{C E}, a_{t}\right)=\left(\alpha E_{t}\left[v_{t+1} \mid v_{t+1} \geq v_{t+1}^{*}\right]\left(L_{t+1}^{C E}\right)^{\alpha-1}-R_{d, t+1}^{C E}\right)\left(1-F_{t}\left(v_{t+1}^{*}\right)\right)
$$

where

$$
E_{t}\left[v_{t+1} \mid v_{t+1} \geq v_{t+1}^{*}\right]=e^{\bar{v}_{t}+\frac{1}{2} \sigma_{v}^{2}} \frac{1-\Phi\left(\frac{\log v_{t+1}^{*}-\bar{v}_{t}}{\sigma_{v}}-\sigma_{v}\right)}{1-\Phi\left(\frac{\log v_{t+1}^{*}-\bar{v}_{t}}{\sigma_{v}}\right)}=e^{\bar{v}_{t}+\frac{1}{2} \sigma_{v}^{2}} \frac{1-\Phi\left(\tilde{v}_{t}-\sigma_{v}\right)}{1-\Phi\left(\tilde{v}_{t}\right)}
$$

where, for ease of notation, I define $\tilde{v}_{t} \equiv \frac{\log v_{t+1}^{*}-\bar{v}_{t}}{\sigma_{v}}$. Now,

$$
\begin{aligned}
\frac{\partial E_{t}\left[v_{t+1} \mid v_{t+1} \geq v_{t+1}^{*}\right]}{\partial \bar{v}_{t}} & =e^{\bar{v}_{t}+\frac{1}{2} \sigma_{v}^{2}}\left(\frac{1-\Phi\left(\tilde{v}_{t}-\sigma_{v}\right)}{1-\Phi\left(\tilde{v}_{t}\right)}+\frac{\frac{1}{\sigma_{v}} \phi\left(\tilde{v}_{t}-\sigma_{v}\right)\left(1-\Phi\left(\tilde{v}_{t}\right)\right)-\frac{1}{\sigma_{v}}\left(1-\Phi\left(\tilde{v}_{t}-\sigma_{v}\right) \phi\left(\tilde{v}_{t}\right)\right)}{\left(1-\Phi\left(\tilde{v}_{t}\right)\right)^{2}}\right) \\
& =\frac{1}{\sigma_{v}} e^{\bar{v}_{t}+\frac{1}{2} \sigma_{v}^{2}} \frac{1-\Phi\left(\tilde{v}_{t}-\sigma_{v}\right)}{1-\Phi\left(\tilde{v}_{t}\right)}\left(\sigma_{v}-\frac{\phi\left(\tilde{v}_{t}\right)}{1-\Phi\left(\tilde{v}_{t}\right)}+\frac{\phi\left(\tilde{v}_{t}-\sigma_{v}\right)}{1-\Phi\left(\tilde{v}_{t}-\sigma_{v}\right)}\right)
\end{aligned}
$$

Provided that the following conditions hold:

(i)

$$
\begin{aligned}
& \lim _{\tilde{v}_{t} \rightarrow+\infty}\left(\sigma_{v}-\frac{\phi\left(\tilde{v}_{t}\right)}{1-\Phi\left(\tilde{v}_{t}\right)}+\frac{\phi\left(\tilde{v}_{t}-\sigma_{v}\right)}{1-\Phi\left(\tilde{v}_{t}-\sigma_{v}\right)}\right)=\left\{\sigma_{v}-\frac{\{0\}}{\{0\}}+\frac{\{0\}}{\{0\}}\right\}= \\
& \lim _{\tilde{v}_{t} \rightarrow-\infty}\left(\sigma_{v}-\frac{-\tilde{v}_{t} \phi\left(\tilde{v}_{t}\right)}{-\phi\left(\tilde{v}_{t}\right)}+\frac{-\left(\tilde{v}_{t}-\sigma_{v}\right) \phi\left(\tilde{v}_{t}-\sigma_{v}\right)}{-\phi\left(\tilde{v}_{t}-\sigma_{v}\right)}\right)=0,
\end{aligned}
$$

(ii)

$$
\lim _{\tilde{v}_{t} \rightarrow-\infty}\left(\sigma_{v}-\frac{\phi\left(\tilde{v}_{t}\right)}{1-\Phi\left(\tilde{v}_{t}\right)}+\frac{\phi\left(\tilde{v}_{t}-\sigma_{v}\right)}{1-\Phi\left(\tilde{v}_{t}-\sigma_{v}\right)}\right)=\left\{\sigma_{v}-\frac{\{0\}}{\{1\}}+\frac{\{0\}}{\{1\}}\right\}=\sigma_{v}
$$

(iii)

$\frac{\partial}{\partial \tilde{v}_{t}}\left(\sigma_{v}-\frac{\phi\left(\tilde{v}_{t}\right)}{1-\Phi\left(\tilde{v}_{t}\right)}+\frac{\phi\left(\tilde{v}_{t}-\sigma_{v}\right)}{1-\Phi\left(\tilde{v}_{t}-\sigma_{v}\right)}\right)=\frac{\partial}{\partial \tilde{v}_{t}}\left(\sigma-\lambda\left(-\tilde{v}_{t}\right)+\lambda\left(-\tilde{v}_{t}+\sigma\right)\right)=\lambda^{\prime}\left(-\tilde{v}_{t}\right)-\lambda^{\prime}\left(-\tilde{v}_{t}+\sigma\right)<0$

where $\lambda\left(\tilde{v}_{t}\right) \equiv \frac{\phi\left(\tilde{v}_{t}\right)}{\Phi\left(\tilde{v}_{t}\right)}$ is an inverse of Mill's ratio, with $\lambda^{\prime}(\cdot)<0$ and $\lambda^{\prime \prime}(\cdot)>0$,

I have that:

$$
\operatorname{sign}\left\{\frac{\partial E_{t}\left[v_{t+1} \mid v_{t+1} \geq v_{t+1}^{*}\right]}{\partial \bar{v}_{t}}\right\}=\operatorname{sign}\left\{\left(\sigma_{v}-\frac{\phi\left(\tilde{v}_{t}\right)}{1-\Phi\left(\tilde{v}_{t}\right)}+\frac{\phi\left(\tilde{v}_{t}-\sigma_{v}\right)}{1-\Phi\left(\tilde{v}_{t}-\sigma_{v}\right)}\right)\right\}=\oplus .
$$


This implies that:

$$
\frac{\partial F\left(L_{t+1}^{C E}, a_{t}\right)}{\partial a_{t}}=\alpha \frac{\partial E_{t}\left[v_{t+1} \mid v_{t+1} \geq v_{t+1}^{*}\right]}{\partial \bar{v}_{t}} \frac{\partial \bar{v}}{\partial a_{t}}\left(L_{t+1}^{C E}\right)^{\alpha-1}\left(1-F_{t}\left(v_{t+1}^{*}\right)\right)>0 .
$$

Using implicit function theorem and equation (A.7), the pro-cyclicality of $L_{t+1}^{C E}$

$$
\frac{d L_{t+1}^{C E}}{d a_{t}}=-\frac{\frac{\partial F\left(L_{t+1}^{C E}, a_{t}\right)}{\partial a_{t}}}{\frac{\partial F\left(L_{t+1}^{C E}, a_{t}\right)}{\partial L_{t+1}^{C E}}}>0
$$

\section{Proposition 5}

Employing the results from the derivation of Propositions 2 and 4, I have that:

$$
\begin{gathered}
\operatorname{sign}\left\{\frac{d}{d a_{t}} \frac{L_{t+1}^{C E}}{L_{t+1}^{F B}}\right\}=\operatorname{sign}\left\{\frac{d L_{t+1}^{C E}}{d a_{t}} L_{t+1}^{F B}-\frac{d L_{t+1}^{F B}}{d a_{t}} L_{t+1}^{C E}\right\}= \\
\operatorname{sign}\left\{\frac{E_{t}\left[\alpha \rho e^{a_{t+1}}\left(L_{t+1}^{C E}\right)^{\alpha-1}\right]+\frac{\partial \xi\left(L_{t+1}^{C E}, N_{t+1}^{C E} ; a_{t}\right)}{\partial a_{t}}}{E_{t}\left[\alpha(1-\alpha) e^{a_{t+1}}\left(L_{t+1}^{C E}\right)^{\alpha-2}\right]+\frac{\partial R_{d, t+1}^{C E}}{\partial L_{t+1}^{C E}}-\frac{\partial \xi\left(L_{t+1}^{C E}, N_{t+1}^{C E} ; a_{t}\right)}{\partial L_{t+1}^{C E}}} L_{t+1}^{F B}-\frac{E_{t}\left[\alpha \rho e^{a_{t+1}}\left(L_{t+1}^{F B}\right)^{\alpha-1}\right]}{E_{t}\left[\alpha(1-\alpha) e^{\left.a_{t+1}\left(L_{t+1}^{F B}\right)^{\alpha-2}\right]+\frac{\partial R_{d, t+1}^{F B}}{\partial L_{t+1}^{F B}}} L_{t+1}^{C E}\right\} .} .\right.
\end{gathered}
$$

This implies that the level of the excessive investment is pro-cyclical if and only if

$$
\frac{\partial \xi\left(L_{t+1}^{C E}, N_{t+1}^{C E} ; a_{t}\right)}{\partial a_{t}}<-\bar{\xi}_{a, t}
$$

where

$$
\bar{\xi}_{a, t} \equiv E_{t}\left[\alpha \rho e^{a_{t+1}}\left(L_{t+1}^{F B}\right)^{\alpha-1}\right] \frac{E_{t}\left[\alpha(1-\alpha) e^{a_{t+1}}\left(L_{t+1}^{C E}\right)^{\alpha-2}\right]+\frac{\partial R_{d, t+1}^{C E}}{\partial L_{t+1}^{C E}}-\frac{\partial \xi\left(L_{t+1}^{C E}, N_{t+1}^{C E} ; a_{t}\right)}{\partial L_{t+1}^{C E}}}{E_{t}\left[\alpha(1-\alpha) e^{a_{t+1}}\left(L_{t+1}^{F B}\right)^{\alpha-2}\right]+\frac{\partial R_{d, t+1}^{F B}}{\partial L_{t+1}^{F B}}} \cdot \frac{L_{t+1}^{C E}}{L_{t+1}^{F B}}-E_{t}\left[\alpha \rho e^{a_{t+1}}\left(L_{t+1}^{C E}\right)^{\alpha-1}\right]
$$

I can also show that the bailout wedge for any level of lending and equity financing is monotonically decreasing in $a_{t}$. To do this, I re-write the bailout wedge as follows:

$$
\begin{aligned}
\xi\left(L_{t+1}, N_{t+1} ; a_{t}\right) & =E_{t}\left[\int_{0}^{\omega_{t+1}^{*}}\left(R_{d, t+1}-\alpha e^{\omega+a_{t+1}} L_{t+1}^{\alpha-1}\right) d \Phi(\omega)\right] \\
& =\int_{v_{t+1}^{*}}^{+\infty}\left(R_{d, t+1}-\alpha v_{t+1} L_{t+1}^{\alpha-1}\right) d F_{t}\left(v_{t+1}\right) \\
& =\left(R_{d, t+1} \alpha E_{t}\left[v_{t+1} \mid v_{t+1} \leq v_{t+1}^{*}\right] L_{t+1}^{\alpha-1}\right) \Phi\left(\tilde{v}_{t+1}\right),
\end{aligned}
$$

where

$$
E_{t}\left[v_{t+1} \mid v_{t+1} \leq v_{t+1}^{*}\right]=e^{\bar{v}_{t}+\frac{1}{2} \sigma_{v}^{2}} \frac{\Phi\left(\tilde{v}_{t}-\sigma_{v}\right)}{\Phi\left(\tilde{v}_{t}\right)}
$$


Now,

$$
\begin{aligned}
\frac{\partial E_{t}\left[v_{t+1} \mid v_{t+1} \leq v_{t+1}^{*}\right]}{\partial \bar{v}_{t}} & =e^{\bar{v}_{t}+\frac{1}{2} \sigma_{v}^{2}}\left(\frac{\Phi\left(\tilde{v}_{t}-\sigma_{v}\right)}{\Phi\left(\tilde{v}_{t}\right)}+\frac{-\frac{1}{\sigma_{v}} \phi\left(\tilde{v}_{t}-\sigma_{v}\right) \Phi\left(\tilde{v}_{t}\right)+\frac{1}{\sigma_{v}} \Phi\left(\tilde{v}_{t}-\sigma_{v}\right) \phi\left(\tilde{v}_{t}\right)}{\Phi\left(\tilde{v}_{t}\right)^{2}}\right) \\
& =\frac{1}{\sigma_{v}} e^{\bar{v}_{t}+\frac{1}{2} \sigma_{v}^{2}} \frac{\Phi\left(\tilde{v}_{t}-\sigma_{v}\right)}{\Phi\left(\tilde{v}_{t}\right)}\left(\sigma_{v}+\frac{\phi\left(\tilde{v}_{t}\right)}{\Phi\left(\tilde{v}_{t}\right)}-\frac{\phi\left(\tilde{v}_{t}-\sigma_{v}\right)}{\Phi\left(\tilde{v}_{t}-\sigma_{v}\right)}\right) .
\end{aligned}
$$

Provided that the following conditions hold:

(i)

$$
\begin{aligned}
& \lim _{\tilde{v}_{t} \rightarrow-\infty}\left(\sigma_{v}+\frac{\phi\left(\tilde{v}_{t}\right)}{\Phi\left(\tilde{v}_{t}\right)}-\frac{\phi\left(\tilde{v}_{t}-\sigma_{v}\right)}{\Phi\left(\tilde{v}_{t}-\sigma_{v}\right)}\right)=\left\{\sigma_{v}+\frac{\{0\}}{\{0\}}-\frac{\{0\}}{\{0\}}\right\}= \\
& \lim _{\tilde{v}_{t} \rightarrow-\infty}\left(\sigma_{v}+\frac{-\tilde{v}_{t} \phi\left(\tilde{v}_{t}\right)}{\phi\left(\tilde{v}_{t}\right)}-\frac{-\left(\tilde{v}_{t}-\sigma_{v}\right) \phi\left(\tilde{v}_{t}-\sigma_{v}\right)}{\phi\left(\tilde{v}_{t}-\sigma_{v}\right)}\right)=0
\end{aligned}
$$

(ii)

$$
\lim _{\tilde{v}_{t} \rightarrow+\infty}\left(\sigma_{v}+\frac{\phi\left(\tilde{v}_{t}\right)}{\Phi\left(\tilde{v}_{t}\right)}-\frac{\phi\left(\tilde{v}_{t}-\sigma_{v}\right)}{\Phi\left(\tilde{v}_{t}-\sigma_{v}\right)}\right)=\left\{\sigma_{v}+\frac{\{0\}}{\{1\}}-\frac{\{0\}}{\{1\}}\right\}=\sigma_{v}
$$

$$
\frac{\partial}{\partial \tilde{v}_{t}}\left(\sigma_{v}+\frac{\phi\left(\tilde{v}_{t}\right)}{\Phi\left(\tilde{v}_{t}\right)}-\frac{\phi\left(\tilde{v}_{t}-\sigma_{v}\right)}{\Phi\left(\tilde{v}_{t}-\sigma_{v}\right)}\right)=\frac{\partial}{\partial \tilde{v}_{t}}\left(\sigma-\lambda\left(\tilde{v}_{t}\right) \lambda\left(\tilde{v}_{t}-\sigma\right)\right)=\lambda^{\prime}\left(\tilde{v}_{t}\right)-\lambda^{\prime}\left(\tilde{v}_{t}-\sigma\right)>0
$$

I have that

$$
\operatorname{sign}\left\{\frac{\partial E_{t}\left[v_{t+1} \mid v_{t+1} \leq v_{t+1}^{*}\right]}{\partial \bar{v}_{t}}\right\}=\operatorname{sign}\left\{\left(\sigma_{v}+\frac{\phi\left(\tilde{v}_{t}\right)}{\Phi\left(\tilde{v}_{t}\right)}-\frac{\phi\left(\tilde{v}_{t}-\sigma_{v}\right)}{\Phi\left(\tilde{v}_{t}-\sigma_{v}\right)}\right)\right\}=\oplus .
$$

This implies that

$$
\frac{\partial \xi\left(L_{t+1}, N_{t+1} ; a_{t}\right)}{\partial a_{t}}=-\alpha \frac{\partial E_{t}\left[v_{t+1} \mid v_{t+1} \leq v_{t+1}^{*}\right]}{\partial \bar{v}_{t}} \frac{\partial \bar{v}_{t}}{\partial a_{t}} \mathrm{E}_{t+1}^{\alpha-1} \Phi\left(\tilde{v}_{t+1}\right)+\xi\left(L_{t+1}, N_{t+1} ; a_{t}\right) \frac{\phi\left(\tilde{v}_{t+1}\right)}{\Phi\left(\tilde{v}_{t+1}\right)} \frac{\partial \tilde{v}_{t}}{\partial \bar{v}_{t}} \frac{\partial \bar{v}_{t}}{\partial a_{t}}<0
$$

\section{Proposition 6}

In a competitive equilibrium with capital regulation in place, each bank solves:

$$
\mathcal{L}=\max _{L_{t+1}, N_{t+1} \leq L_{t+1}} E\left[\sum_{t=0}^{\infty} \beta^{t}\left(\left\{e^{\omega_{t}+a_{t}} L_{t}^{\alpha}-R_{d, t} L_{t}+R_{d, t} N_{t}\right\}^{+}-N_{t+1}+\lambda_{t}\left(N_{t+1}-\zeta_{t} L_{t+1}\right)\right)\right],
$$

where $\lambda_{t}$ is the Lagrange multiplier associated with the capital constraint. The corresponding first-order conditions are given by:

$$
\begin{aligned}
\left(\frac{\partial \mathcal{L}}{\partial N_{t+1}}\right):-1+\lambda_{t}+\beta R_{d, t+1}^{C E}-\beta E_{t}\left[\int_{0}^{\omega_{t+1}^{*}} R_{d, t+1}^{C E} d \Phi(\omega)\right] & \leq 0 \\
& =0 \quad \text { if } \quad N_{t+1}^{C E}>0
\end{aligned}
$$




$$
\begin{gathered}
\left(\frac{\partial \mathcal{L}}{\partial L_{t+1}}\right):-\lambda_{t} \zeta_{t}+E_{t}\left[\alpha e^{a_{t+1}}\left(L_{t+1}^{C E}\right)^{\alpha-1}\right]-R_{d, t+1}^{C E}+\xi\left(L_{t+1}^{C E}, N_{t+1}^{C E} ; a_{t}\right) \leq 0 \\
=0 \quad \text { if } \quad L_{t+1}^{C E}>0 \\
\left(\frac{\partial}{\partial \lambda_{t}}\right): N_{t+1}^{C E}-\zeta_{t} L_{t+1}^{C E} \geq 0, \quad \text { if } \quad \lambda_{t}>0 \\
=0
\end{gathered}
$$

Suppose first that the capital constraint is slack, i.e., $N_{t+1}^{C E}>\zeta_{t} L_{t+1}^{C E}$. This means that the Lagrange multiplier is equal to zero, which in turn implies that the bank's objective function is strictly decreasing in $N_{t+1}$, implying a corner solution for the level of equity financing $N_{t+1}^{C E}=0$. This is a contradiction.

\section{Proposition 7}

Substituting equation (17) into the bank's first order conditions with respect to lending 15, I obtain that:

$$
E_{t}\left[\alpha e^{a_{t+1}}\left(L_{t+1}^{\zeta^{L}}\right)^{\alpha-1}\right]=R_{d, t+1}^{\zeta^{L}}
$$

which implies that $L_{t+1}^{\zeta_{L}}=L_{t+1}^{F B}$. In an equilibrium with lending capital requirement in place, the deposit rate is equal to:

$$
R_{d, t+1}^{\zeta^{L}}=\frac{1}{\beta}-\frac{1}{\beta}\left(\left(1-\zeta_{t}^{L}\right) L_{t+1}^{\zeta^{L}}\right)^{-\eta}
$$

and the bailout rate is defined by:

$$
e^{\omega_{t+1}^{*}+a_{t+1}}\left(L_{t+1}^{\zeta^{L}}\right)^{\alpha}=R_{d, t+1}^{\zeta^{L}}\left(1-\zeta_{t}^{L}\right) L_{t+1}^{\zeta^{L}}
$$

Given that the following conditions hold:

(i)

$$
\begin{aligned}
\frac{\partial}{\partial \zeta_{t}}\left(\theta\left(L_{t+1}^{F B}, \zeta_{t}\right)-R_{d, t+1}^{F B}\right) & =\left(1-\zeta_{t}\right) \frac{\partial R_{d, t+1}^{\zeta^{L}}}{\partial \zeta_{t}}+\left(\frac{1}{\beta}-R_{d, t+1}^{\zeta^{L}}\right) \\
& =-\eta \frac{1}{\beta}\left(\left(1-\zeta_{t}\right) L_{t+1}^{F B}\right)^{-\eta}+\frac{1}{\beta}\left(\left(1-\zeta_{t}\right) L_{t+1}^{F B}\right)^{-\eta} \\
& =(1-\eta) \frac{1}{\beta}\left(\left(1-\zeta_{t}\right) L_{t+1}^{F B}\right)^{-\eta}>0
\end{aligned}
$$

(ii)

$$
\frac{\partial \tilde{\xi}\left(L_{t+1}^{F B}, \zeta_{t} ; a_{t}\right)}{\partial \zeta_{t}}=E_{t}\left[\int_{0}^{\omega_{t+1}^{*}}\left(-R_{d, t+1}^{\zeta^{L}}+\left(1-\zeta_{t}\right) \frac{\partial R_{d, t+1}^{\zeta^{L}}}{\partial \zeta_{t}}\right) d \Phi(\omega)\right]+E_{t}\left[\frac{\partial \omega_{t+1}^{*}}{\partial \zeta_{t}}\left(1-\zeta_{t}\right)(1-\alpha) R_{d, t+1}^{\zeta^{L}} \phi\left(\omega_{t+1}^{*}\right)\right]<0
$$


with

$$
\frac{\partial \omega_{t+1}^{*}}{\partial \zeta_{t}}=-\frac{1}{1-\zeta_{t}}+\frac{1}{R_{d, t+1}^{\zeta^{L}}} \frac{\partial R_{d, t+1}^{\zeta^{L}}}{\partial \zeta_{t}}<0
$$

(iii)

$$
\theta\left(L_{t+1}^{F B}, 0\right)=R_{d, t+1}^{F B} \quad \& \quad \tilde{\xi}\left(L_{t+1}^{F B}, 0 ; a_{t}\right)>0
$$

there is a unique solution to equation (17).

\section{Proposition 8}

Substituting equation (18) into the bank's first order condition with respect to lending (15), I obtain that:

$$
E_{t}\left[\alpha e^{a_{t+1}}\left(L_{t+1}^{\zeta^{D}}\right)^{\alpha-1}\right]=R_{d, t+1}^{\zeta^{D}}
$$

which implies that $L_{t+1}^{\zeta_{D}}=\frac{L_{t+1}^{F B}}{1-\zeta_{t}^{D}}$ and $D_{t+1}^{\zeta^{D}}=D_{t+1}^{F B}$. In an equilibrium with liquidity capital requirement in place, the deposit rate is equal to:

$$
R_{d, t+1}^{\zeta^{D}}=\frac{1}{\beta}-\frac{1}{\beta}\left(\left(1-\zeta_{t}^{D}\right) L_{t+1}^{\zeta^{D}}\right)^{-\eta}=R_{d, t+1}^{F B},
$$

and the bailout rate is defined by:

$$
e^{\omega_{t+1}^{*}+a_{t+1}}\left(L_{t+1}^{\zeta^{D}}\right)^{\alpha}=R_{d, t+1}^{\zeta^{D}}\left(1-\zeta_{t}^{D}\right) L_{t+1}^{\zeta^{D}},
$$

or, equivalently:

$$
e^{\omega_{t+1}^{*}+a_{t+1}}\left(L_{t+1}^{F B}\right)^{\alpha}=R_{d, t+1}^{\zeta^{D}}\left(1-\zeta_{t}^{D}\right)^{\alpha} L_{t+1}^{F B} .
$$

Given that the following conditions hold:

(i)

$$
\frac{\partial}{\partial \zeta_{t}}\left(\left(1-\zeta_{t}\right)^{\alpha-1} \theta\left(\frac{L_{t+1}^{F B}}{1-\zeta_{t}} ; \zeta_{t}\right)-R_{d, t+1}^{F B}\right)=(1-\alpha)\left(1-\zeta_{t}\right)^{\alpha-2} \theta\left(\frac{L_{t+1}^{F B}}{1-\zeta_{t}} ; \zeta_{t}\right)+\left(1-\zeta_{t}\right)^{\alpha-1}\left(\frac{1}{\beta}-R_{d, t+1}^{\zeta^{D}}\right)>0
$$

(ii)

$$
\begin{aligned}
\frac{\partial}{\partial \zeta_{t}}\left(\left(1-\zeta_{t}\right)^{\alpha-1} \tilde{\xi}\left(\frac{L_{t+1}^{F B}}{1-\zeta_{t}} ; \zeta_{t}\right)\right) & =-\alpha\left(1-\zeta_{t}\right)^{\alpha-1} E_{t}\left[\int_{0}^{\omega_{t+1}^{*}} R_{d, t+1}^{\zeta^{D}} d \Phi(\omega)\right] \\
& +E_{t}\left[\frac{\partial \omega_{t+1}^{*}}{\partial \zeta_{t}}\left(1-\zeta_{t}\right)^{\alpha}(1-\alpha) R_{d, t+1}^{\zeta^{D}} \phi\left(\omega_{t+1}^{*}\right)\right],
\end{aligned}
$$

with

$$
\frac{\partial \omega_{t+1}^{*}}{\partial \zeta_{t}}=-\frac{\alpha}{1-\zeta_{t}}<0
$$

(iii)

$$
\theta\left(L_{t+1}^{F B}, 0\right)=R_{d, t+1}^{F B} \quad \& \quad \tilde{\xi}\left(L_{t+1}^{F B}, 0 ; a_{t}\right)>0
$$


there is a unique solution to equation (18).

\section{B Tables and Figures}

\section{TABle B1: Configuration of Model Parameters}

\begin{tabular}{llll}
\hline \hline Description & Symbol & Value & Source/Target \\
\hline Subjective Discount Factor & $\beta$ & 0.975 & Standard \\
Risk Aversion Coefficient & $\gamma$ & 1.000 & Standard \\
Elasticity of Deposits and Consumption & $\eta$ & 1.200 & St.dev. of debt-consumption ratio \\
Deposits Weight & $\chi$ & 0.010 & Average liquidity premium \\
& & & \\
Firm Capital Share & $\alpha_{f}$ & 0.355 & Capital-output ratio \\
Firm Operating Cost & $o_{f}$ & 0.055 & St.dev. of investment-capital ratio \\
& & & \\
Bank Capital Share & $\alpha_{b}$ & 0.780 & Capital-output ratio \\
Bank Operating Cost & $o_{b}$ & 0.065 & Profit-to-loan ratio \\
Bank Output Weight & $\bar{a}_{b}$ & -1.35 & Capital ratio in two sectors \\
Capital Adequacy Ratio & $\bar{\zeta}$ & 0.073 & Average leverage ratio \\
& & & \\
Depreciation Rate & $\delta$ & 0.075 & Investment-capital ratio \\
& $\sigma_{\omega}$ & 0.95 & Process for Solow residuals \\
Persistence of Productivity Schock & $\rho_{a}$ & 0.020 & Bailout rate \\
Std of Productivity Schock & 0.335 & 0.500 & Idiosyncratic volatility dispersion \\
Std of Idiosyncratic Shock & & &
\end{tabular}

This table reports the benchmark configuration of the model parameters calibrated at annual frequency. 


\section{TABle B2: First Aggregate Moments}

\begin{tabular}{|c|c|c|c|c|}
\hline & \multirow[b]{2}{*}{ Data } & \multicolumn{3}{|c|}{ Model } \\
\hline & & Mean & $2.5 \%$ & $97.5 \%$ \\
\hline & \multicolumn{4}{|c|}{ Aggregate Sector } \\
\hline Capital-Output, $K / Y$ & 3.03 & 2.99 & 2.86 & 3.13 \\
\hline \multirow[t]{2}{*}{ Investment-Capital, $I / K$} & 0.07 & 0.08 & 0.07 & 0.08 \\
\hline & \multicolumn{4}{|c|}{ Market Fraction } \\
\hline Capital Weight, $K_{b} / K$ & 0.46 & 0.45 & 0.40 & 0.51 \\
\hline \multirow[t]{2}{*}{ Output Weight, $Y_{b} / Y$} & 0.28 & 0.28 & 0.23 & 0.33 \\
\hline & \multicolumn{4}{|c|}{ Banking Sector } \\
\hline Capital-Output, $K_{b} / Y_{b}$ & 4.96 & 4.87 & 4.79 & 4.94 \\
\hline Investment-Capital, $I_{b} / K_{b}$ & 0.05 & 0.08 & 0.07 & 0.09 \\
\hline Capital Adequacy Ratio, $N / L, \%$ & 7.26 & 7.26 & 7.26 & 7.26 \\
\hline Profit-Lending, $\pi / L$ & 0.04 & 0.05 & 0.05 & 0.05 \\
\hline Liquidity Premium, $R_{f}-R_{d}, \%$ & 0.57 & 0.56 & 0.46 & 0.65 \\
\hline \multirow[t]{2}{*}{ Bailout Rate, $\%$} & 0.76 & 0.79 & 0.56 & 1.06 \\
\hline & \multicolumn{4}{|c|}{ Bank-Independent Sector } \\
\hline Capital-Output, $K_{f} / Y_{f}$ & 2.29 & 2.28 & 2.23 & 2.33 \\
\hline Investment-Capital, $I_{f} / K_{f}$ & 0.09 & 0.08 & 0.07 & 0.08 \\
\hline
\end{tabular}

This table reports the first moments computed as averages of the data and model series. The summary statistics in the data are computed in the annual sample for the 1980-2008 period. The mean, as well as $2.5 \%$ and $97.5 \%$ values, capture the model moment distributions across the samples whose size equals the data. 


\section{Table B3: Second Aggregate Moments}

\begin{tabular}{|c|c|c|c|c|}
\hline & \multirow[b]{2}{*}{ Data } & \multicolumn{3}{|c|}{ Model } \\
\hline & & Mean & $2.5 \%$ & $97.5 \%$ \\
\hline & \multicolumn{4}{|c|}{ Aggregate Sector } \\
\hline Consumption, $\sigma(\Delta c)$ & 1.28 & 0.83 & 0.61 & 1.14 \\
\hline Output, $\sigma(\Delta y)$ & 2.00 & 2.02 & 1.66 & 2.41 \\
\hline \multirow[t]{2}{*}{ Investment, $\sigma(\Delta i)$} & 4.36 & 7.16 & 5.96 & 8.47 \\
\hline & \multicolumn{4}{|c|}{ Banking Sector } \\
\hline Output, $\sigma\left(\Delta y_{b}\right)$ & 2.54 & 2.22 & 1.71 & 2.84 \\
\hline Investment, $\sigma\left(\Delta i_{b}\right)$ & 9.28 & 12.49 & 10.40 & 14.89 \\
\hline Lending, $\sigma(\Delta l)$ & 2.60 & 1.53 & 0.97 & 2.32 \\
\hline Debt-Consumpion Ratio, $\sigma(\Delta d-\Delta c)$ & 3.67 & 0.79 & 0.47 & 1.25 \\
\hline \multirow[t]{2}{*}{ Profits, $\sigma(\Delta \pi)$} & 13.59 & 10.58 & 8.44 & 13.09 \\
\hline & \multicolumn{4}{|c|}{ Bank-Independent Sector } \\
\hline Output, $\sigma\left(\Delta y_{f}\right)$ & 2.07 & 2.00 & 1.67 & 2.38 \\
\hline Investment, $\sigma\left(\Delta i_{f}\right)$ & 3.84 & 3.09 & 2.54 & 3.70 \\
\hline Liquidity Premium, $\sigma\left(R_{f}-R_{d}\right)$ & 0.35 & 0.03 & 0.01 & 0.07 \\
\hline
\end{tabular}

This table reports the second moments computed as standard deviations of the data and model series. $\sigma(\Delta x)$ is the standard deviation of annual log growth rates of $X$. The summary statistics in the data are computed in the annual sample for the 1980-2008 period. The mean, as well as $2.5 \%$ and $97.5 \%$ values, capture the model moment distributions across the samples whose size equals the data. The statistics are expressed in percentages. 


\section{TABle B4: Business Cycle Correlations}

\begin{tabular}{|c|c|c|c|c|}
\hline & \multirow[b]{2}{*}{ Data } & \multicolumn{3}{|c|}{ Model } \\
\hline & & Mean & $2.5 \%$ & $97.5 \%$ \\
\hline & \multicolumn{4}{|c|}{ Aggregate Sector } \\
\hline Consumption, $\rho(\Delta c, \Delta y)$ & 0.77 & 0.89 & 0.86 & 0.93 \\
\hline \multirow[t]{2}{*}{ Investment, $\rho(\Delta i, \Delta y)$} & 0.84 & 0.97 & 0.93 & 0.99 \\
\hline & \multicolumn{4}{|c|}{ Banking Sector } \\
\hline Output, $\rho\left(\Delta y_{b}, \Delta y\right)$ & 0.82 & 0.95 & 0.93 & 0.97 \\
\hline Investment, $\rho\left(\Delta i_{b}, \Delta y\right)$ & 0.70 & 0.95 & 0.91 & 0.97 \\
\hline Lending, $\rho(\Delta l, \Delta y)$ & 0.47 & 0.69 & 0.64 & 0.74 \\
\hline Deposits, $\rho(\Delta d-\Delta c, \Delta y)$ & 0.54 & 0.37 & 0.22 & 0.55 \\
\hline Profits, $\rho(\Delta \pi, \Delta y)$ & 0.15 & 0.79 & 0.74 & 0.84 \\
\hline \multirow[t]{2}{*}{ Liquidity Premium, $\rho\left(R_{f}-R_{d}, \Delta y\right)$} & -0.21 & 0.04 & -0.32 & 0.38 \\
\hline & \multicolumn{4}{|c|}{ Bank-Independent Sector } \\
\hline Output, $\rho\left(\Delta y_{f}, \Delta y\right)$ & 0.96 & 0.99 & 0.98 & 1.00 \\
\hline Investment, $\rho\left(\Delta i_{f}, \Delta y\right)$ & 0.59 & 0.94 & 0.92 & 0.95 \\
\hline
\end{tabular}

This table reports the correlations of aggregate variables with the output growth in the data and in the model. $\rho(\Delta x, \Delta y)$ is the correlation of annual growth rates of $X$ with annual output growth rates; $\rho\left(R_{f}-R_{d}, \Delta y\right)$ is the correlation of annual liquidity premium (in levels) with annual output growth rates; $\rho(p, \Delta y)$ is the correlation of fraction of bailed out banks with the annual output growth rates. The summary statistics in the data are computed in the annual sample for the $1980-2008$ period. The mean, as well as $2.5 \%$ and $97.5 \%$ values, capture the model moment distributions across the samples whose size equals the data. 


\section{TABle B5: Optimal Bank Capital Policy (Benchmark Quantitative Model)}

PANEL A: Level-Log Regressions

\begin{tabular}{|c|c|c|c|c|c|}
\hline & (1) & (2) & (3) & (4) & (5) \\
\hline Constant & 4.93 & 4.93 & 4.93 & 4.93 & 4.93 \\
\hline \multirow[t]{2}{*}{ Credit gap } & 2.64 & & & 2.64 & 1.91 \\
\hline & $(1.60,3.48)$ & & & $(1.60,3.48)$ & $(0.75,2.93)$ \\
\hline \multirow[t]{2}{*}{ Bank credit } & & 2.51 & & & \\
\hline & & $(2.45,2.57)$ & & & \\
\hline \multirow[t]{2}{*}{$G D P$} & & & 5.45 & 8.17 & 7.91 \\
\hline & & & $(5.24,5.72)$ & $(8.16,8.18)$ & $(7.84,7.99)$ \\
\hline \multirow[t]{2}{*}{ Liquidity premium } & & & & & -172.77 \\
\hline & & & & & $(-224.16,-117.29)$ \\
\hline \multirow[t]{2}{*}{$\mathrm{R}^{2}$} & 0.1366 & 0.5033 & 0.8175 & 0.9998 & 0.9999 \\
\hline & $(0.0431,0.2465)$ & $(0.4062,0.5927)$ & $(0.7877,0.8469)$ & $(0.9997,0.9998)$ & $(0.9998,0.9999)$ \\
\hline
\end{tabular}

Panel B: Normalized Level-Log Regressions

\begin{tabular}{|c|c|c|c|c|c|}
\hline & $(1)$ & $(2)$ & (3) & (4) & $(5)$ \\
\hline Constant & 4.93 & 4.93 & 4.93 & 4.93 & 4.93 \\
\hline \multirow[t]{2}{*}{ Credit gap } & 0.09 & & & 0.09 & 0.06 \\
\hline & $(0.05,0.11)$ & & & $(0.05,0.11)$ & $(0.02,0.09)$ \\
\hline \multirow[t]{2}{*}{ Bank credit } & & 0.08 & & & \\
\hline & & $(0.07,0.09)$ & & & \\
\hline \multirow[t]{2}{*}{$G D P$} & & & 0.16 & 0.69 & 0.67 \\
\hline & & & $(0.15,0.18)$ & $(0.63,0.76)$ & $(0.61,0.74)$ \\
\hline \multirow[t]{2}{*}{ Liquidity premium } & & & & & -0.01 \\
\hline & & & & & $(-0.02,-0.01)$ \\
\hline \multirow[t]{2}{*}{$\mathrm{R}^{2}$} & 0.1366 & 0.5033 & 0.8175 & 0.9998 & 0.9999 \\
\hline & $(0.0431,0.2465)$ & $(0.4062,0.5927)$ & $(0.7877,0.8469)$ & $(0.9997,0.9998)$ & $(0.9998,0.9999)$ \\
\hline
\end{tabular}

Panel A of this table presents results from level-log regressions of the form $\zeta_{t}^{*}=\zeta_{s s}+\sum_{j=1}^{N} \zeta_{x_{j}} x_{t}^{j}+\varepsilon_{t}$, while Panel B presents results from normalized level-log regressions, where independent variables are scaled by their standard deviations. The dependent variable is the Ramsey policy rule in year $t$ expressed in percentages (1 to 100). The independent variables include (i) credit gap $\log \frac{L_{t}}{Y_{t}}-\log \frac{L_{s s}}{Y_{s s}}$; (ii) bank credit $\log L_{t}-\log L_{s s}$; (iii) GDP $\log Y_{t}-\log Y_{s s}$; (iv) liquidity premium $\left(r_{f, t}-r_{d, t}\right)-\left(r_{f, s s}-r_{d, s s}\right)$. Reported coefficients are the mean values across the samples, while the numbers reported in parentheses are the $2.5 \%$ and $97.5 \%$ values. Reported $\mathrm{R}^{2} \mathrm{~s}$ are the mean values across the samples, while the numbers reported in parentheses are the $2.5 \%$ and $97.5 \%$ values. 


\section{TABle B6: Optimal Bank Capital Policy (Quantitative Model with Liquidity Shocks)}

PANEL A: Level-Log Regressions

\begin{tabular}{|c|c|c|c|c|c|}
\hline & (1) & $(2)$ & $(3)$ & $(4)$ & $(5)$ \\
\hline Constant & 4.93 & 4.93 & 4.93 & 4.93 & 4.92 \\
\hline \multirow[t]{2}{*}{ Credit gap } & 1.71 & & & 1.71 & 1.67 \\
\hline & $(0.41,2.96)$ & & & $(0.41,2.96)$ & $(0.61,2.58)$ \\
\hline \multirow[t]{2}{*}{ Bank credit } & & 2.20 & & & \\
\hline & & $(1.74,2.64)$ & & & \\
\hline \multirow[t]{2}{*}{$G D P$} & & & 5.26 & 8.57 & 7.87 \\
\hline & & & $(4.62,5.93)$ & $(8.18,8.97)$ & $(7.77,7.97)$ \\
\hline \multirow[t]{2}{*}{ Liquidity premium } & & & & & -139.24 \\
\hline & & & & & $(-145.78,-132.49)$ \\
\hline \multirow[t]{2}{*}{$\mathrm{R}^{2}$} & 0.0584 & 0.3435 & 0.6577 & 0.9107 & 0.9766 \\
\hline & $(0.0024,0.1551)$ & $(0.2161,0.4717)$ & $(0.5562,0.7417)$ & $(0.8820,0.9330)$ & $(0.9702,0.9820)$ \\
\hline
\end{tabular}

PANEL B: Normalized Level-Log Regressions

\begin{tabular}{|c|c|c|c|c|c|}
\hline & (1) & $(2)$ & (3) & (4) & (5) \\
\hline Constant & 4.93 & 4.93 & 4.93 & 4.93 & 4.92 \\
\hline \multirow[t]{2}{*}{ Credit gap } & 0.06 & & & 0.06 & 0.06 \\
\hline & $(0.01,0.10)$ & & & $(0.01,0.10)$ & $(0.02,0.09)$ \\
\hline \multirow[t]{2}{*}{ Bank credit } & & 0.07 & & & \\
\hline & & $(0.06,0.09)$ & & & \\
\hline \multirow[t]{2}{*}{$G D P$} & & & 0.16 & 0.74 & 0.68 \\
\hline & & & $(0.13,0.18)$ & $(0.66,0.83)$ & $(0.62,0.74)$ \\
\hline \multirow[t]{2}{*}{ Liquidity premium } & & & & & -0.09 \\
\hline & & & & & $(-0.09,-0.08)$ \\
\hline \multirow[t]{2}{*}{$\mathrm{R}^{2}$} & 0.0584 & 0.3435 & 0.6577 & 0.9107 & 0.9766 \\
\hline & $(0.0024,0.1551)$ & $(0.2161,0.4717)$ & $(0.5562,0.7417)$ & $(0.8820,0.9330)$ & $(0.9702,0.9820)$ \\
\hline
\end{tabular}

Panel A of this table presents results from level-log regressions of the form $\zeta_{t}^{*}=\zeta_{s s}+\sum_{j=1}^{N} \zeta_{x_{j}} x_{t}^{j}+\varepsilon_{t}$, while Panel B presents results from normalized level-log regressions, where independent variables are scaled by their standard deviations. The dependent variable is the Ramsey policy rule in year $t$ expressed in percentages (1 to 100). The independent variables include (i) credit gap $\log \frac{L_{t}}{Y_{t}}-\log \frac{L_{s s}}{Y_{s s}}$; (ii) bank credit $\log L_{t}-\log L_{s s}$; (iii) GDP $\log Y_{t}-\log Y_{s s}$; (iv) liquidity premium $\left(r_{f, t}-r_{d, t}\right)-\left(r_{f, s s}-r_{d, s s}\right)$. Reported coefficients are the mean values across the samples, while the numbers reported in parentheses are the $2.5 \%$ and $97.5 \%$ values. Reported $\mathrm{R}^{2} \mathrm{~s}$ are the mean values across the samples, while the numbers reported in parentheses are the $2.5 \%$ and $97.5 \%$ values. 
Figure B1: Exogenous TFP Shock.

\section{Benchmark Quantitative Model with Fixed Capital Requirement}

(a) TFP

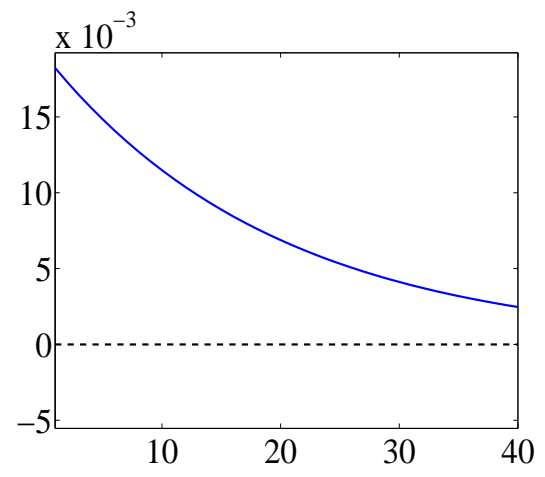

(d) Lending

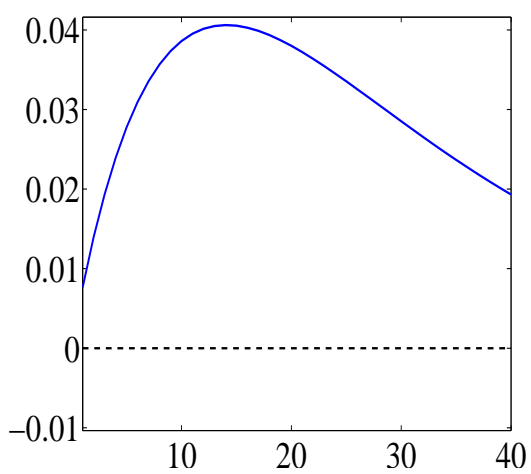

(b) Output

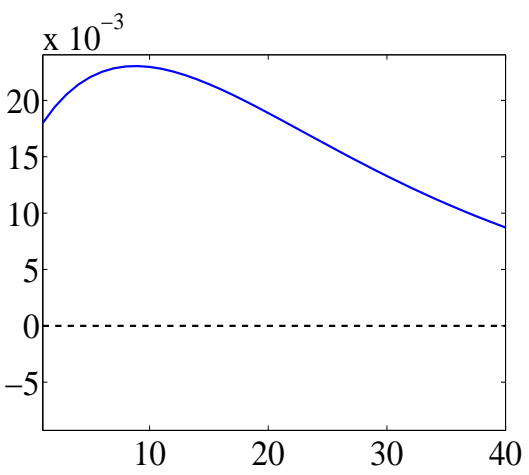

(e) Deposit-Consumption Ratio

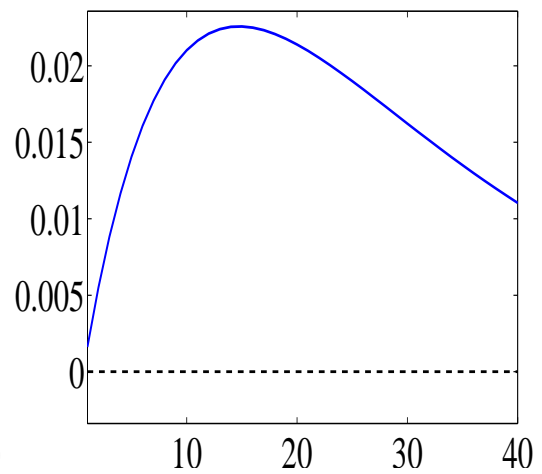

(c) Consumption

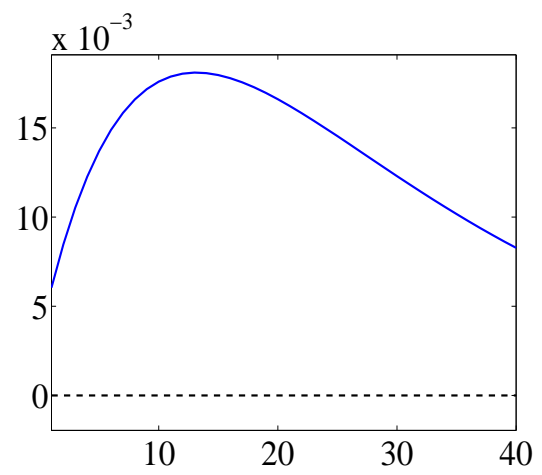

(f) Liquidity Premium

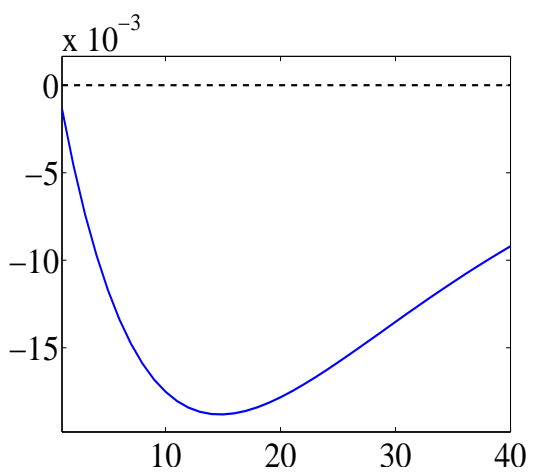

(g) Probability of Bailout

(h) Bailout Wedge
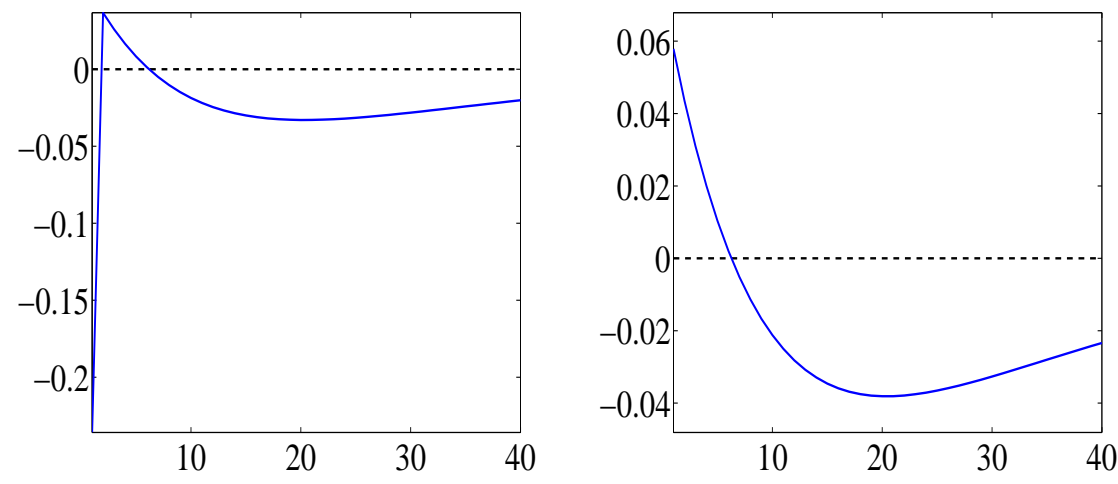

The figures show the effect of a one standard deviation shock to log productivity on the variables of the benchmark quantitative model, as captured by the impulse response functions (blue solid lines). Banks are subject to a fixed capital requirement of $7.26 \%$. All model quantities are in logs. 
Figure B2: Exogenous TFP Shock.

\section{Benchmark Quantitative Model with Ramsey Capital Requirement}

(a) TFP

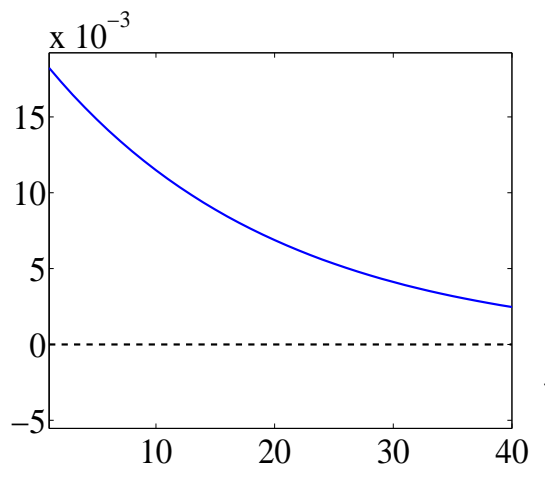

(d) Lending

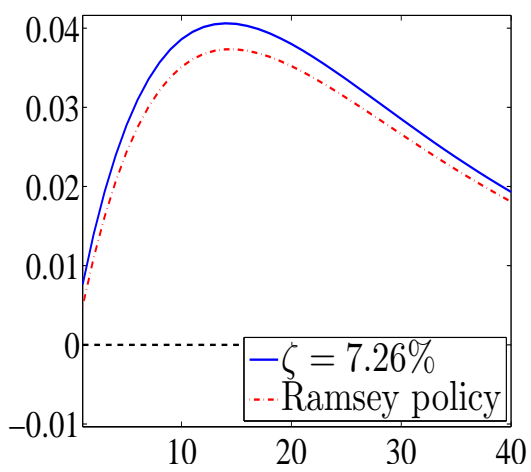

(g) Probability of Bailout

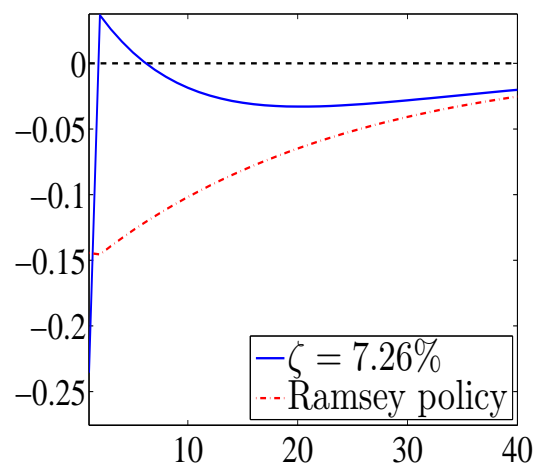

(b) Output

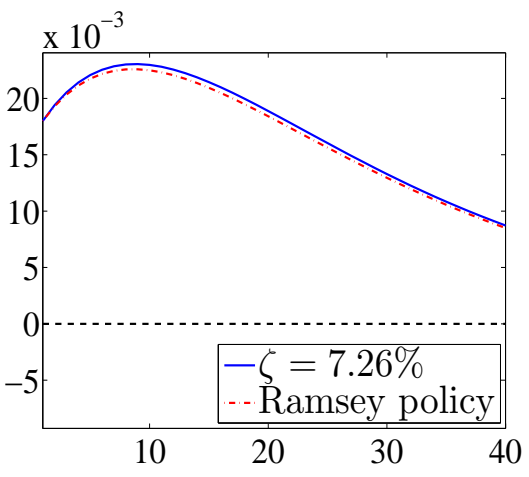

(e) Deposit-Consumption Ratio

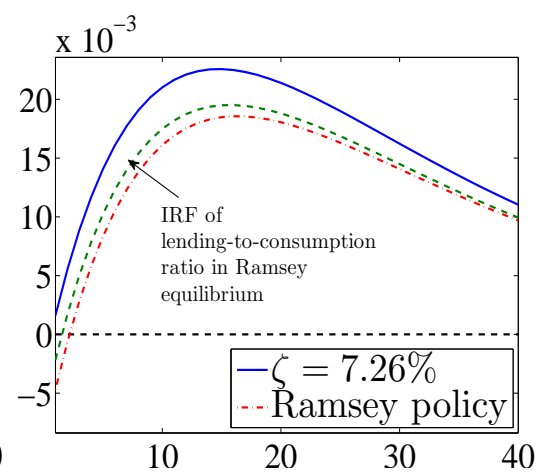

(h) Bailout Wedge

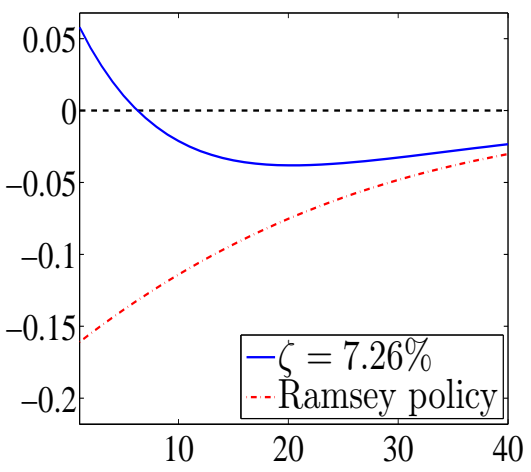

(c) Consumption

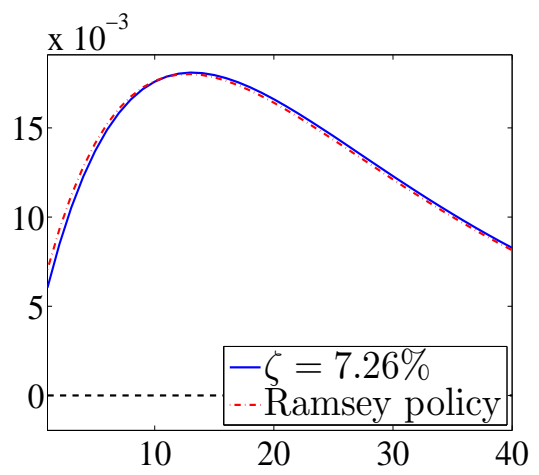

(f) Liquidity Premium

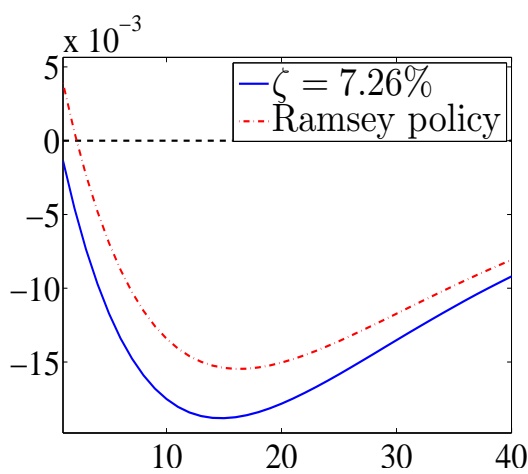

(i) Ramsey Policy

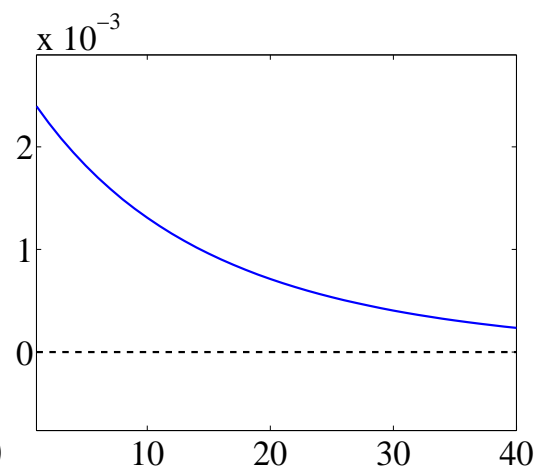

The figures show the effect of a one standard deviation shock to log productivity on the variables of the benchmark quantitative model, as captured by the impulse response functions. The figures provide a comparison of the effects when banks are subject to a fixed capital requirement of $7.26 \%$ (blue solid lines) and when banks face the optimal Ramsey policy (red dash-dotted lines). All model quantities are in logs. 
Figure B3: Exogenous Liquidity Shock.

\section{Quantitative Model with Liquidity Shocks and Fixed Capital Requirement}

(a) $\chi$

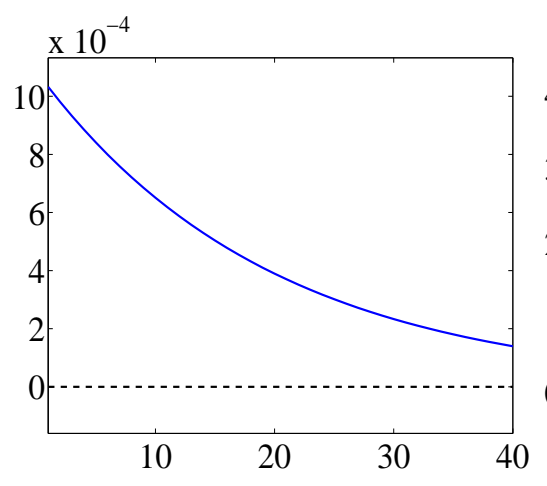

(d) Lending

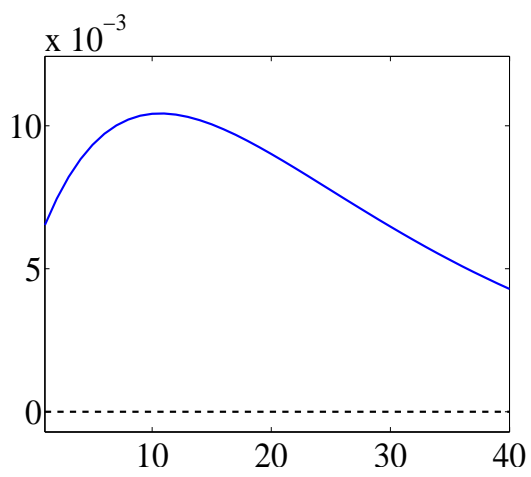

(b) Output

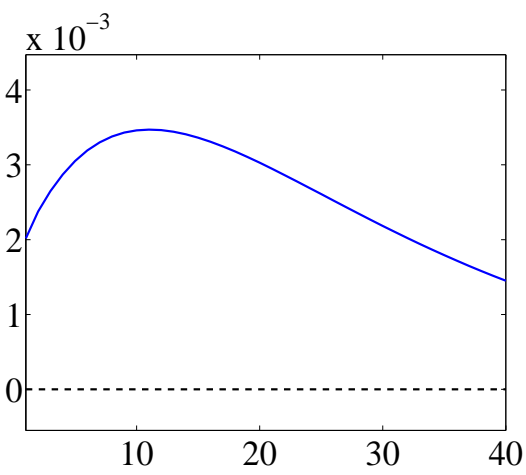

(e) Deposit-Consumption Ratio

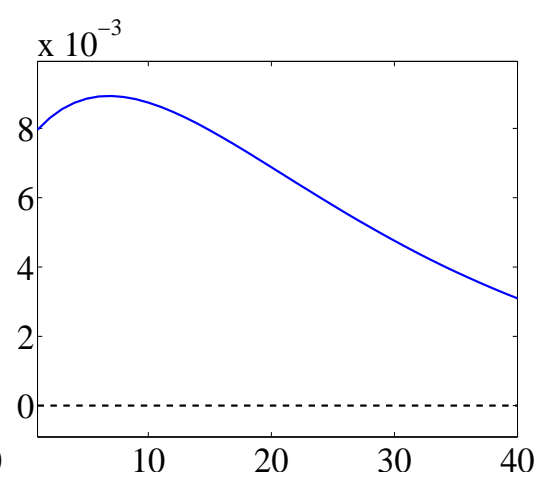

(c) Consumption

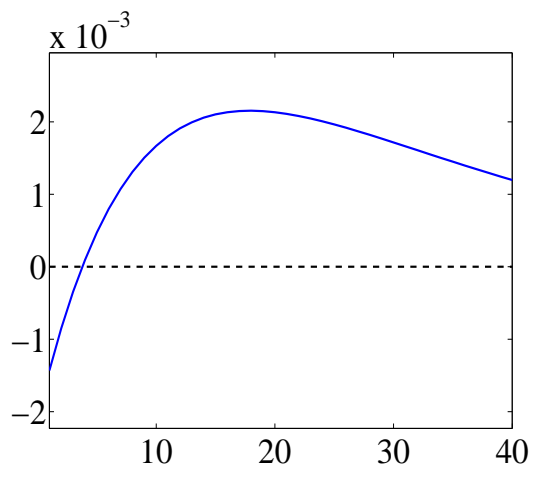

(f) Liquidity Premium

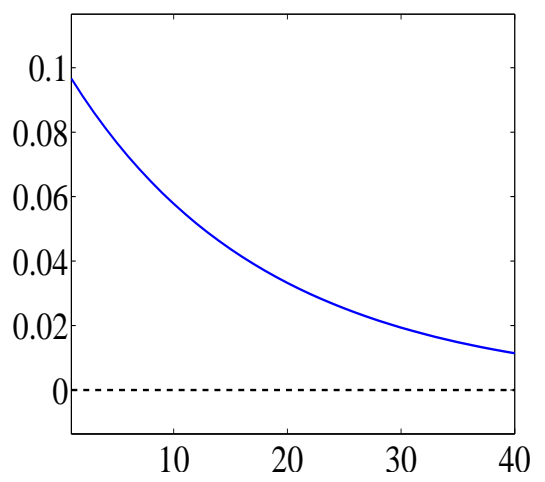

(g) Probability of Bailout

(h) Bailout Wedge
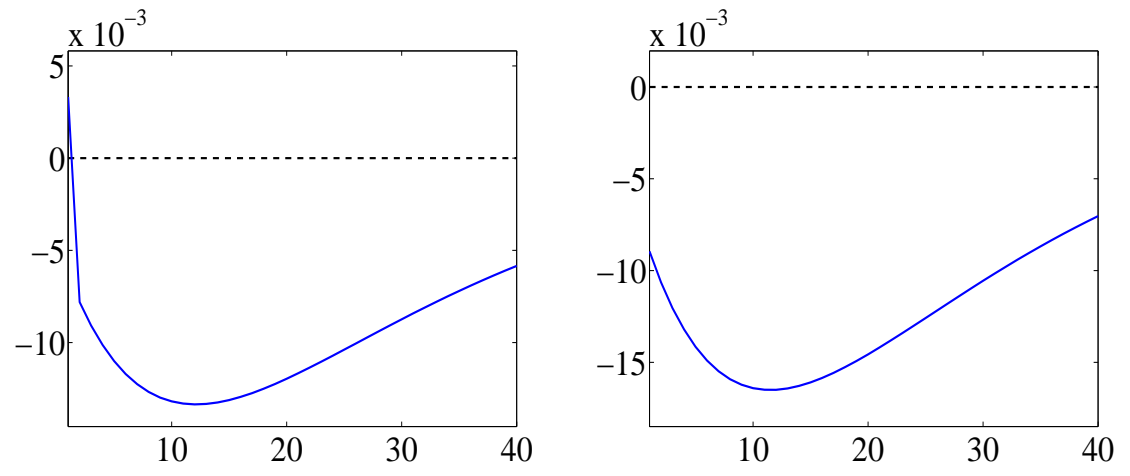

The figures show the effect of a one standard deviation shock to log productivity on the variables of the quantitative model with liquidity shocks, as captured by the impulse response functions (blue solid lines). Banks are subject to a fixed capital requirement of $7.26 \%$. All model quantities are in logs. 
Figure B4: Exogenous Liquidity Shock.

\section{Quantitative Model with Liquidity Shocks and Ramsey Capital Requirement}

(a) TFP

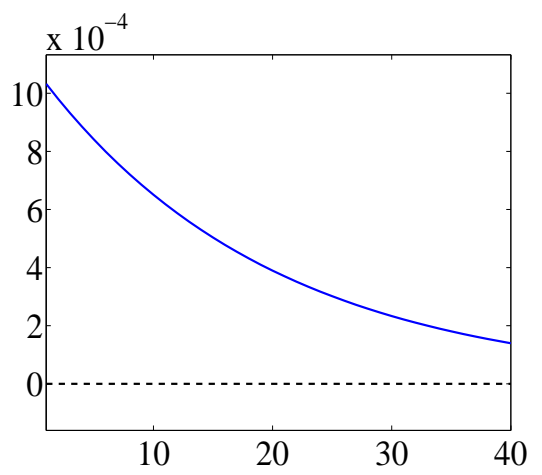

(d) Lending

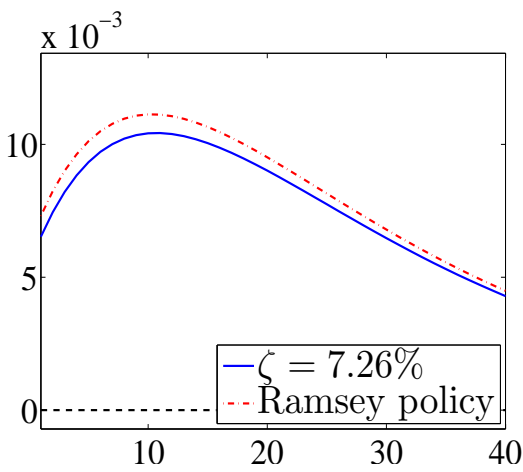

(g) Probability of Bailout

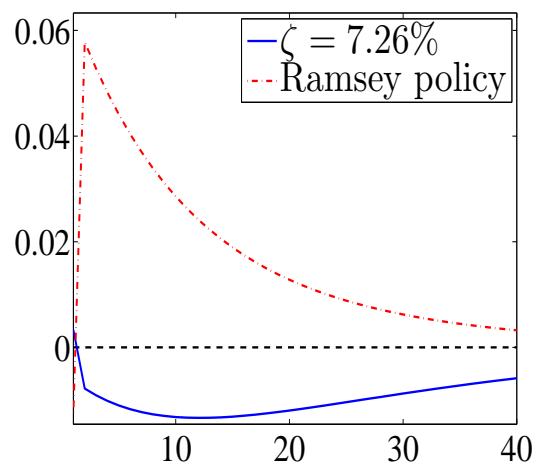

(b) Output

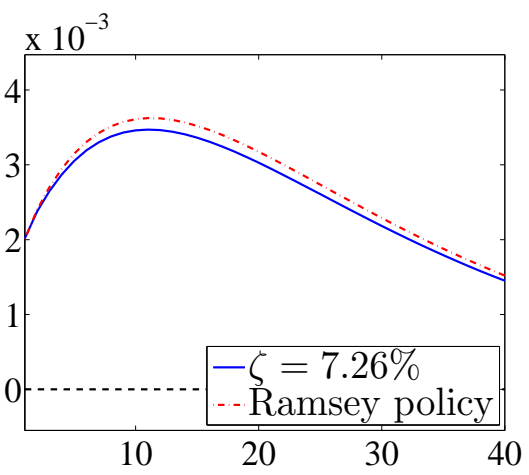

(e) Deposit-Consumption Ratio

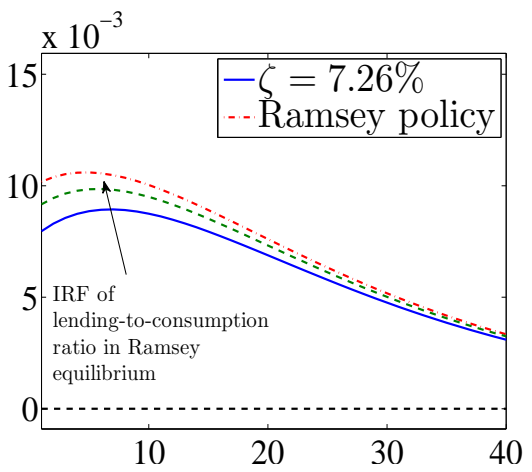

(h) Bailout Wedge

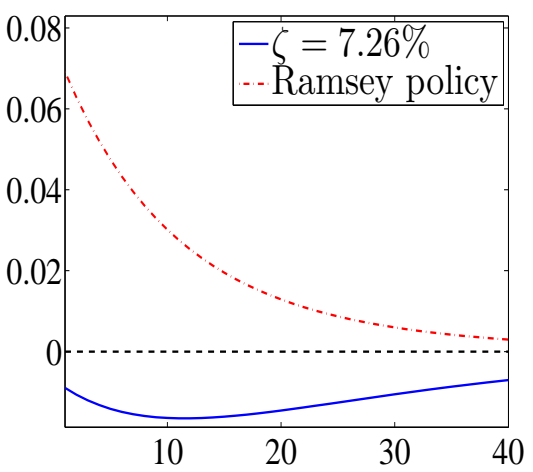

(c) Consumption

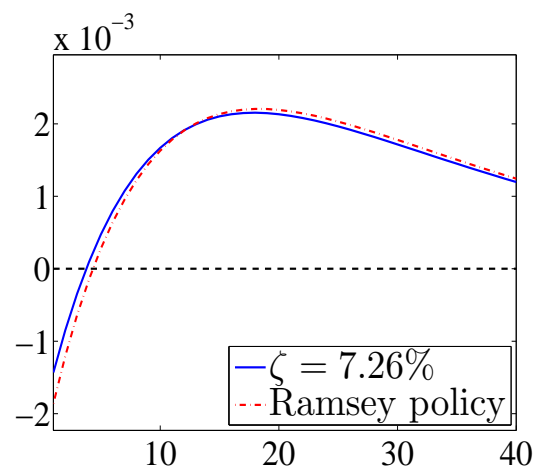

(f) Liquidity Premium

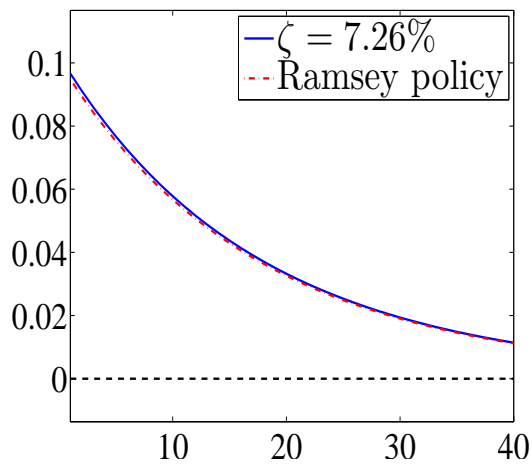

(i) Ramsey Policy

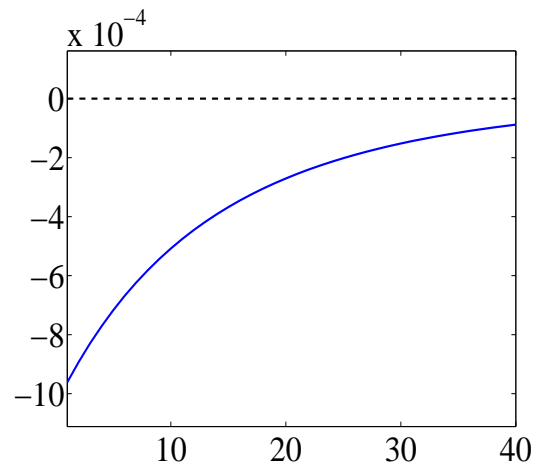

The figures show the effect of a one standard deviation shock to log productivity on the variables of the quantitative model with liquidity shocks, as captured by the impulse response functions. The figures provide a comparison of the effects when banks are subject to a fixed capital requirement of $7.26 \%$ (blue solid lines) and when banks face the optimal Ramsey policy (red dash-dotted lines). All model quantities are in logs. 


\section{Ramsey Equilibrium}

A Ramsey planner maximizes the lifetime utility of households subject to the resource constraint and implementability conditions:

$$
\begin{array}{ll} 
& \max _{C_{t}, L_{t+1}, N_{t+1}, D_{t+1}, K_{f, t+1}} E\left[\sum_{t=0}^{\infty} \beta^{t} u\left(C_{t}, D_{t+1}\right)\right] \\
\text { with } & u\left(C_{t}, D_{t+1}\right)=\frac{v\left(C_{t}, D_{t+1}\right)^{1-\gamma}}{1-\gamma}-1 \\
\text { s.t. } & C_{t}=R_{d, t} D_{t}-D_{t+1}+R_{k, t} K_{f, t}^{\alpha_{f}}-I_{f, t}-o_{f} K_{f, t}+Z_{t}+\Pi_{t}-T_{t}, \\
& E_{t}\left[M_{t, t+1}\left(R_{k, t+1}+\left(1-\delta-o_{f}\right)\right)\right]=1, \\
& N_{t+1}+D_{t+1}=L_{t+1}, \\
& E_{t}\left[M_{t, t+1}\left(R_{l, t+1}+\left(1-\delta-o_{b}\right)\right)\right]=\theta_{t}-\tilde{\xi}_{t}, \\
& C_{t}+I_{b, t}+I_{f, t}=Y_{b, t}+Y_{f, t}-o_{b} L_{t}-o_{f} K_{f, t},
\end{array}
$$

where the taxes and net proceeds from banks' and firms' activity are, respectively, equal to:

$$
\begin{aligned}
T_{t} & =\int_{0}^{1} \max \left\{R_{d, t} D_{t}-e^{\omega_{j, t}+a_{t}} L_{t}^{\alpha_{b}}-\left(1-\delta-o_{b}\right) L_{t}, 0\right\} d j, \\
Z_{t} & =\int_{0}^{1} z_{j, t} d j, \quad \text { with } \quad z_{j, t}=\max \left\{e^{\omega_{j, t}+a_{t}} L_{t}^{\alpha_{b}}+\left(1-\delta-o_{b}\right) L_{t}-R_{d, t} D_{t}, 0\right\}-N_{t+1}, \\
\Pi_{t} & =Y_{f, t}-R_{k, t} K_{f, t} .
\end{aligned}
$$

The rate of return on deposits, the stochastic discount factor, the liquidity and risk-shifting cost of lending, the rate of return on loans and capital are, correspondingly, defined by (19), (20), (21), (22), (23) and (24). The optimal Ramsey policy requires a capital ratio that equals:

$$
\zeta_{t}=\frac{N_{t+1}}{L_{t+1}}
$$

The Ramsey problem can be further simplified. By substituting expressions (C.6), (C.7) and (C.8) in the household's budget constraint (C.1), I obtain the resource constraint (C.5), therefore implying that I can omit it.

Proposition C1 The allocation rules $\left\{C_{t}, D_{t},\left\{z_{j, t}, l_{j, t+1}, n_{j, t+1}, d_{j, t+1}\right\}_{j \in \Omega}, K_{f, t+1}\right\}_{t=0}^{\infty} \quad$ and policies $\left\{\zeta_{t}, T_{t}\right\}_{t=0}^{\infty}$ in a competitive equilibrium satisfy conditions (C.1)-(C.9). Furthermore, given the allocation rules and policies that satisfy (C.1)-(C.9), we can construct the price rules $\left\{M_{t, t+1}, R_{d, t+1}, R_{l, t+1}, R_{k, t+1}\right\}_{t=0}^{\infty}$ that together with the given allocations and policies constitute a competitive equilibrium.

Proof. The first part of the proof is quite straightforward and follows from the fact that the competitive equilibrium is symmetric. For the second part of the proof, I use the Ramsey allocations to construct the 
prices as follows:

$$
\begin{aligned}
M_{t, t+1} & =\left(\frac{v\left(C_{t+1}, D_{t+2}\right)}{v\left(C_{t}, D_{t+1}\right)}\right)^{\frac{1}{\tilde{\eta}}-\gamma}\left(\frac{C_{t+1}}{C_{t}}\right)^{-\frac{1}{\tilde{\eta}}}, \\
R_{d, t+1} & =\frac{1}{E_{t}\left[M_{t, t+1}\right]}\left(1-\chi\left(\frac{D_{t+1}}{C_{t}}\right)^{-\frac{1}{\eta}}\right) \\
R_{l, t+1} & =\alpha_{b} e^{\bar{a}_{b}+a_{t+1}} L_{t+1}^{\alpha_{b}-1} \\
R_{k, t+1} & =\alpha_{f} e^{a_{t+1}} K_{f, t+1}^{\alpha_{f}-1} .
\end{aligned}
$$

The expressions for the SDF, deposits rate and rate of return on capital along with the budget constraint (C.1) and condition (C.2) ensure that the households choose their optimal allocations for consumption and deposits. Similarly, the expression for the rate of return on loans together with the capital constraint (C.9), balance sheet constraint (C.3) and condition (C.4) ensures that the banks choose their optimal lending level and capital structure. The net distributions to the banks' shareholders (C.7) are defined by the same expressions in the competitive and Ramsey equilibria. The government budget constraint (C.6) and resource constraint (C.5) are identical.

\section{Welfare Costs of Capital Requirement}

The compensating variation $\varpi$, which is the permanent change in consumption that households are willing to accept to move from the economy with a fixed level of capital requirement $\zeta^{0}$ to the world with a capital ratio of $\zeta^{1}$, is defined by:

$$
E_{\zeta^{0}}\left[\sum_{t=0}^{\infty} \beta^{t} \frac{\left((1+\varpi) \tilde{C}_{t}\right)^{1-\gamma}-1}{1-\gamma}\right]=E_{\zeta^{1}}\left[\sum_{t=0}^{\infty} \beta^{t} \frac{\tilde{C}_{t}^{1-\gamma}-1}{1-\gamma}\right]
$$

or, equivalently:

$$
\varpi=\left(\frac{E_{\zeta^{1}}\left[\sum_{t=0}^{+\infty} \beta^{t} \tilde{C}_{t}^{1-\gamma}\right]}{E_{\zeta^{0}}\left[\sum_{t=0}^{+\infty} \beta^{t} \tilde{C}_{t}^{1-\gamma}\right]}\right)^{\frac{1}{1-\gamma}}-1
$$

To obtain an estimate of expected lifetime utility, I first solve for agents' decision rules in a competitive equilibrium, varying the capital regulation in place. Next, I perform 1,000 simulations of a Ramsey equilibrium. Within each simulation, at a random point on the time path, a new regime of capital charges is introduced. Then, using agents' decision rules, I generate 10, 000 observations for the households' consumption and deposits from the period when a new regime has been introduced on. Finally, I evaluate the realized utility under the new regime and average it over the simulations. This approach allows me to take into account the transition dynamics between different policy regimes.

It is crucial to take into the account the transition dynamics to get the correct welfare ranking. In a competitive equilibrium with a lower level of capital requirement, the financial intermediaries accumulate a higher stock of capital. In the long-run, this delivers a higher level of consumption, but it is costly for the households in the short run, since they have to reduce consumption in order to boost capital investment. So, 
if I were to compare the realized utility based on the simulations where I burn initial observations, I would find that economies with strict capital requirements always generate lower welfare results than economies with low capital ratios. To understand why the compensation variation is affected by the transition dynamics and changes in the steady state levels, define consumption as the product of its cycle component, denoted by $\tilde{C}_{t}^{*}$, and level component, denoted by $g_{t}: 34$

$$
\tilde{C}_{t}=g_{t} \tilde{C}_{t}^{*}
$$

By taking a second-order Taylor expansion of the momentary utility function, I obtain:

$$
E\left[\left(\tilde{C}_{t}^{*}\right)^{1-\gamma}\right] \approx 1-\frac{1}{2} \gamma(1-\gamma) \sigma_{\tilde{C}_{t}^{*}}^{2}
$$

Substituting the above expression in (D.1) delivers:

$$
(1+\varpi)^{1-\gamma}\left(1-\frac{1}{2} \gamma(1-\gamma) \sigma_{\tilde{C}_{t}^{* \zeta^{0}}}^{2}\right)\left(\sum_{t=0}^{\infty} \beta^{t}\left(g_{t}^{\zeta^{0}}\right)^{1-\gamma}\right)=\left(1-\frac{1}{2} \gamma(1-\gamma) \sigma_{\tilde{C}_{t}^{* \zeta^{1}}}^{2}\right)\left(\sum_{t=0}^{\infty} \beta^{t}\left(g_{t}^{\zeta^{1}}\right)^{1-\gamma}\right) .
$$

By taking logs and using that $\log (1+x) \approx x$, I get:

$$
\varpi \approx-\frac{1}{2} \gamma\left(\sigma_{\tilde{C}_{t}^{* \zeta^{1}}}^{2}-\sigma_{\tilde{C}_{t}^{* \zeta^{0}}}^{2}\right)+\frac{1}{1-\gamma}\left(\log \left(\sum_{t=0}^{\infty} \beta^{t}\left(g_{t}^{\zeta^{1}}\right)^{1-\gamma}\right)-\log \left(\sum_{t=0}^{\infty} \beta^{t}\left(g_{t}^{\zeta^{0}}\right)^{1-\gamma}\right)\right) .
$$

Recall that the Lucas cost of eliminating business cycle risk in this framework is equal to $-\frac{1}{2} \gamma \sigma_{\tilde{C}_{t}^{*}}^{2}$.

\footnotetext{
${ }^{34}$ The level component $g_{t}$ captures the transition dynamics (temporary trend) between a steady state of the economy with a fixed level of capital requirement $\zeta^{0}$ to a steady state of the world with a capital ratio of $\zeta^{1}$.
} 